\title{
Design of Concise, Scalable Route to a Cholecystokinin 1 (CCK 1) Receptor Antagonist
}

\author{
Jimmy T. Liang, Neelakandha S. Mani, ${ }^{*}$ and Todd K. Jones \\ Johnson \& Johnson Pharmaceutical Research \& Development,LLC, 3210 Merryfield \\ Row, La Jolla, CA 92121
}

\section{Supporting Information Available}

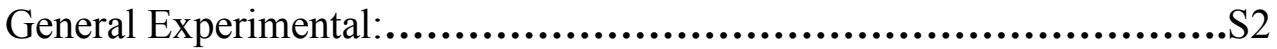

\section{Section 1}

First route (Scheme of Evans's enolate alkylation method)..............S2

Experimental procedure..............................................S2-S7

${ }^{1} \mathrm{H}$ and ${ }^{13} \mathrm{C}$ NMR NMR spectra of intermediates.........................S8-S25

\section{Section 2}

Second route (Equation 2 and Schemes 1\& 3).........................S26

${ }^{1} \mathrm{H}$ and ${ }^{13} \mathrm{C}$ NMR NMR spectra of all intermediates.....................S27-S43

Chiral HPLC traces of $\mathbf{1 0}$ after enzymatic resolution and of $\mathbf{1}$............S38

\section{Section 3}

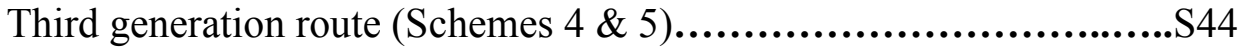

${ }^{1} \mathrm{H}$ and ${ }^{13} \mathrm{C}$ NMR NMR spectra.......................................S45-S56

Chiral HPLC traces of 1 after crystallization..............................S53-S54 


\section{General.}

${ }^{1} \mathrm{H}$ NMR and ${ }^{13} \mathrm{C}$ NMR spectra were recorded using a $400 \mathrm{MHz}$ or a $500 \mathrm{MHz}$ spectrometer. Chemical shifts, $\delta$, are reported in ppm downfield from TMS as an internal standard or relative to residual $\mathrm{CDCl}_{3}$ signals at $7.26\left({ }^{1} \mathrm{H}\right)$ and $77.0\left({ }^{13} \mathrm{C}\right)$, and coupling constants are reported in $\mathrm{Hz}$. HPLC reverse phase separations were determined by an HPLC instrument equipped with a stationary phase $4.6 \mathrm{~mm} \times 150 \mathrm{~mm}$ XDB-C $8,5 \mathrm{um}$, column. The mobile phase was a gradient containing acetonitrile/water with $0.05 \% \mathrm{v} / \mathrm{v}$ of TFA [0-8 $\mathrm{min} .1 \% / 99 \%-99 \% / 1 \% ; 8-10 \mathrm{~min}$ $99 \% / 1 \% ; 10-10.5 \min 99 \% / 1 \%-1 \% / 99 \% ; 10.5-12 \min 1 \% / 99 \%]$. The flow rate was 0.75 $\mathrm{mL} / \mathrm{min}$ with sample volume at $5 \mu \mathrm{L}$ and UV detection at 220 and $254 \mathrm{~nm}$. HPLC chiral separations were determined by an HPLC instrument equipped with a stationary phase $4.6 \mathrm{~mm} \mathrm{x}$ $250 \mathrm{~mm}$ Chiralcel AD, $10 \mathrm{um}$, column. The mobile phase was isocratic containing 85/15 ethanol/hexane with $.07 \% \mathrm{v} / \mathrm{v}$ of TFA. The flow rate was $1 \mathrm{~mL} / \mathrm{min}$ with sample volume at $5 \mu \mathrm{L}$ and UV detection at 220 and $254 \mathrm{~nm}$. Melting points were determined using an Electrothermal instrument and are uncorrected. Mass Spectra were determined on a micro TOF mass spectrometer using electrospray ionization. Optical rotations were determined using a polarimeter with a $1.00 \mathrm{dm}$ quartz-window cell (1 mL capacity). Flash column chromatography was conducted using silica gel 60 (230-400 mesh).

\section{Section 1}

\section{Synthesis of 1 by the first generation route}
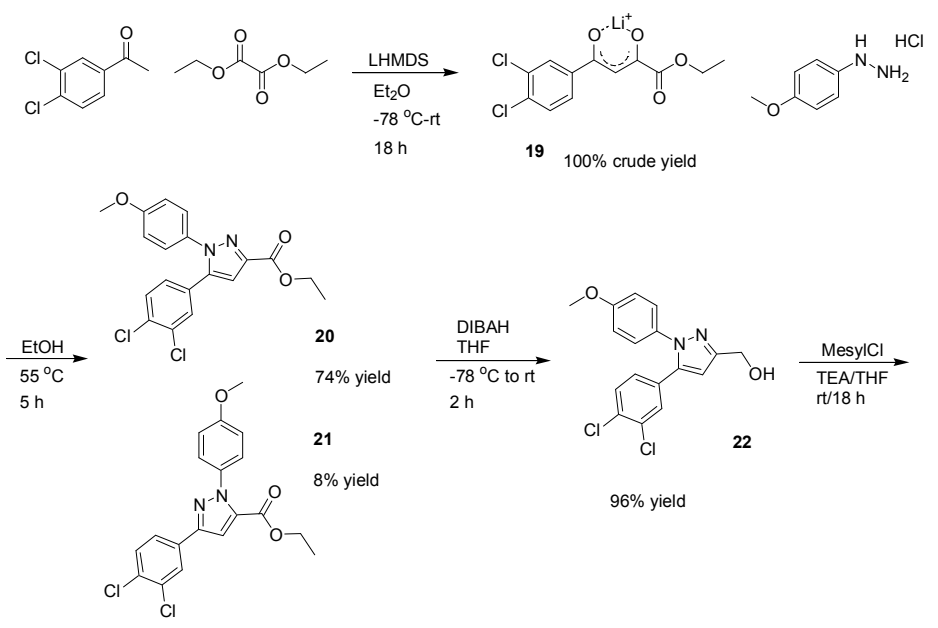


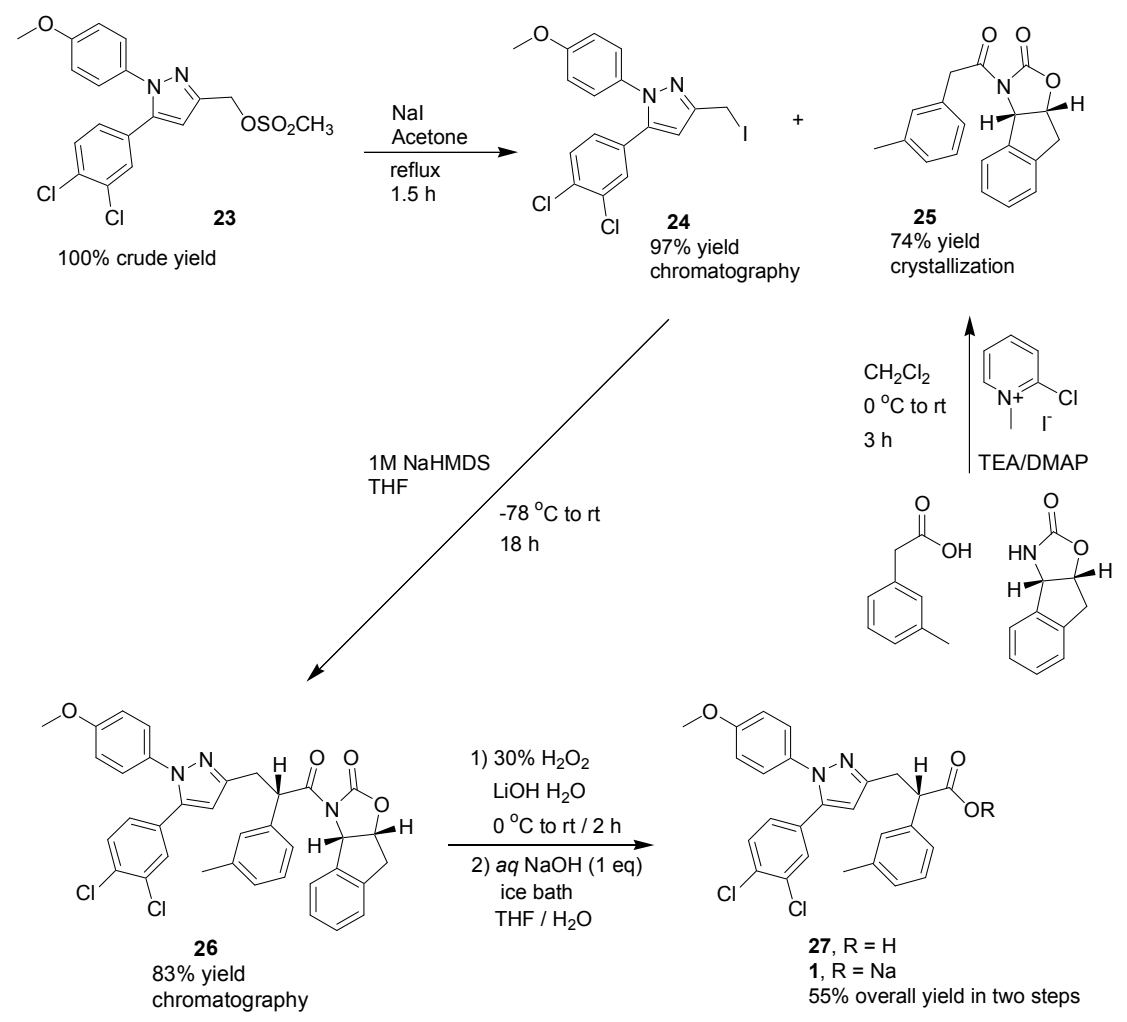

\section{Lithium 4-(3,4-dichlorophenyl)-4-hydroxy-2-oxo-but-3-enoic acid ethyl ester (19).}

In a dried 1-L round-bottomed flask, 1.0 M LHMDS in THF (265 mL, $0.265 \mathrm{~mol})$ was concentrated under reduced pressure to a solid using a rotary evaporator at $25-30{ }^{\circ} \mathrm{C}$. Anhydrous $\mathrm{Et}_{2} \mathrm{O}(200 \mathrm{~mL})$ was added and this stirred suspension of LHMDS in $\mathrm{Et}_{2} \mathrm{O}$ was cooled to $-78{ }^{\circ} \mathrm{C}$ under $\mathrm{N}_{2}$. 3,4-Dichloracetophenone $(50 \mathrm{~g}, 0.265 \mathrm{~mol})$ in $\mathrm{Et}_{2} \mathrm{O}(200 \mathrm{~mL})$ was slowly added to the reaction mixture over $15 \mathrm{~min}$. The mixture was allowed to stir for $60 \mathrm{~min}$ and diethyl oxalate (36 $\mathrm{mL}, 0.265 \mathrm{~mol})$ in $\mathrm{Et}_{2} \mathrm{O}(75 \mathrm{~mL})$ was then added over $20 \mathrm{~min}$. After $90 \mathrm{~min}$, the mixture was allowed to warm to room temperature and stirred overnight. The light yellow solids were filtered and washed with $\mathrm{Et}_{2} \mathrm{O}$ then dried under vacuum to afford $78.4 \mathrm{~g}$ of $\mathbf{1 9}$ as a solid in $100 \%$ crude yield. This material was used in the next step without further purification and analysis.

\section{5-(3,4-Dichlorophenyl)-1-(4-methoxyphenyl)-1H-pyrazole-3-carboxylic acid ethyl ester (20).}

A stirred suspension of the lithium salt $19(90.7 \mathrm{~g}, 0.307 \mathrm{~mol})$ and 4-methoxyphenyl hydrazine hydrochloride ( $54 \mathrm{~g}, 0.309 \mathrm{~mol})$ in $\mathrm{EtOH}(600 \mathrm{~mL})$ was heated to $55^{\circ} \mathrm{C}$ for $5 \mathrm{~h}$ then stirred at room temperature overnight. HPLC analysis showed a 4/1 mixture of (1,5)-pyrazole 20 and (1,3)-pyrazole 21 in the reaction mixture. The precipitated solids were filtered and washed with EtOH. The solids were recrystallized with $1 / 1 \mathrm{CH}_{3} \mathrm{CN} / \mathrm{MeOH}$ to recover $9 \mathrm{~g}$ of the minor $(1,3)$ pyrazole 21. Crystallization was repeated several times to recover $71 \mathrm{~g}$ of the major $(1,5)$ - 
pyrazole ester 20. The crude filtrate was evaporated and the residue purified by silica gel column chromatography (eluting with 4/1 hexanes/ethyl acetate) to afford another $17.6 \mathrm{~g}$ of pyrazole ester 20 for a total combined yield of 74\%. 20: ${ }^{1} \mathrm{H}$ NMR (400 $\left.\mathrm{MHz}, \mathrm{CDCl}_{3}\right): \delta 7.37(\mathrm{~d}, J=2.0 \mathrm{~Hz}$, $1 \mathrm{H}), 7.35$ (d, $J=8.4 \mathrm{~Hz}, 1 \mathrm{H}), 7.26-7.21(\mathrm{~m}, 2 \mathrm{H}), 7.04(\mathrm{~s}, 1 \mathrm{H}), 6.97(\mathrm{dd}, J=8.0,1.0 \mathrm{~Hz}, 1 \mathrm{H})$, 6.95-6.88 (m, 2H), 4.45 (q, $J=7.1 \mathrm{~Hz}, 2 \mathrm{H}), 3.84(\mathrm{~s}, 3 \mathrm{H}), 1.42(\mathrm{t}, J=7.1 \mathrm{~Hz}, 3 \mathrm{H}) .{ }^{13} \mathrm{C} \mathrm{NMR}(100$ $\left.\mathrm{MHz}, \mathrm{CDCl}_{3}\right): \delta 162.1,159.7,144.1,142.0,132.9,132.8,132.0,130.5,130.3,129.4,127.7$, 127.0, 114.3, 109.9, 61.1, 55.5, and 14.3. HRMS: $\mathrm{m} / \mathrm{z}$ calcd for $\mathrm{C}_{19} \mathrm{H}_{16} \mathrm{~N}_{2} \mathrm{O}_{3} \mathrm{Cl}_{2}[\mathrm{M}+\mathrm{H}]^{+}$ 391.0611, found 391.0614.

21: ${ }^{1} \mathrm{H}$ NMR (400 MHz, $\left.\mathrm{CDCl}_{3}\right): \delta 7.98(\mathrm{~d}, J=2.0 \mathrm{~Hz}, 1 \mathrm{H}), 7.71-7.68(\mathrm{dd}, J=2.0,8.4 \mathrm{~Hz}, 1 \mathrm{H})$, $7.48(\mathrm{~d}, J=8.4 \mathrm{~Hz}, 1 \mathrm{H}), 7.41-7.37$ (m, 2H), 7.27 (d, $J=5.8 \mathrm{~Hz}, 1 \mathrm{H}), 7.00-6.97$ (m, 2H), 4.30$4.24(\mathrm{q}, J=7.2 \mathrm{~Hz}, 2 \mathrm{H}), 3.87(\mathrm{~s}, 3 \mathrm{H}), 1.31-1.27(\mathrm{t}, J=7.2 \mathrm{~Hz}, 3 \mathrm{H}) .{ }^{13} \mathrm{C} \mathrm{NMR}(100 \mathrm{MHz}$, $\left.\mathrm{CDCl}_{3}\right): \delta 159.9,158.9,148.9,135.1,133.3,133.0,132.4,132.2,130.7,127.6,127.3,124.9$, 113.8, 109.1, 61.3, 55.6, and 14.1. HRMS: $\mathrm{m} / \mathrm{z}$ calcd for $\mathrm{C}_{19} \mathrm{H}_{16} \mathrm{~N}_{2} \mathrm{O}_{3} \mathrm{Cl}_{2}[\mathrm{M}+\mathrm{H}]^{+}$391.0611, found 391.0604.

\section{[5-(3,4-Dichlorophenyl)-1-(4-methoxyphenyl)-1H-pyrazol-3-yl]-methanol (22).}

To a stirred solution of pyrazole ester $20(55.7 \mathrm{~g}, 0.140 \mathrm{~mol})$ in THF $(150 \mathrm{~mL})$ at $-78{ }^{\circ} \mathrm{C}$ under $\mathrm{N}_{2}$ was slowly added a 1.0M solution of DIBAH (350 mL, $\left.0.35 \mathrm{~mol}\right)$ over $45 \mathrm{~min}$. The solution was allowed to stir for $20 \mathrm{~min}$ then warmed to room temperature over $90 \mathrm{~min}$. The mixture was then cooled to $0{ }^{\circ} \mathrm{C}$ and slowly cool saturated aqueous solution of potassium sodium tartrate (300 $\mathrm{mL})$ and EtOAc $(400 \mathrm{~mL})$ were added. The slurry mixture was stirred overnight whereupon both layers became clear. The organic layer was extracted with EtOAc $(2 \times 75 \mathrm{~mL})$, dried with $\mathrm{Na}_{2} \mathrm{SO}_{4}$, filtered and concentrated to a jelly-like substance. The crude product was dried under vacuum to recover $46.8 \mathrm{~g}$ of the pyrazole alcohol 22 in $96 \%$ yield as a solid. This was used in the next step without further purification. ${ }^{1} \mathrm{H}$ NMR (400 MHz, CDCl3): $\delta 7.39$ (d, $\left.J=2.1 \mathrm{~Hz}, 1 \mathrm{H}\right)$, $7.34(\mathrm{~d}, J=3.6 \mathrm{~Hz}, 1 \mathrm{H}), 7.20-7.09$ (m, 2H), 6.97 (dd, $J=8.36,2.1 \mathrm{~Hz}, 1 \mathrm{H}), 6.91-6.79$ (m, 2H), $6.43(\mathrm{~s}, 1 \mathrm{H}), 4.69(\mathrm{~s}, 2 \mathrm{H}), 3.74(\mathrm{~s}, 3 \mathrm{H}) .{ }^{13} \mathrm{C} \mathrm{NMR}\left(100 \mathrm{MHz}, \mathrm{CDCl}_{3}\right): \delta 159.2,152.7,141.7$, $132.8,132.6,132.5,130.5,130.3,130.3,127.7,126.7,114.4,106.1,59.1$, and 55.5. HRMS: $\mathrm{m} / \mathrm{z}$ calcd for $\mathrm{C}_{17} \mathrm{H}_{14} \mathrm{~N}_{2} \mathrm{O}_{2} \mathrm{Cl}_{2}[\mathrm{M}+\mathrm{H}]^{+} 349.0505$, found 349.0505 .

\section{Methanesulfonic acid 5-(3,4-dichlorophenyl)-1-(4-methoxyphenyl)-1H-pyrazol-3-ylmethyl ester (23).}

To a stirred solution of pyrazole alcohol $22(7.2 \mathrm{~g}, 0.020 \mathrm{~mol})$ in THF (125 mL) and TEA (4.6 $\mathrm{mL}, 0.033 \mathrm{~mol})$ was added methanesulfonyl chloride $(2.5 \mathrm{~mL}, 0.031 \mathrm{~mol})$. The reaction was stirred at $45{ }^{\circ} \mathrm{C}$ for $4 \mathrm{~h}$ whereupon precipitation developed. The reaction mixture was cooled to 
room temperature, quenched with $\mathrm{H}_{2} \mathrm{O}(75 \mathrm{~mL})$ then washed with EtOAc $(3 \times 50 \mathrm{~mL})$. The extracted organic layer was dried over anhydrous $\mathrm{Na}_{2} \mathrm{SO}_{4}$, filtered, and concentrated to oil. This crude pyrazole mesylate 23 was immediately used in the next step. ${ }^{1} \mathrm{H}$ NMR (400 MHz, $\left.\mathrm{CDCl}_{3}\right)$ : $\delta$ 7.38-7.34 (m, 2H), 7.19 (d, $J=9.0 \mathrm{~Hz}, 2 \mathrm{H}), 6.96(\mathrm{dd}, J=8.36,2.01 \mathrm{~Hz}, 1 \mathrm{H}), 6.90(\mathrm{~d}, J=9.0$ $\mathrm{Hz}, 2 \mathrm{H}), 6.66(\mathrm{~s}, 1 \mathrm{H}), 5.34(\mathrm{~s}, 2 \mathrm{H}), 3.84(\mathrm{~s}, 3 \mathrm{H}), 3.08(\mathrm{~s}, 3 \mathrm{H}) ;{ }^{13} \mathrm{C} \mathrm{NMR}\left(100 \mathrm{MHz}, \mathrm{CDCl}_{3}\right): \delta$ 159.5, 146.0, 142.1, 132.9, 132.8, 132.1, 130.5, 130.3, 129.7, 127.7, 126.7, 114.4, 107.9, 64.9, 55.5, and 38.2. Anal. Calcd for $\mathrm{C}_{18} \mathrm{H}_{16} \mathrm{Cl}_{2} \mathrm{~N}_{2} \mathrm{O}_{4} \mathrm{~S}: \mathrm{C}, 50.59 ; \mathrm{H}, 3.77 ; \mathrm{N}, 6.56$. Found: $\mathrm{C}, 50.26 ; \mathrm{H}$, $4.13 ; \mathrm{N}, 6.42$.

\section{5-(3,4-Dichlorophenyl)-3-iodomethyl-1-(4-methoxyphenyl)-1H-pyrazole (24).}

To a stirred solution of pyrazole mesylate $\mathbf{2 3}(8.8 \mathrm{~g}, 0.020 \mathrm{~mol})$ in acetone $(175 \mathrm{~mL})$ was added $\mathrm{NaI}$ (4.64 g, $0.031 \mathrm{~mol}$ ) and resulting suspension was refluxed for $90 \mathrm{~min}$. The thick slurry was cooled to room temperature, quenched with $\mathrm{H}_{2} \mathrm{O}(200 \mathrm{~mL})$, and extracted with EtOAc $(3 \mathrm{x}$ $75 \mathrm{~mL}$ ). The combined organic layer was dried over anhydrous $\mathrm{Na}_{2} \mathrm{SO}_{4}$, filtered and concentrated to dark colored oil. The crude oil was purified by silica gel column chromatography (eluting with 85/15 hexanes/ethyl acetate) to recover $9.15 \mathrm{~g}$ (97\% yield after 2 steps) of iodo pyrazole 24. ${ }^{1} \mathrm{H}$ NMR $\left(400 \mathrm{MHz}, \mathrm{CDCl}_{3}\right): \delta 7.38-7.37(\mathrm{~d}, J=2.0 \mathrm{~Hz}, 1 \mathrm{H}), 7.35-7.33(\mathrm{~d}, J=8.3$ $\mathrm{Hz}, 1 \mathrm{H}), 7.19-7.17$ (d, $J=8.8 \mathrm{~Hz}, 2 \mathrm{H}), 6.96-6.94$ (dd, $J=2.0,6.3 \mathrm{~Hz}, 1 \mathrm{H}), 6.89-6.87$ (d, $J=9.1$ $\mathrm{Hz}, 2 \mathrm{H}), 6.55$ (s, 1H), 4.47 (s, 2H), $3.83(\mathrm{~s}, 3 \mathrm{H}) ;{ }^{13} \mathrm{C} \mathrm{NMR}\left(100 \mathrm{MHz}, \mathrm{CDCl}_{3}\right): \delta 159.2,150.6$, $141.8,132.8,132.6,132.4,130.5,130.3,130.1,127.7,126.7,114.4,107.5,55.5$, and -4.7 . HRMS: $\mathrm{m} / \mathrm{z}$ calcd for $\mathrm{C}_{17} \mathrm{H}_{14} \mathrm{~N}_{2} \mathrm{OCl}_{2} \mathrm{I}[\mathrm{M}+\mathrm{H}]^{+} 458.9522$, found 458.9511

\section{3-(2-m-Tolyl-acetyl)-3,3a,8,8a-tetrahydro-indeno[1,2-d]oxazol-2-one (25).}

To a stirred solution of $m$-tolylacetic acid $(8.57 \mathrm{~g}, 0.057 \mathrm{~mol}), 2$-chloro-1-methylpyridinium iodide (19 g, $0.074 \mathrm{~mol})$ and (3aS-cis)-(-)-3,3a,8,8a-tetrahydro-2 $H$-indeno[1,2- $d$-oxazol-2-one $(10 \mathrm{~g}, 0.0571 \mathrm{~mol})$ in $\mathrm{CH}_{2} \mathrm{Cl}_{2}(130 \mathrm{~mL})$ were added, TEA $(18 \mathrm{~mL}, 0.1291 \mathrm{~mol})$ and DMAP (1.39 $\mathrm{g}, 0.011 \mathrm{~mol}$ ) at $0{ }^{\circ} \mathrm{C}$. The reaction was stirred at room temperature for $3 \mathrm{~h}$ then treated with hexane $(130 \mathrm{~mL})$. The resulting slurry was passed through a pad of silica gel, eluting with $3 / 2$ ethyl acetate/hexanes. The filtrate was concentrated to oil and recrystallized in hot hexanes to recover $13 \mathrm{~g}$ (74\% yield) 25 as a white solid. ${ }^{1} \mathrm{H}$ NMR (400 MHz, $\left.\mathrm{CDCl}_{3}\right): \delta 7.62-7.64(\mathrm{~d}, J=7.6$ $\mathrm{Hz}, 1 \mathrm{H}), 7.08-7.37(\mathrm{~m}, 7 \mathrm{H}), 5.94-5.96(\mathrm{~d}, J=6.8 \mathrm{~Hz}, 1 \mathrm{H}), 5.27-5.31(\mathrm{~m}, 1 \mathrm{H}), 4.17-4.35$ (dd, $J=$ 15.9, 39.1 Hz, 2H), 3.39-3.40 (d, $J=3.5 \mathrm{~Hz}, 2 \mathrm{H}), 2.34(\mathrm{~s}, 3 \mathrm{H}) ;{ }^{13} \mathrm{C} \mathrm{NMR}\left(100 \mathrm{MHz}, \mathrm{CDCl}_{3}\right): \delta$ $171.7,153.0,139.5,139.0,138.2,133.4,130.5,129.9,128.4,128.2,128.0,127.4,126.8,125.2$, 78.1, 63.3, 41.4, 38.0, and 21.4. HRMS: $\mathrm{m} / \mathrm{z}$ calcd for $\mathrm{C}_{19} \mathrm{H}_{18} \mathrm{NO}_{3}[\mathrm{M}+\mathrm{H}]^{+}$308.1281, found 
308.1281. Anal. Calcd for $\mathrm{C}_{19} \mathrm{H}_{17} \mathrm{NO}_{3}: \mathrm{C}, 74.25 ; \mathrm{H}, 5.58 ; \mathrm{N}, 4.56$. Found: $\mathrm{C}, 74.37 ; \mathrm{H}, 5.78 ; \mathrm{N}$, 4.60.

\section{3-\{3-[5-(3,4-Dichlorophenyl)-1-(4-methoxyphenyl)-1H-pyrazol-3-yl]-2-m-tolyl-propionyl\}- 3,3a, 8,8a-tetrahydro-indeno[1,2-d] oxazol-2-one (26).}

To a stirred solution of the chiral auxiliary $25(12 \mathrm{~g}, 0.039 \mathrm{~mol})$ in THF $(100 \mathrm{~mL})$ was added $1 \mathrm{M} \mathrm{NaHMDS}$ in THF $(41 \mathrm{~mL}, 0.041 \mathrm{~mol})$ at $-78^{\circ} \mathrm{C}$. The mixture was stirred for $45 \mathrm{~min}$ at -78 ${ }^{\circ} \mathrm{C}$ then treated with the iodo pyrazole $24(18.39 \mathrm{~g}, 0.040 \mathrm{~mol})$ in THF $(100 \mathrm{~mL})$. The reaction mixture was allowed to warm up to room temperature overnight then quenched with $\mathrm{H}_{2} \mathrm{O}$ (100 $\mathrm{mL})$. The quenched mixture was concentrated to half the volume and then extracted with EtOAc $(3 \times 75 \mathrm{~mL})$. The combined organic layer was washed with brine, dried over anhydrous $\mathrm{Na}_{2} \mathrm{SO}_{4}$, filtered and concentrated to an oil. The crude oil was purified by silica gel column chromatography (eluting with $7 / 3$ hexanes/ethyl acetate) to obtain $20.7 \mathrm{~g}(83 \%)$ of the chiral pyrazole 26 as white foam. ${ }^{1} \mathrm{H}$ NMR (400 $\left.\mathrm{MHz}, \mathrm{CDCl}_{3}\right): \delta 7.51-7.53(\mathrm{~d}, J=7.6 \mathrm{~Hz}, 1 \mathrm{H}), 7.11$ $7.35(\mathrm{~m}, 8 \mathrm{H}), 6.93-6.99(\mathrm{~m}, 3 \mathrm{H}), 6.74-6.82(\mathrm{~m}, 3 \mathrm{H}), 6.20(\mathrm{~s}, 1 \mathrm{H}), 5.89-5.90(\mathrm{~d}, J=6.8 \mathrm{~Hz}, 1 \mathrm{H})$, 5.56-5.60 (q, $J=6.1,4.5 \mathrm{~Hz}, 1 \mathrm{H}), 5.11-5.15(\mathrm{~m}, 1 \mathrm{H}), 3.8(\mathrm{~s}, 3 \mathrm{H}), 3.69-3.76(\mathrm{dd}, J=10.6,4.1 \mathrm{~Hz}$, $1 \mathrm{H}), 3.33$ (br s, 2H), 3.05-3.10 (dd, $J=4.8,9.8 \mathrm{~Hz}, 1 \mathrm{H}), 2.37(\mathrm{~s}, 3 \mathrm{H}) ;{ }^{13} \mathrm{C}$ NMR $(100 \mathrm{MHz}$, $\left.\mathrm{CDCl}_{3}\right): \delta 173.8,158.7,152.4,150.8,140.7,139.4,139.1,138.4,138.3,132.7,132.5,132.1$, $130.6,130.2$, 130.1, 129.7, 129.3, 128.6, 128.4, 127.9, 127.7, 127.3, 126.3, 125.8, 125.0, 114.1, 107.1, 63.5, 55.5, 55.4, 47.9, 37.8, 33.2, and 21.5. HRMS: $\mathrm{m} / \mathrm{z}$ calcd for $\mathrm{C}_{36} \mathrm{H}_{30} \mathrm{~N}_{3} \mathrm{O}_{4} \mathrm{Cl}_{2}[\mathrm{M}+\mathrm{H}]^{+}$ 638.1608 , found 638.1606 .

\section{(S)-3-[5-(3,4-Dichloro-phenyl)-1-(4-methoxy-phenyl)-1H-pyrazol-3-yl]-2-m-tolyl-propionic acid (27).}

To a stirred solution of the chiral pyrazole 26 (20.65 g, $0.032 \mathrm{~mol})$ in THF (230 mL) and $\mathrm{H}_{2} \mathrm{O}(45 \mathrm{~mL})$ at $0{ }^{\circ} \mathrm{C}$ was added $30 \% \mathrm{H}_{2} \mathrm{O}_{2}(15 \mathrm{~mL}, 0.147 \mathrm{~mol})$ followed by $\mathrm{LiOH}$ monohydrate (2.75 g, $0.065 \mathrm{~mol})$ in $\mathrm{H}_{2} \mathrm{O}(15 \mathrm{~mL})$. The cooling bath was removed allowing the reaction to warm up to room temperature. After $90 \mathrm{~min}$, the reaction mixture was cooled to $0{ }^{\circ} \mathrm{C}$ and quenched with $1.5 \mathrm{~N} \mathrm{Na}_{2} \mathrm{SO}_{3}(20 \mathrm{~mL})$ while maintaining $\mathrm{pH}$ near 9-10. The mixture was concentrated to a quarter of the volume under reduced pressure, diluted with $\mathrm{H}_{2} \mathrm{O}(200 \mathrm{~mL})$ then acidified to $\mathrm{pH} 1-2$ using $3 \mathrm{~N} \mathrm{HCl}$. The acidic solution was extracted with EtOAc $(3 \mathrm{x} 100 \mathrm{~mL})$. The combined organic layers were washed with water, brine, dried over anhydrous $\mathrm{Na}_{2} \mathrm{SO}_{4}$, filtered and concentrated to a quarter of the volume and set aside at room temperature. Solid crystals developed overnight were filtered and the solids washed with cold, 1/1 hexanes/ethyl acetate. The white solids were recovered to afford most of $(3.72 \mathrm{~g}, 66 \%)$ the chiral auxiliary. 
The filtrate was evaporated to obtain the crude acid as an oil. The crude product was purified by flash chromatography using silica gel column and eluting with $7 / 3$ hexanes/ethyl acetate with $0.3 \% \mathrm{MeOH}$. The desired fractions were combined to afford $12.7 \mathrm{~g}$ of the pyrazole acid 27 in $82 \%$ yield as orange oil. ${ }^{1} \mathrm{H}$ NMR $\left(400 \mathrm{MHz}, \mathrm{CDCl}_{3}\right): \delta 7.12-7.31(\mathrm{~m}, 9 \mathrm{H}), 6.89-6.91(\mathrm{dd}, J=$ 2.0, 6.3 Hz, 1H), 6.85-6.87 (d, $J=9.1 \mathrm{~Hz}, 2 \mathrm{H}), 6.21(\mathrm{~s}, 1 \mathrm{H}), 4.07-4.15(\mathrm{~m}, 1 \mathrm{H}), 3.82(\mathrm{~s}, 3 \mathrm{H})$, 3.49-3.55 (dd, $J=9.3,5.3 \mathrm{~Hz}, 1 \mathrm{H}), 3.08-3.14(\mathrm{dd}, J=5.8,9.1 \mathrm{~Hz}, 1 \mathrm{H}), 2.35(\mathrm{~s}, 3 \mathrm{H}) ;{ }^{13} \mathrm{C} \mathrm{NMR}$ $\left(100 \mathrm{MHz}, \mathrm{CDCl}_{3}\right): \delta 178.4,159.0,150.6,141.0,138.4,138.2,132.6,132.5,132.2,130.4,130.3$, 130.2, 128.8, 128.6, 128.4, 127.7, 126.6, 125.1, 114.2, 107.1, 55.5, 51.2, 31.7, and 21.4. HRMS: $\mathrm{m} / \mathrm{z}$ calcd for $\mathrm{C}_{26} \mathrm{H}_{23} \mathrm{~N}_{2} \mathrm{Cl}_{2} \mathrm{O}_{3}[\mathrm{M}+\mathrm{H}]^{+}$481.1080, found 481.1084. Anal. Calcd for $\mathrm{C}_{26} \mathrm{H}_{22} \mathrm{~N}_{2} \mathrm{Cl}_{2} \mathrm{O}_{3}$ : C, 64.87; H, 4.61; N, 5.82. Found: C, 64.80; H, 4.85; N, 6.0. 
5-(3,4-Dichlorophenyl)-1-(4-methoxyphenyl)-1H-pyrazole-3-carboxylic acid ethyl ester (20).

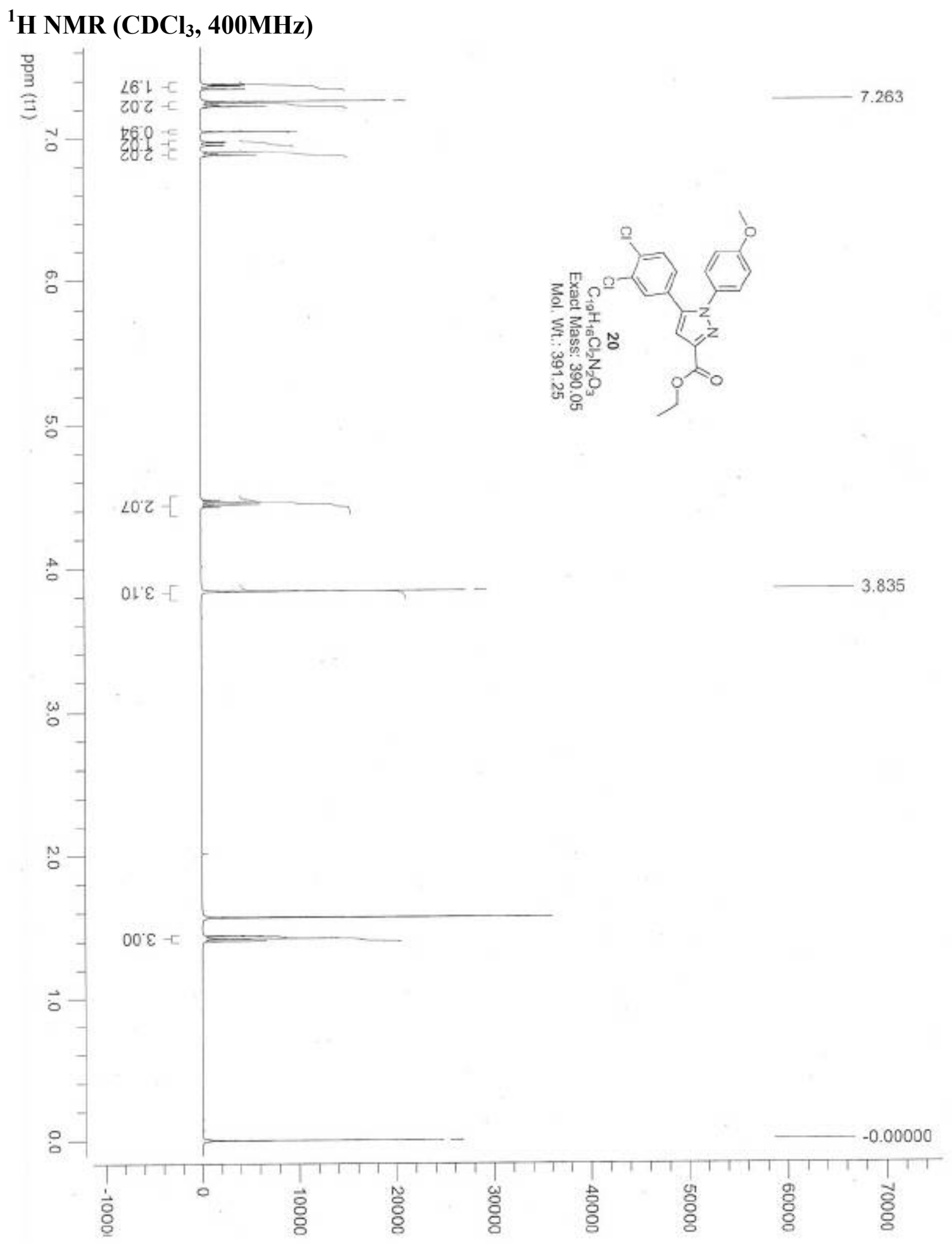


5-(3,4-Dichlorophenyl)-1-(4-methoxyphenyl)-1H-pyrazole-3-carboxylic acid ethyl ester (20). ${ }^{13} \mathrm{C}$ NMR (CDCl $\left.3,100 \mathrm{MHz}\right)$

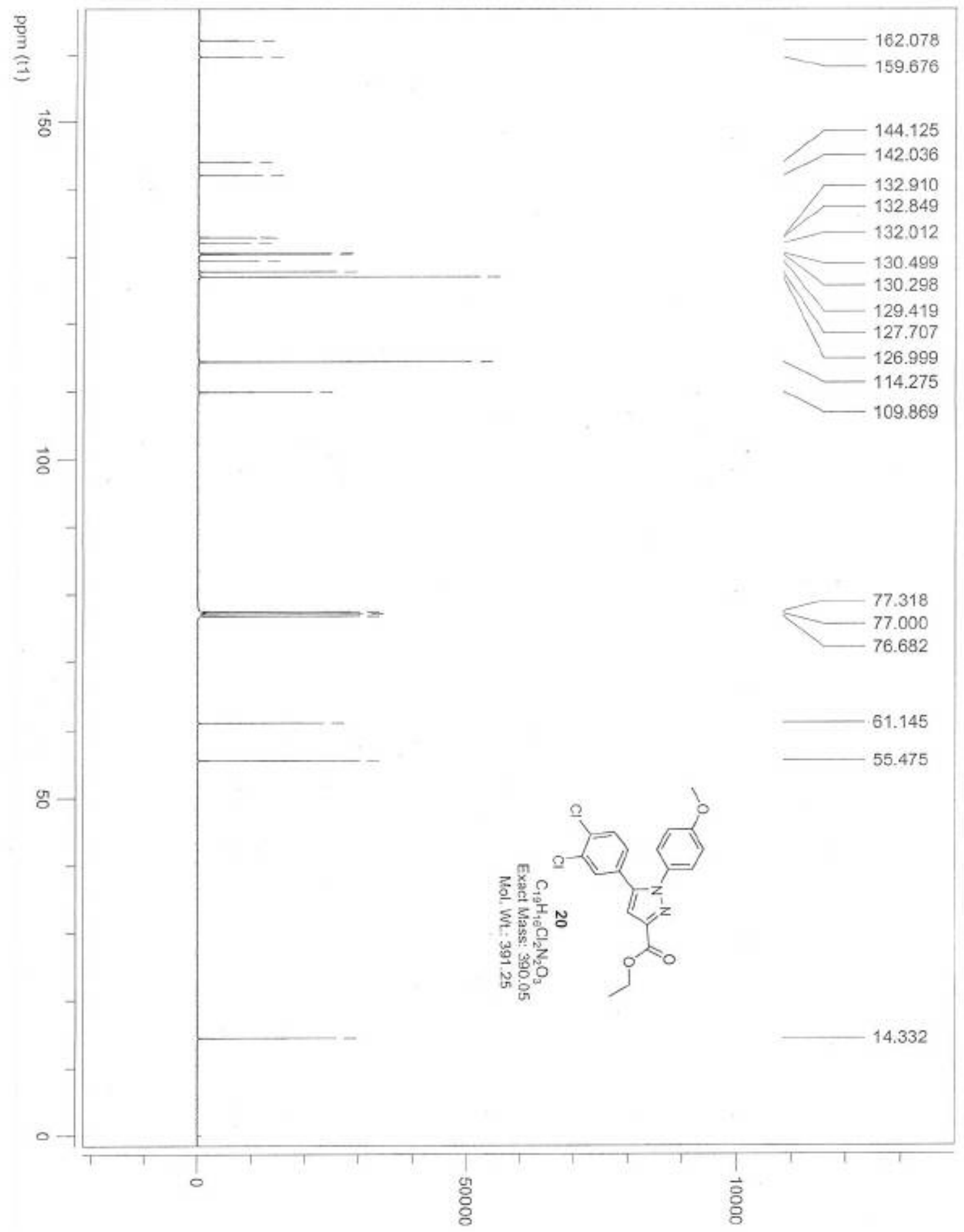


5-(3,4-Dichlorophenyl)-2-(4-methoxyphenyl)-2H-pyrazole-3-carboxylic acid (21)

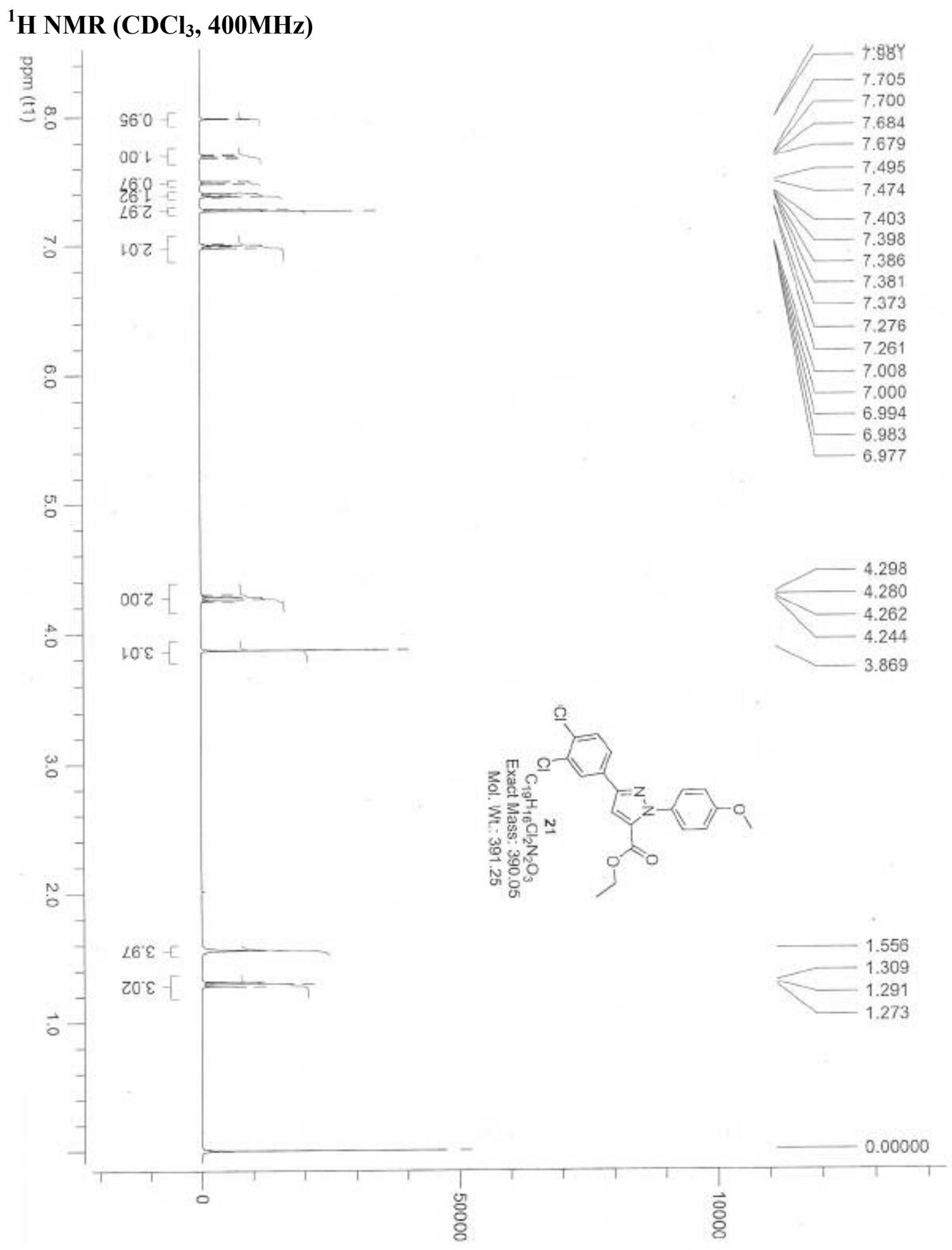


5-(3,4-Dichlorophenyl)-2-(4-methoxyphenyl)-2H-pyrazole-3-carboxylic acid (21)

${ }^{13} \mathrm{C}$ NMR $\left(\mathrm{CDCl}_{3}, 100 \mathrm{MHz}\right)$

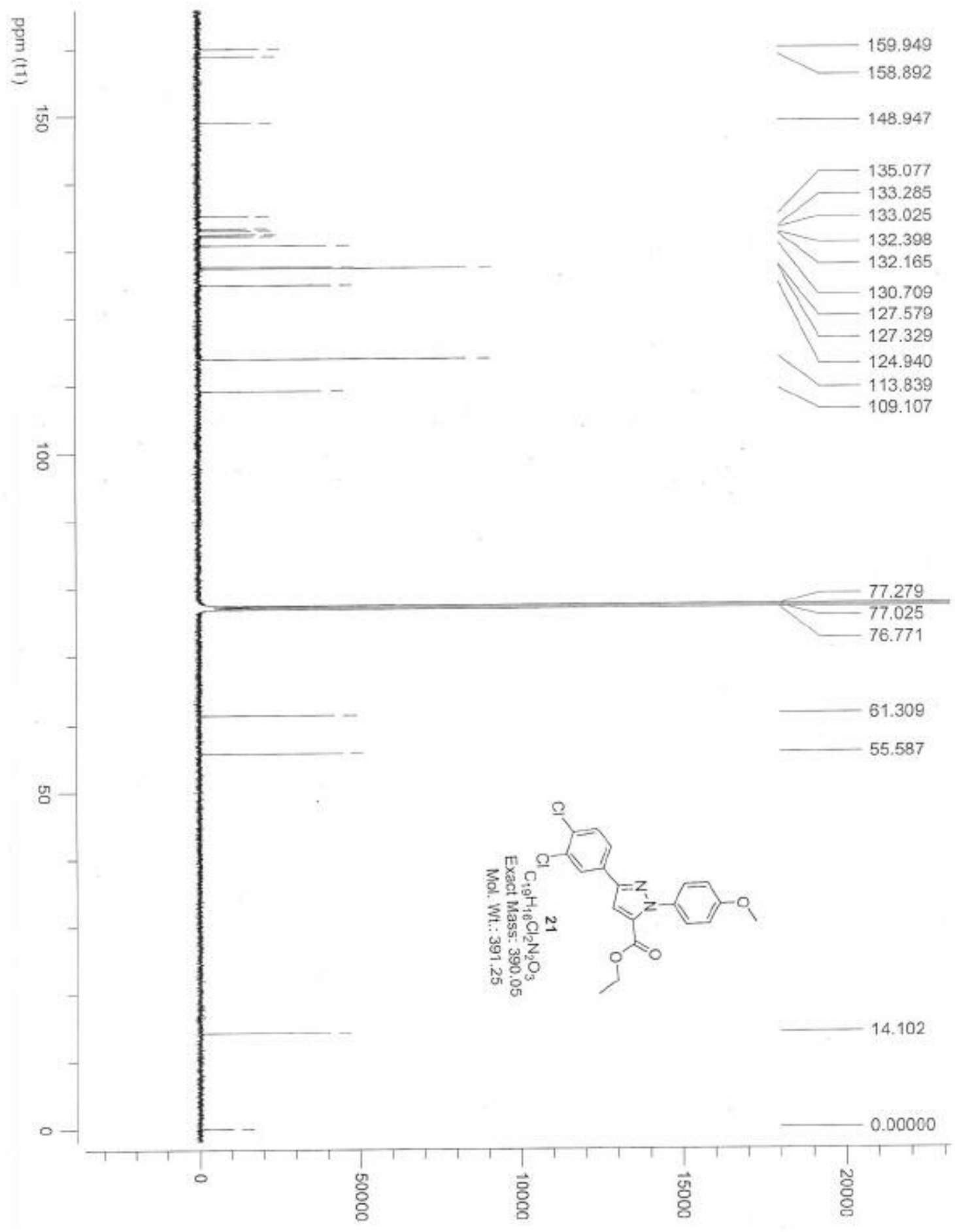


[5-(3,4-Dichlorophenyl)-1-(4-methoxyphenyl)-1H-pyrazol-3-yl]-methanol (22)

${ }^{1} \mathrm{H}$ NMR (CDCl, $\left.400 M H z\right)$

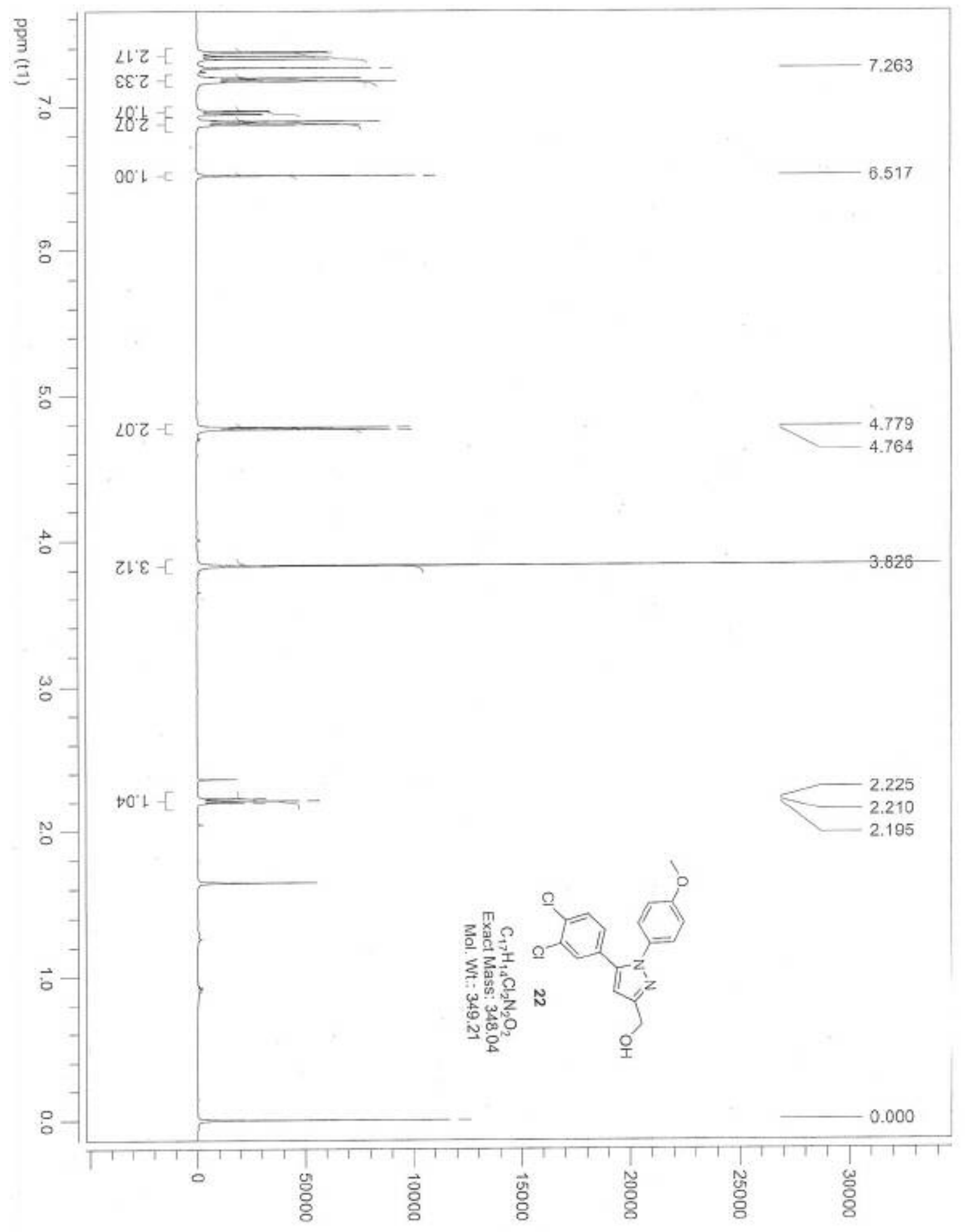


S-13

[5-(3,4-Dichlorophenyl)-1-(4-methoxyphenyl)-1H-pyrazol-3-yl]-methanol (22)

${ }^{13} \mathrm{C}$ NMR ( $\left.\mathrm{CDCl}_{3}, 100 \mathrm{MHz}\right)$

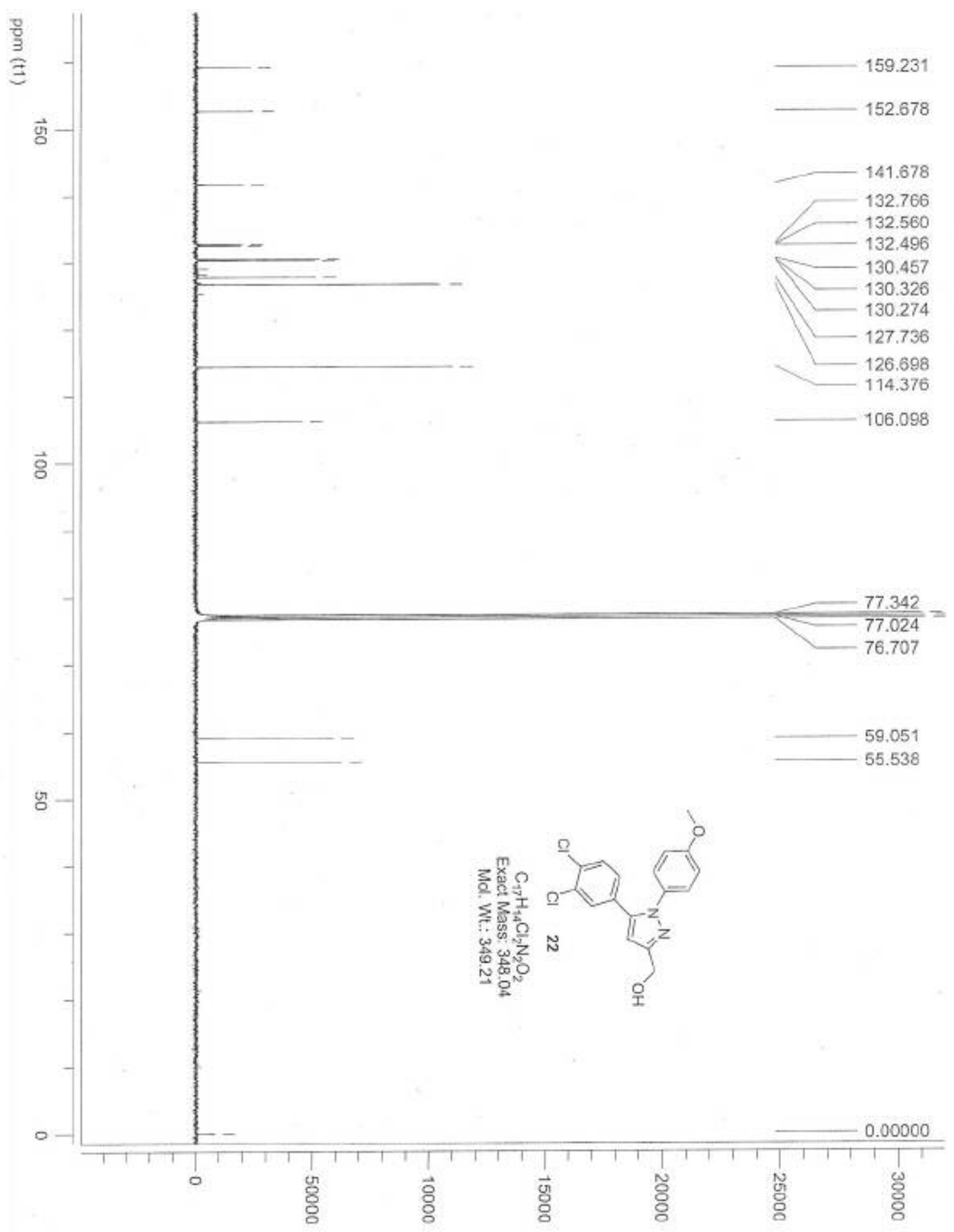


Methanesulfonic acid 5-(3,4-dichlorophenyl)-1-(4-methoxyphenyl)-1H-pyrazol-3-ylmethyl ester (23).

\section{${ }^{1} \mathrm{H}$ NMR (CDCl 3 , 400MHz)}

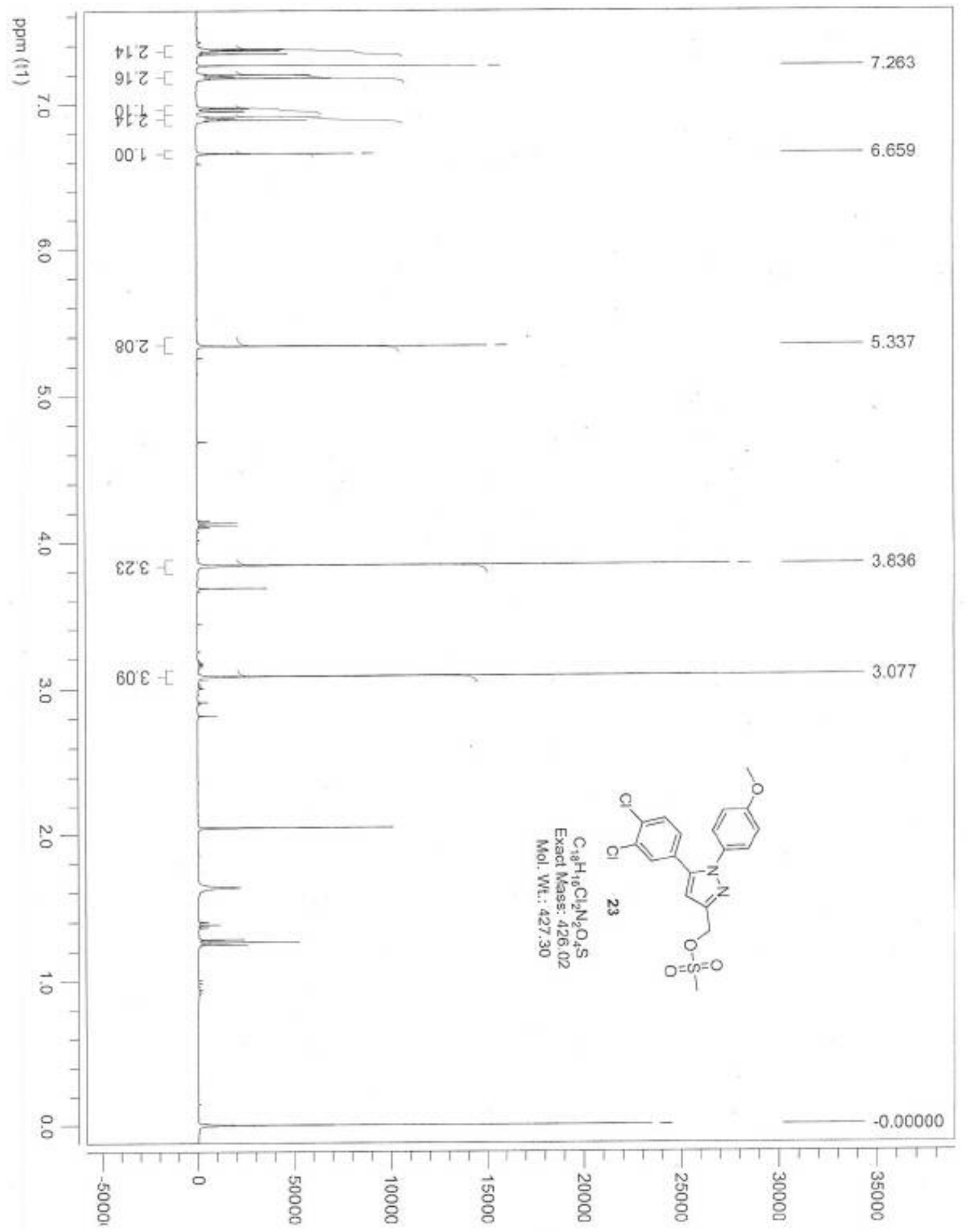


Methanesulfonic acid 5-(3,4-dichlorophenyl)-1-(4-methoxyphenyl)-1H-pyrazol-3-ylmethyl ester (23).

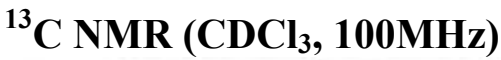

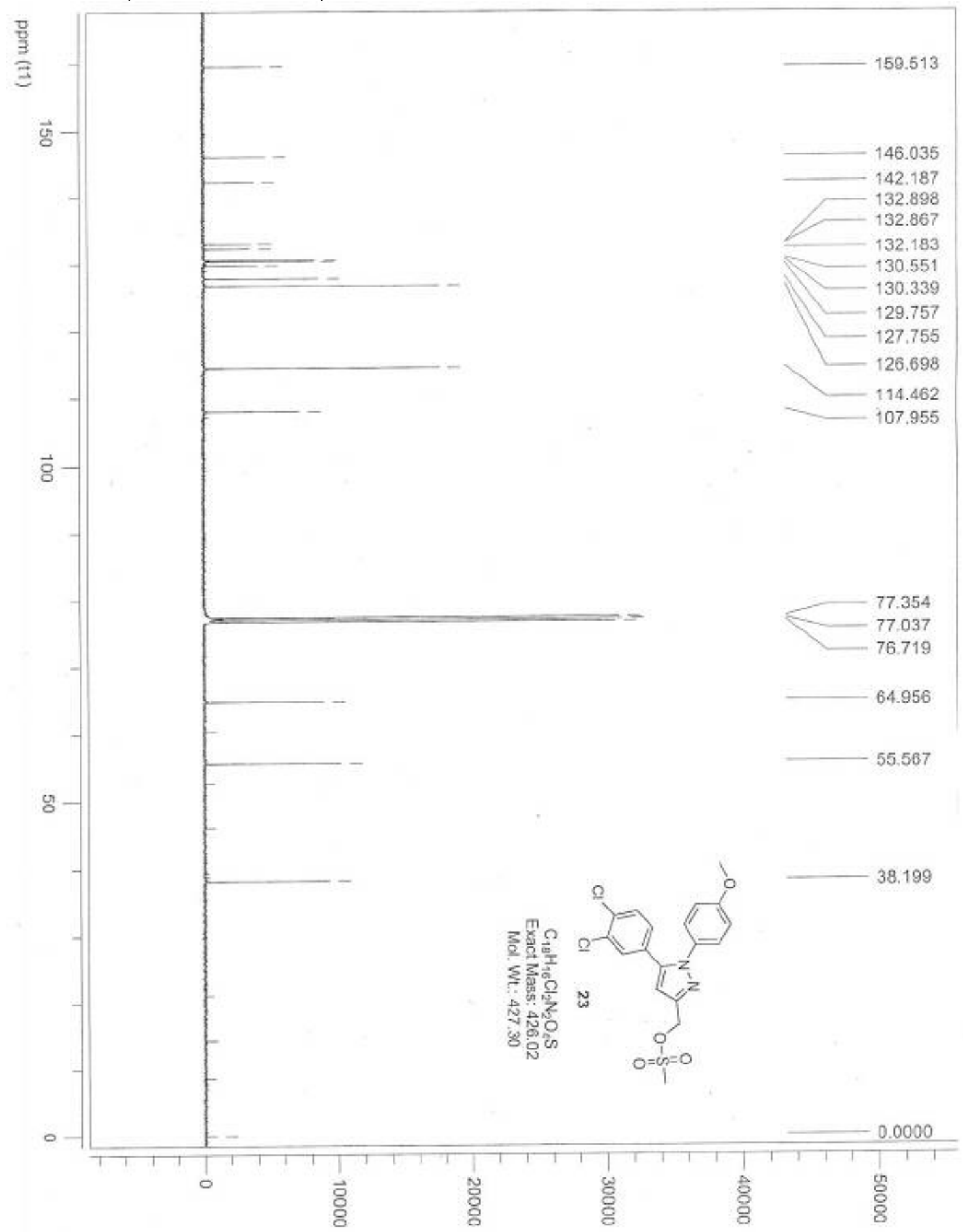


5-(3,4-Dichlorophenyl)-3-iodomethyl-1-(4-methoxyphenyl)-1H-pyrazole (24).

\section{${ }^{1} \mathrm{H} \mathrm{NMR}\left(\mathrm{CDCl}_{3}, 400 \mathrm{MHz}\right)$}

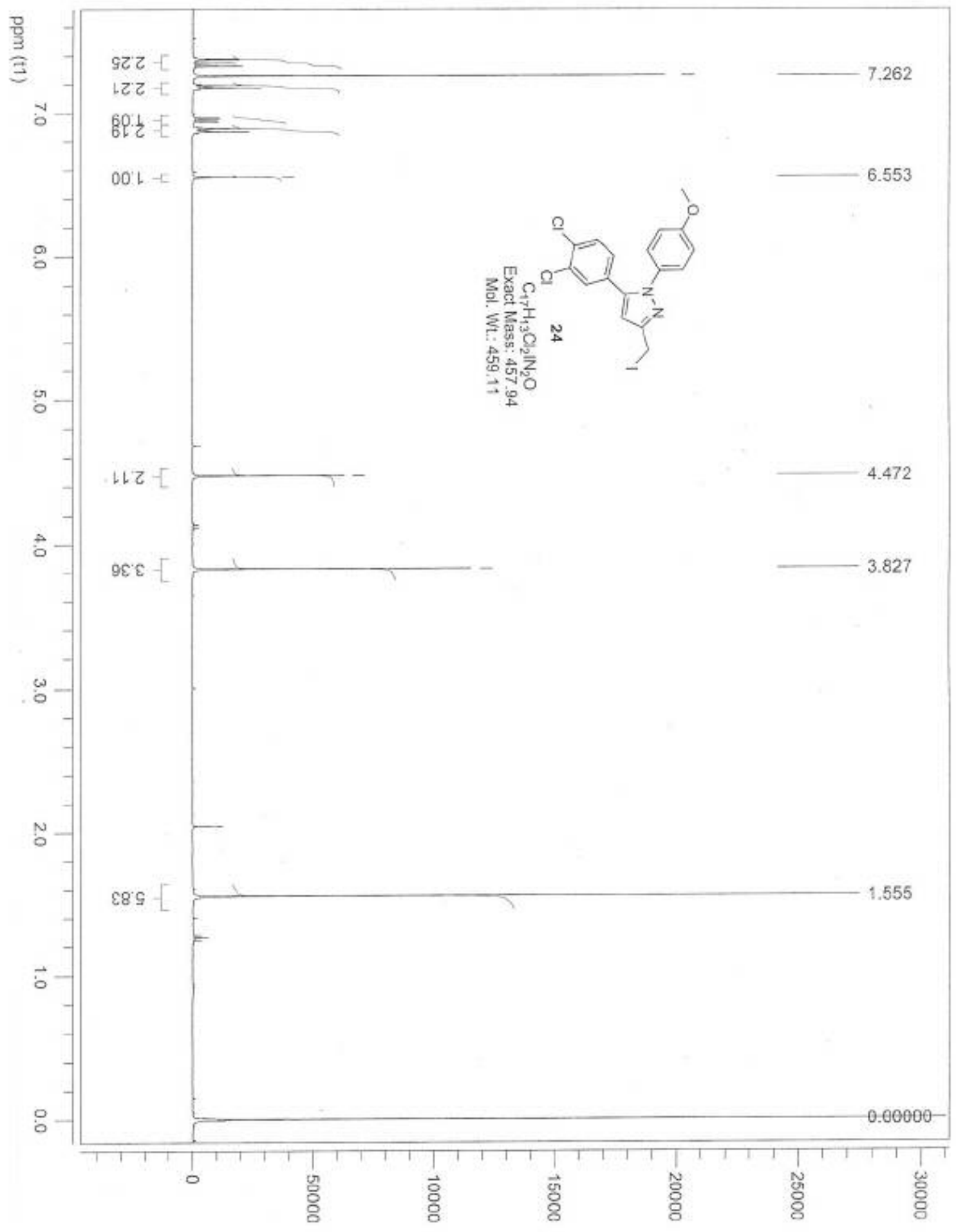


5-(3,4-Dichlorophenyl)-3-iodomethyl-1-(4-methoxyphenyl)-1H-pyrazole (24).

\section{${ }^{13} \mathrm{C}$ NMR (CDCl $\left.3,100 \mathrm{MHz}\right)$}

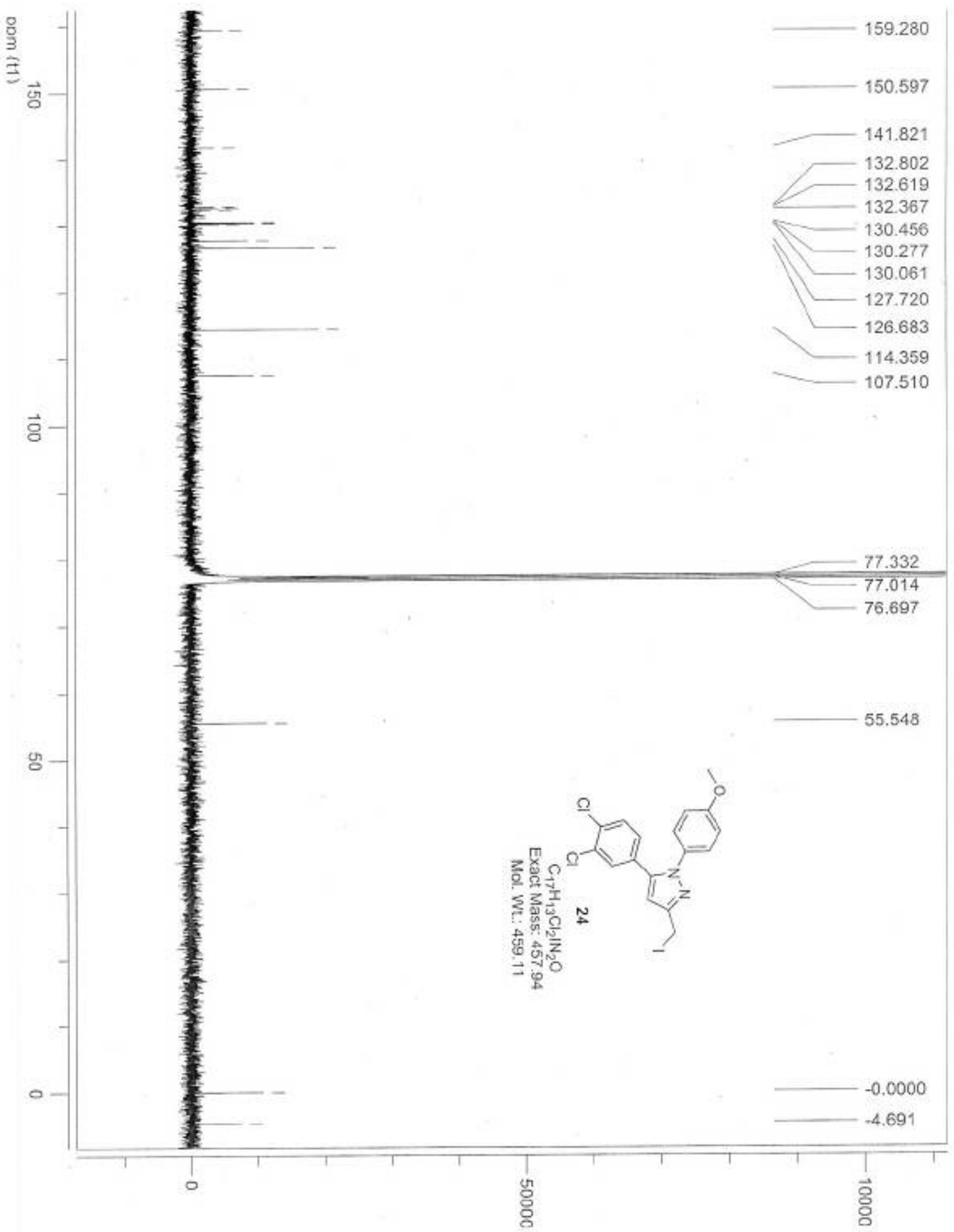


3-(2-m-Tolyl-acetyl)-3,3a,8,8a-tetrahydro-indeno[1,2-d]oxazol-2-one (25).

\section{${ }^{1} \mathrm{H} \mathrm{NMR}\left(\mathrm{CDCl}_{3}, 400 \mathrm{MHz}\right)$}

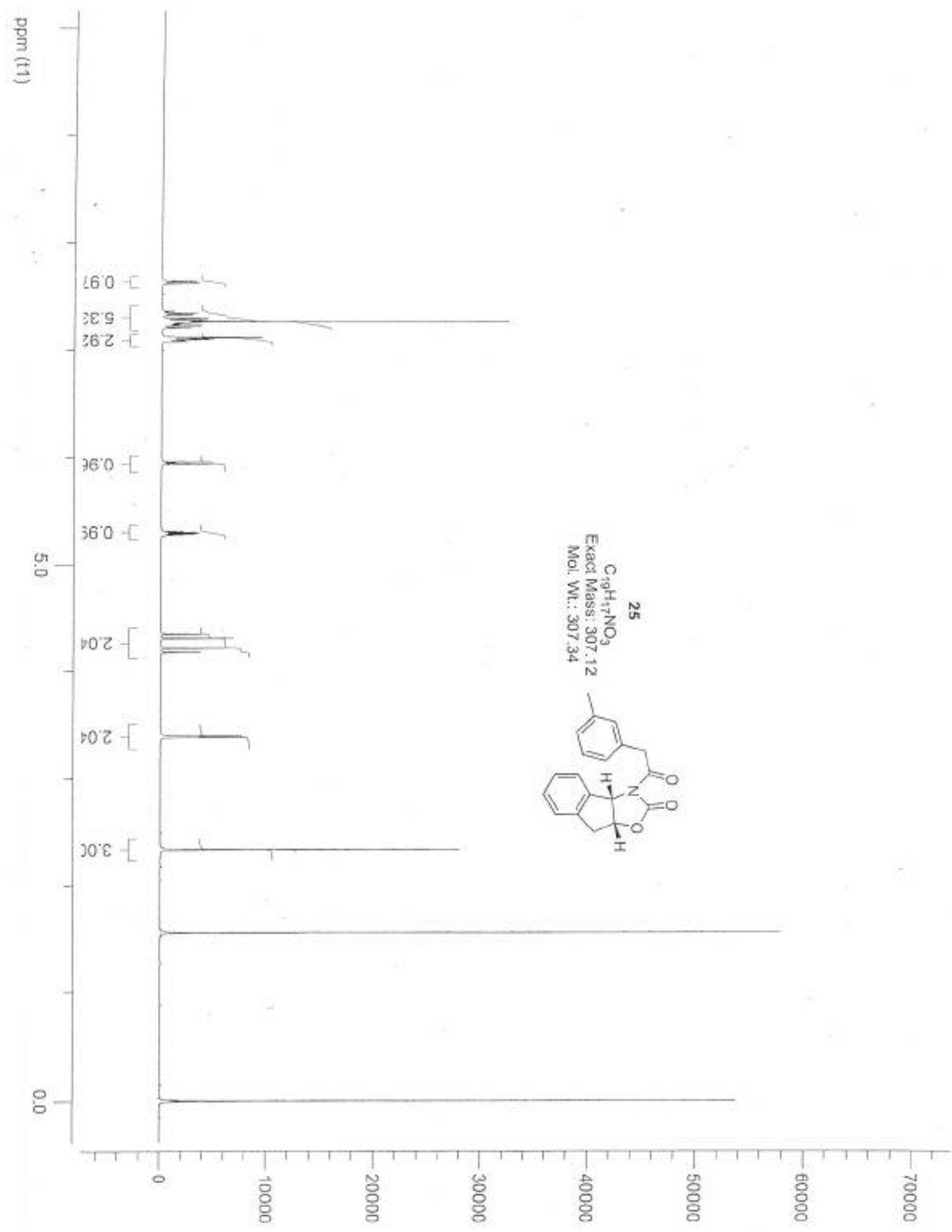


3-(2-m-Tolyl-acetyl)-3,3a,8,8a-tetrahydro-indeno[1,2-d]oxazol-2-one (25).

\section{${ }^{13} \mathrm{C}$ NMR $\left(\mathrm{CDCl}_{3}, 100 \mathrm{MHz}\right)$}

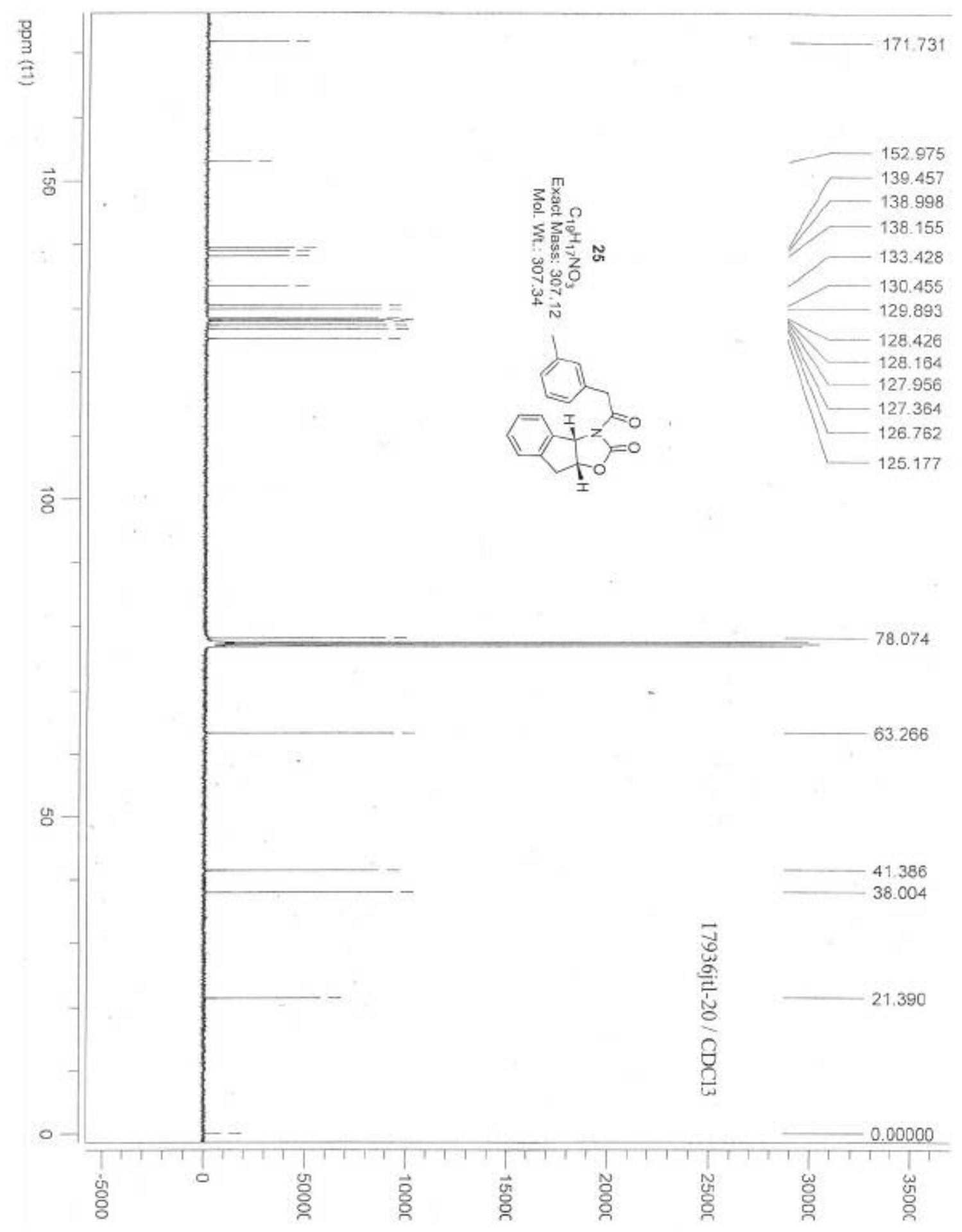


3-\{3-[5-(3,4-Dichlorophenyl)-1-(4-methoxyphenyl)-1H-pyrazol-3-yl]-2-m-tolyl-propionyl\}3,3a, 8,8a-tetrahydro-indeno[1,2-d] oxazol-2-one (26).

${ }^{1} \mathrm{H}$ NMR (CDCl $\left.3,400 \mathrm{MHz}\right)$

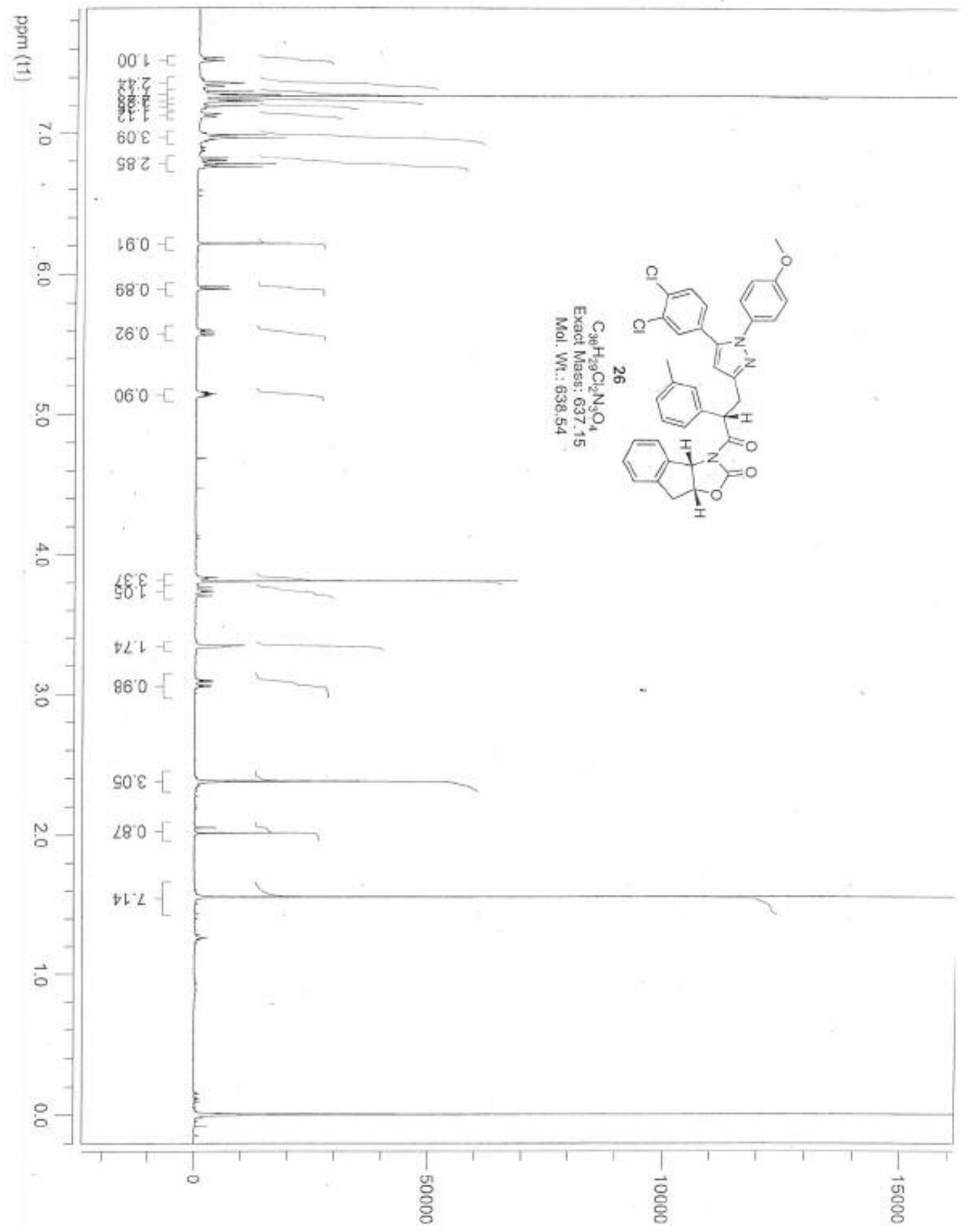


3-\{3-[5-(3,4-Dichlorophenyl)-1-(4-methoxyphenyl)-1H-pyrazol-3-yl]-2-m-tolyl-propionyl\}3,3a, 8,8a-tetrahydro-indeno[1,2-d] oxazol-2-one (26).

\section{${ }^{13} \mathrm{C}$ NMR $\left(\mathrm{CDCl}_{3}, 100 \mathrm{MHz}\right)$}

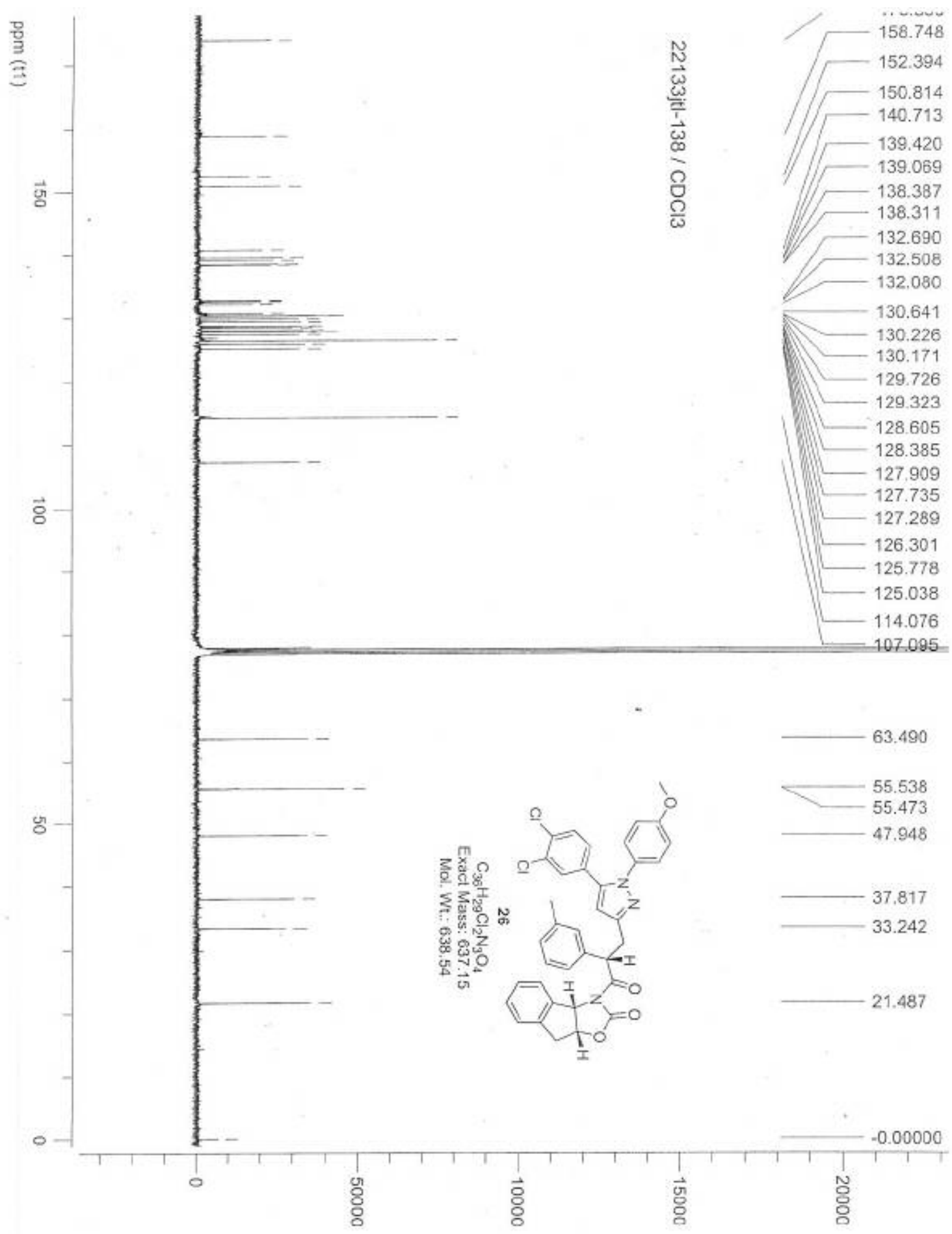


(S)-3-[5-(3,4-Dichloro-phenyl)-1-(4-methoxy-phenyl)-1H-pyrazol-3-yl]-2-m-tolyl-propionic acid (27).

${ }^{1} \mathrm{H}$ NMR $\left(\mathrm{CDCl}_{3}, 400 \mathrm{MHz}\right)$

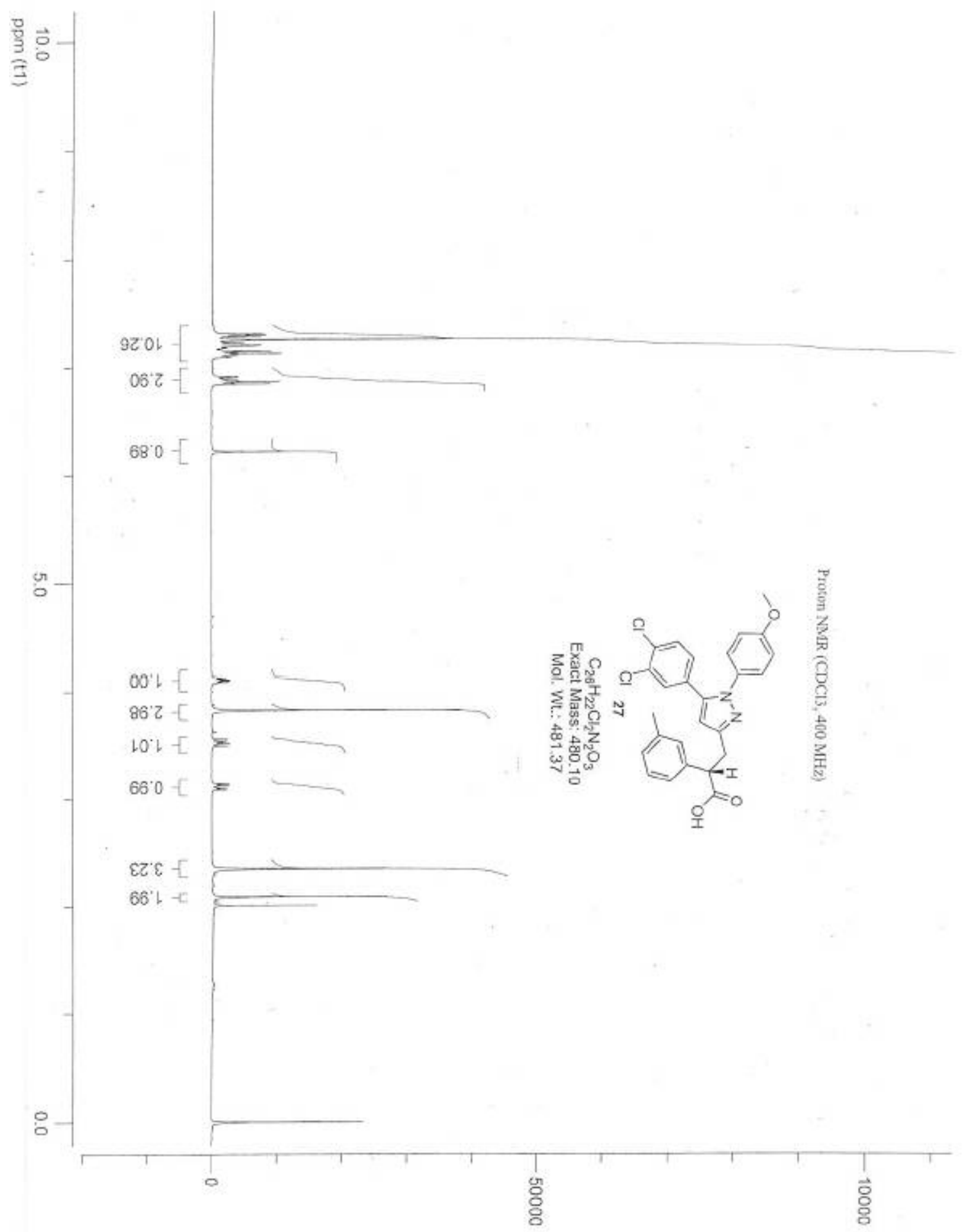


(S)-3-[5-(3,4-Dichloro-phenyl)-1-(4-methoxy-phenyl)-1H-pyrazol-3-yl]-2-m-tolyl-propionic acid (27).

${ }^{13} \mathrm{C}$ NMR (CDCl $\left.3,100 \mathrm{MHz}\right)$

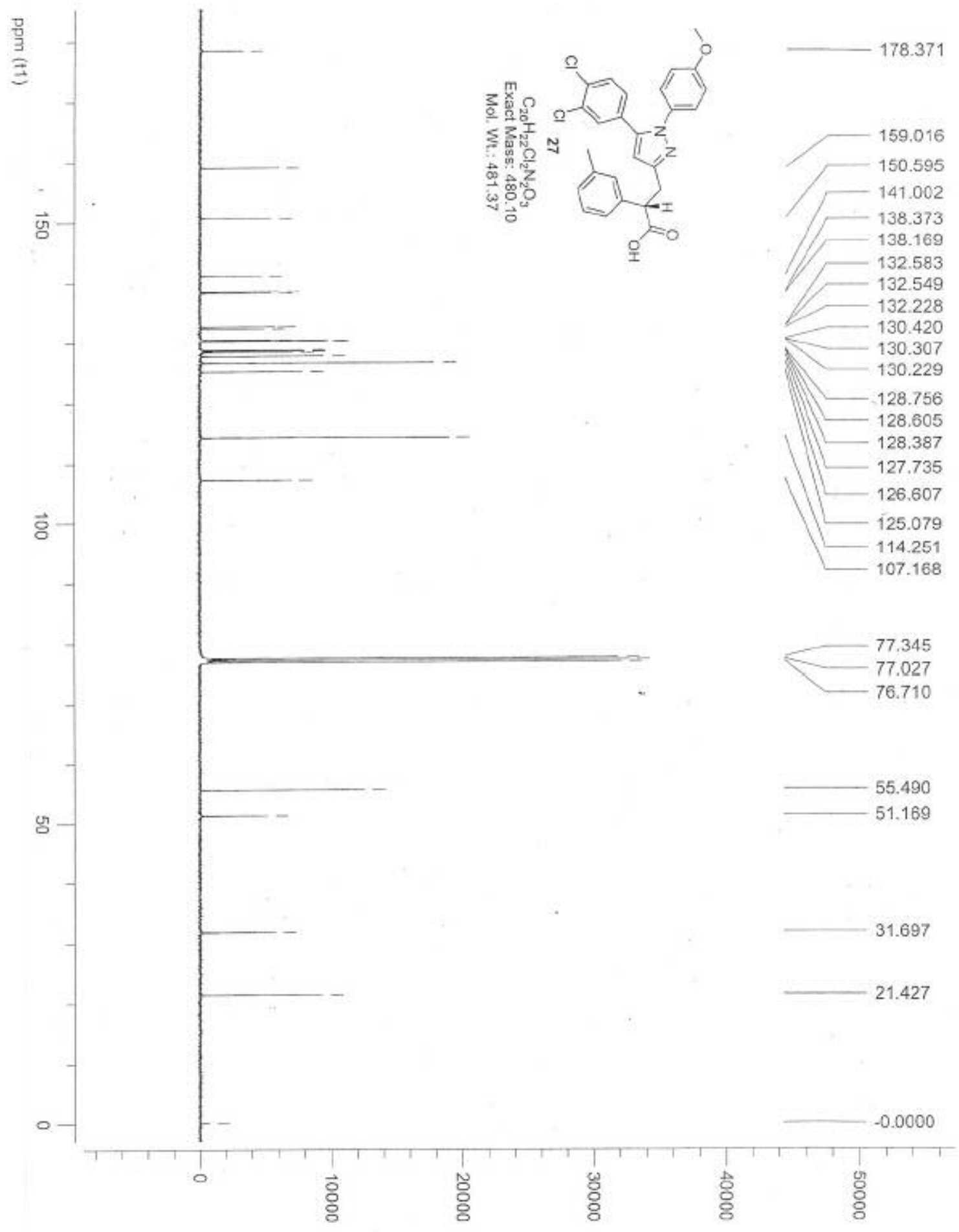


(S)-Sodium;3-[5-(3,4-dichloro-phenyl)-1-(4-methoxy-phenyl)-1H-pyrazol-3-yl]-2-m-tolylpropionate (1).

${ }^{1} \mathrm{H}$ NMR (D) $\left.\mathbf{O}, 500 \mathrm{MHz}\right)$

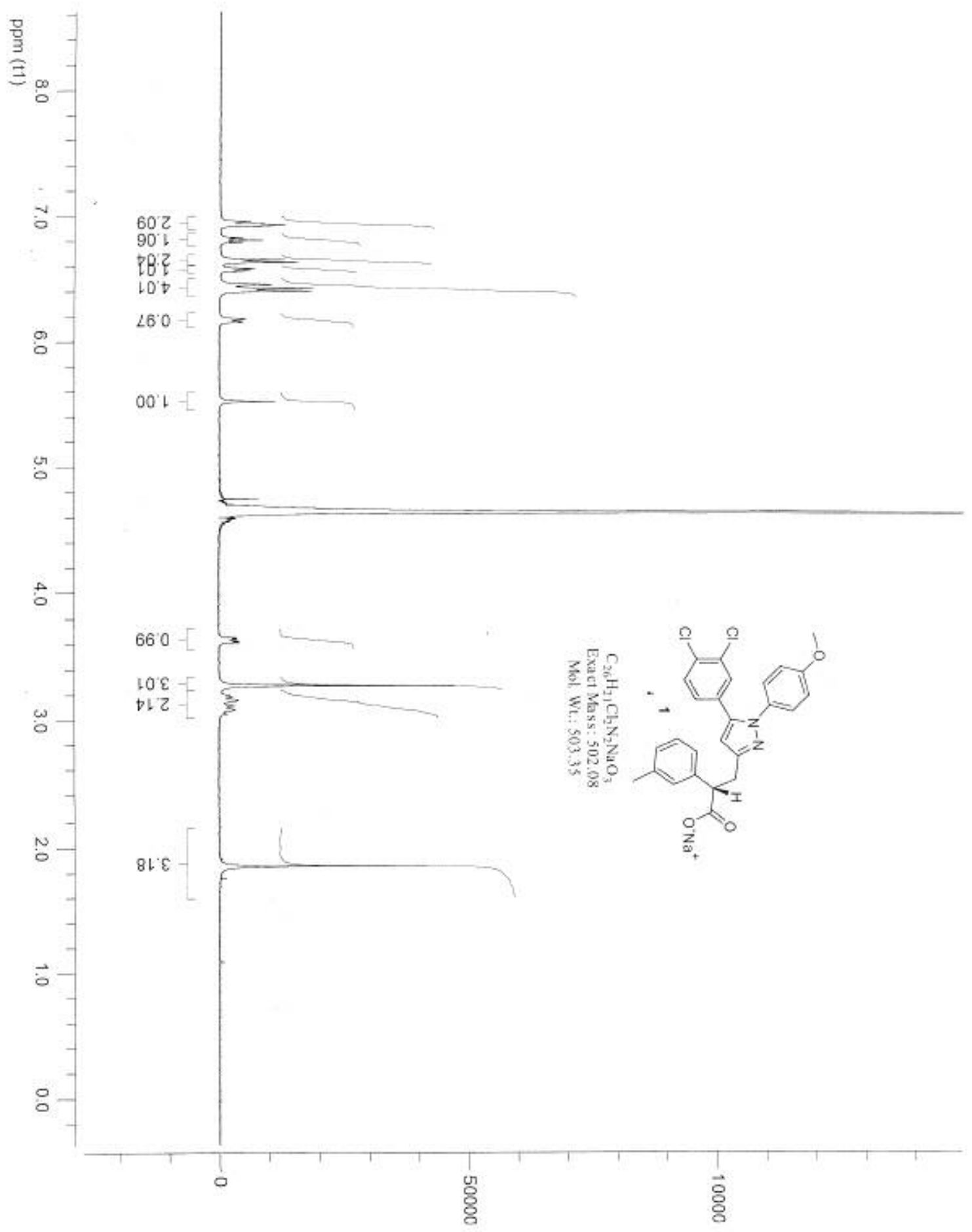


(S)-Sodium;3-[5-(3,4-dichloro-phenyl)-1-(4-methoxy-phenyl)-1H-pyrazol-3-yl]-2-m-tolylpropionate (1).

${ }^{13}$ C NMR (DMSO, 100MHz)

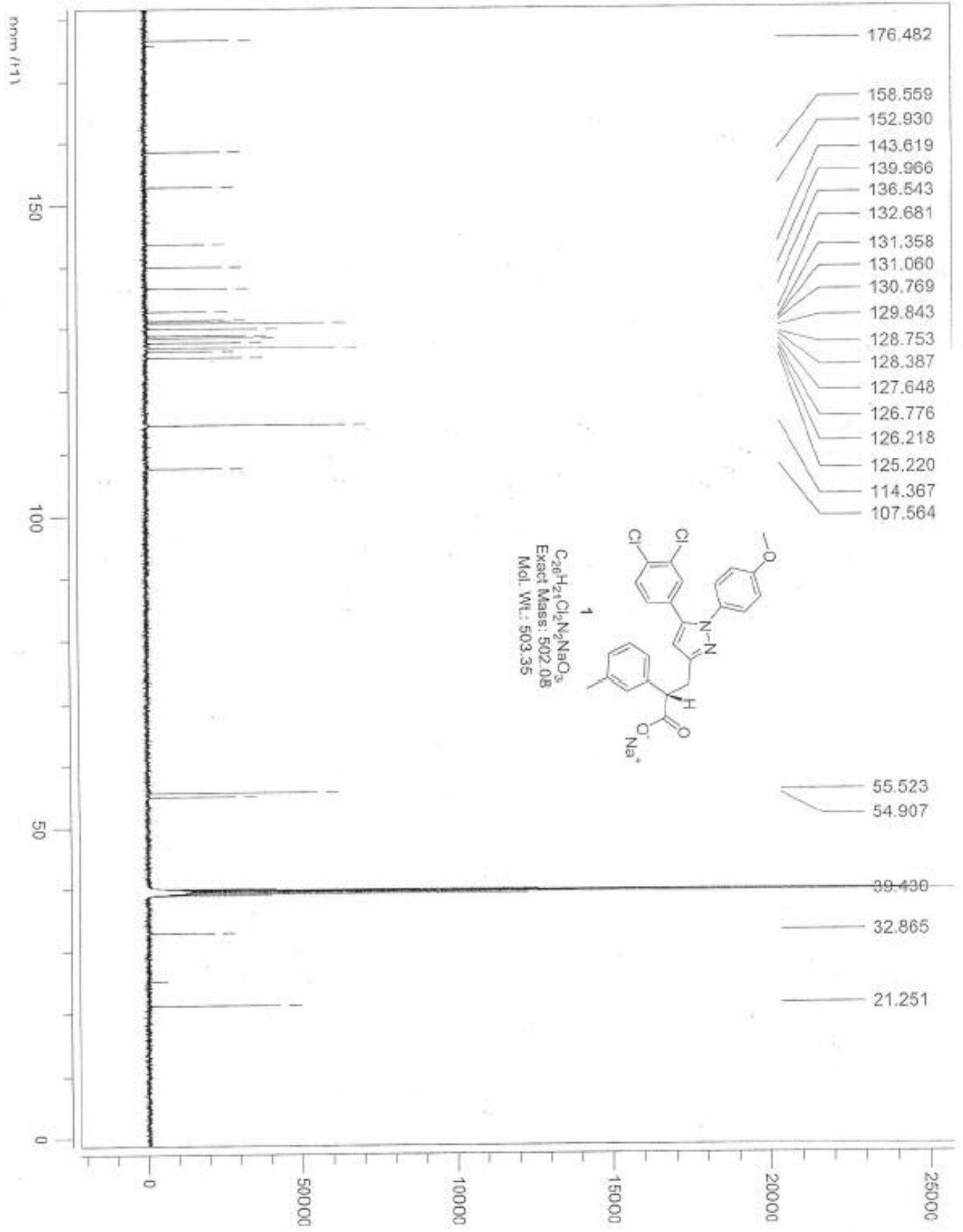




\section{Section 2: $1 \mathrm{H}$ and 13C Spectra}

\section{Synthesis of by the second route (Equation 2, Schemes $1 \& 3$ )}

\section{Equation 2}

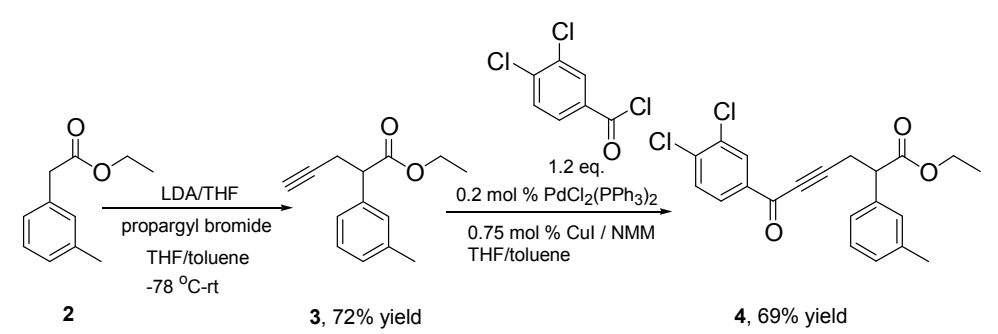

Scheme 1

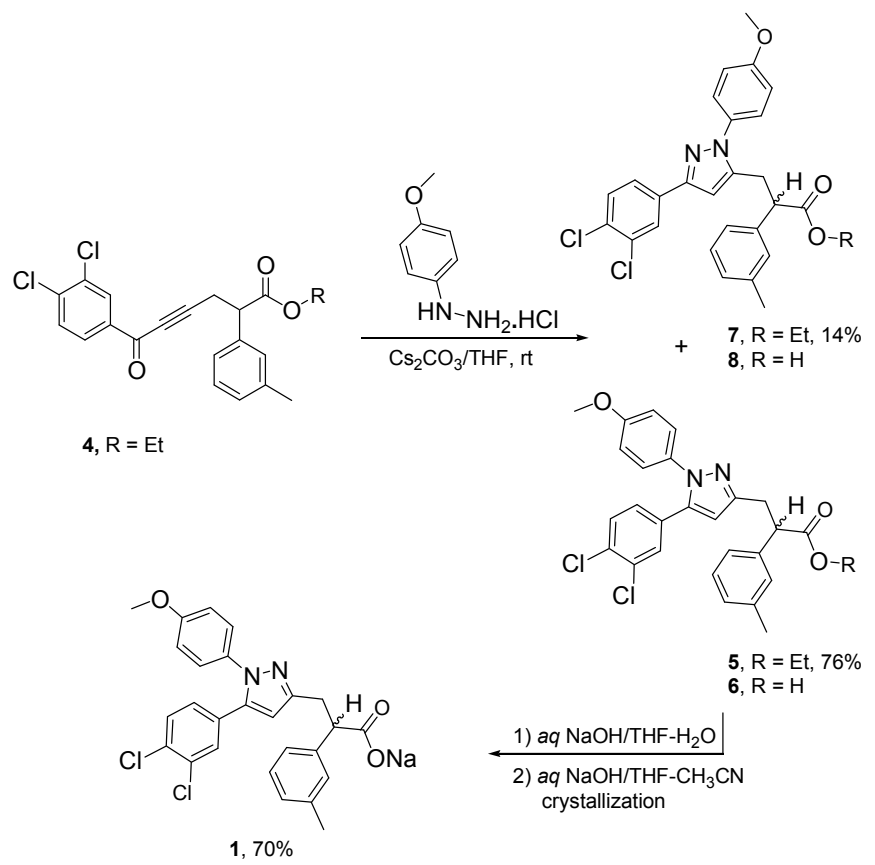


Scheme 3

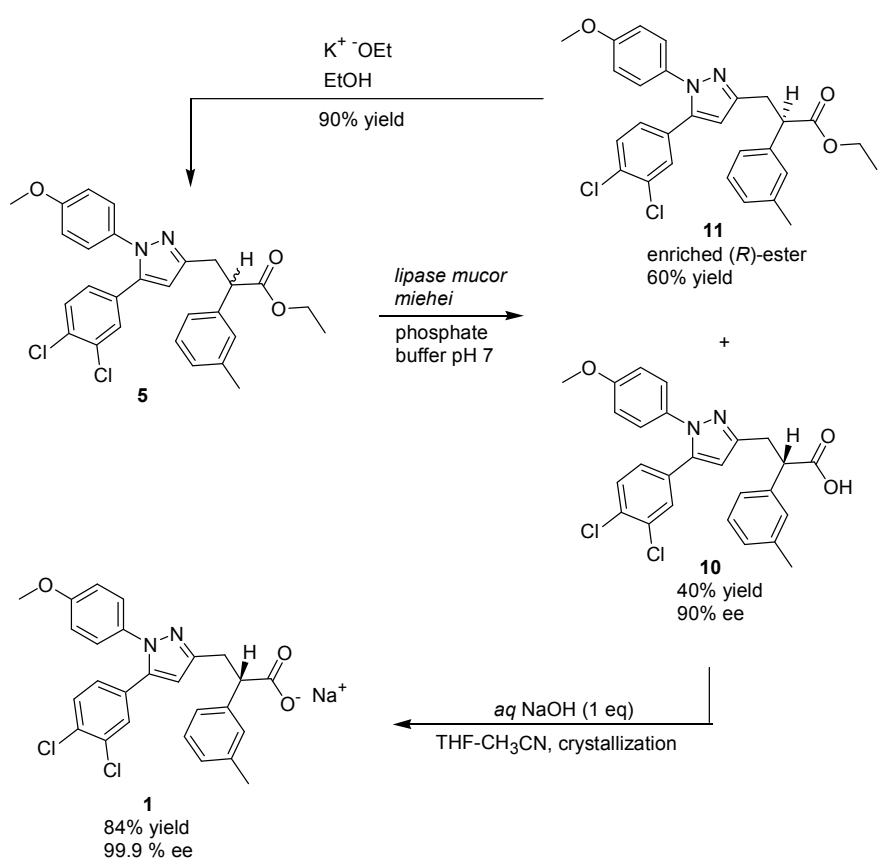


2-m-Tolyl-pent-4-ynoic acid ethyl ester (3)

${ }^{1} \mathrm{H}$ NMR $\left(\mathrm{CDCl}_{3}, 400 \mathrm{MHz}\right)$

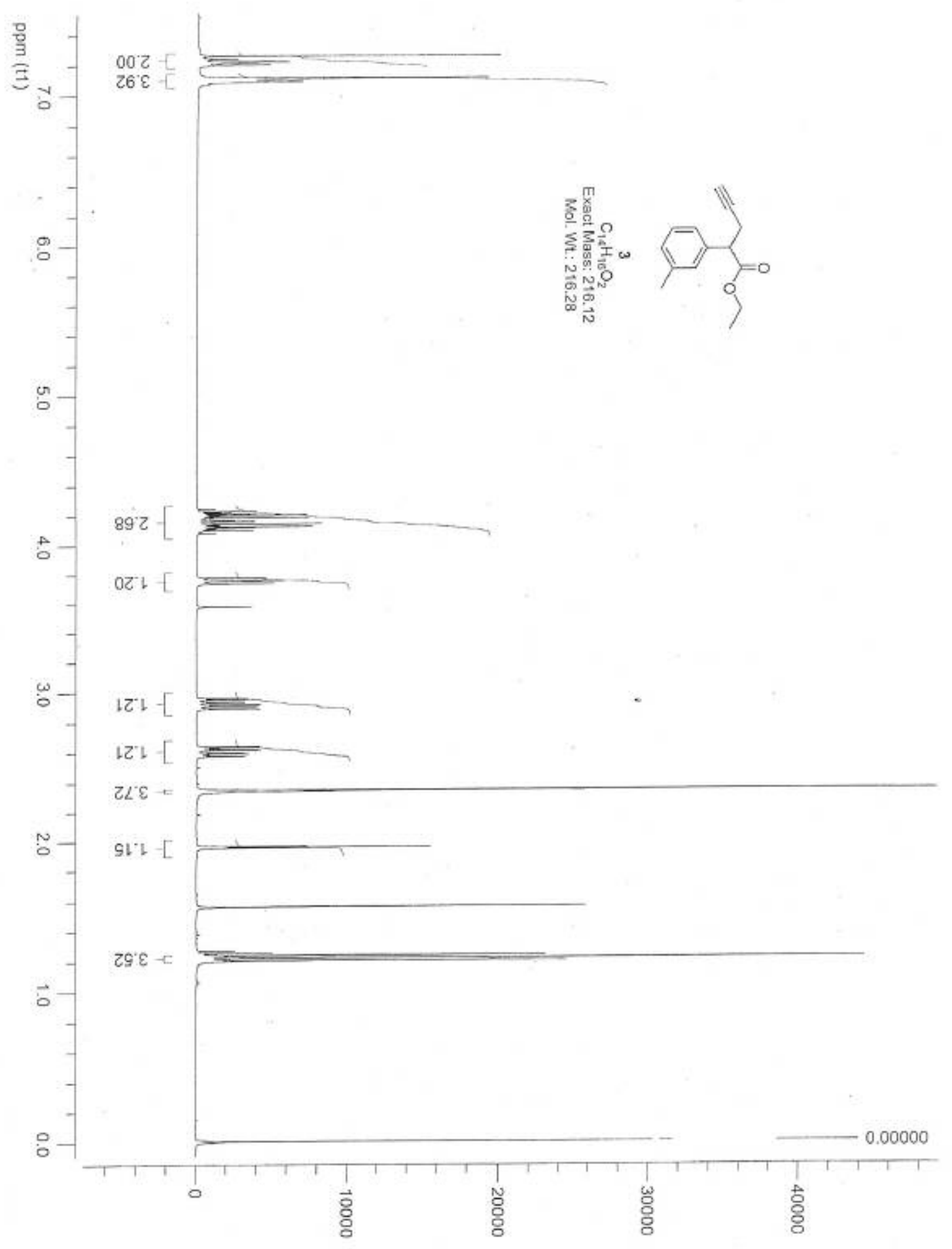


2-m-Tolyl-pent-4-ynoic acid ethyl ester (3)

${ }^{13} \mathrm{C}$ NMR (CDCl $\left.3,100 \mathrm{MHz}\right)$

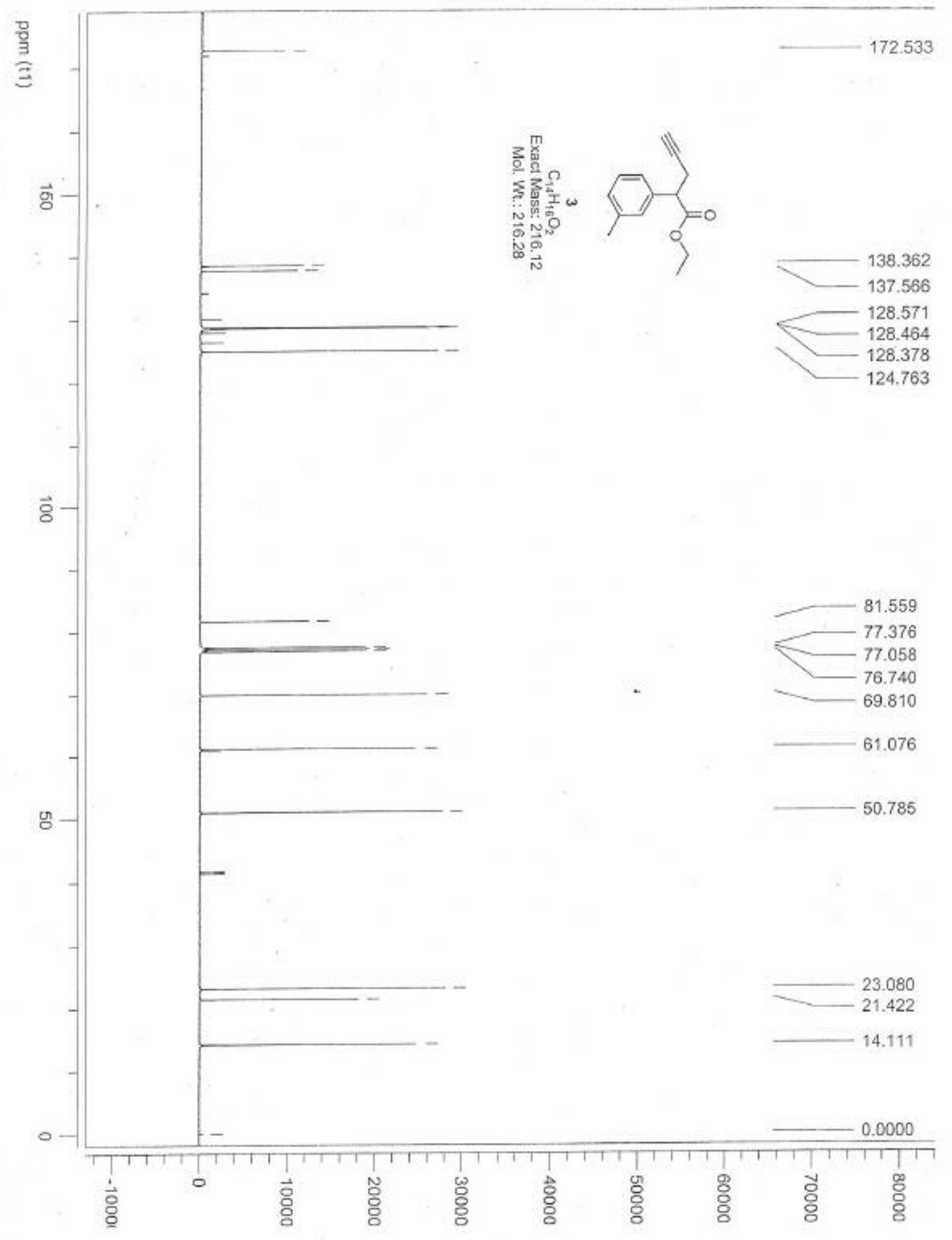


6-(3,4-Dichloro-phenyl)-6-oxo-2-m-tolyl-hex-4-ynoic acid ethyl ester (4)

${ }^{1} \mathrm{H}$ NMR (CDCl, $\left.400 \mathrm{MHz}\right)$

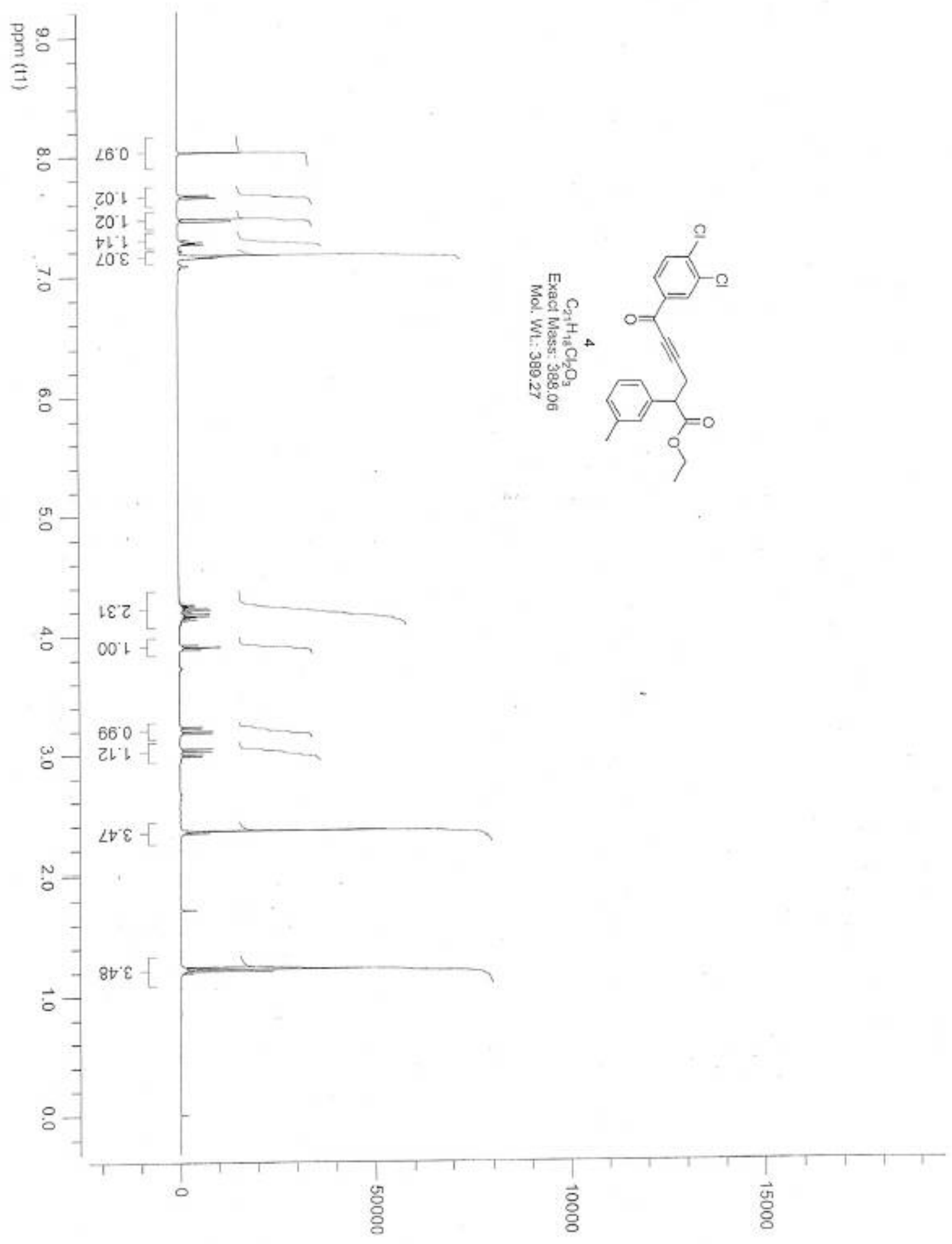


6-(3,4-Dichloro-phenyl)-6-0xo-2-m-tolyl-hex-4-ynoic acid ethyl ester (4)

${ }^{13} \mathrm{C}$ NMR (CDCl $\left.3,100 M H z\right)$

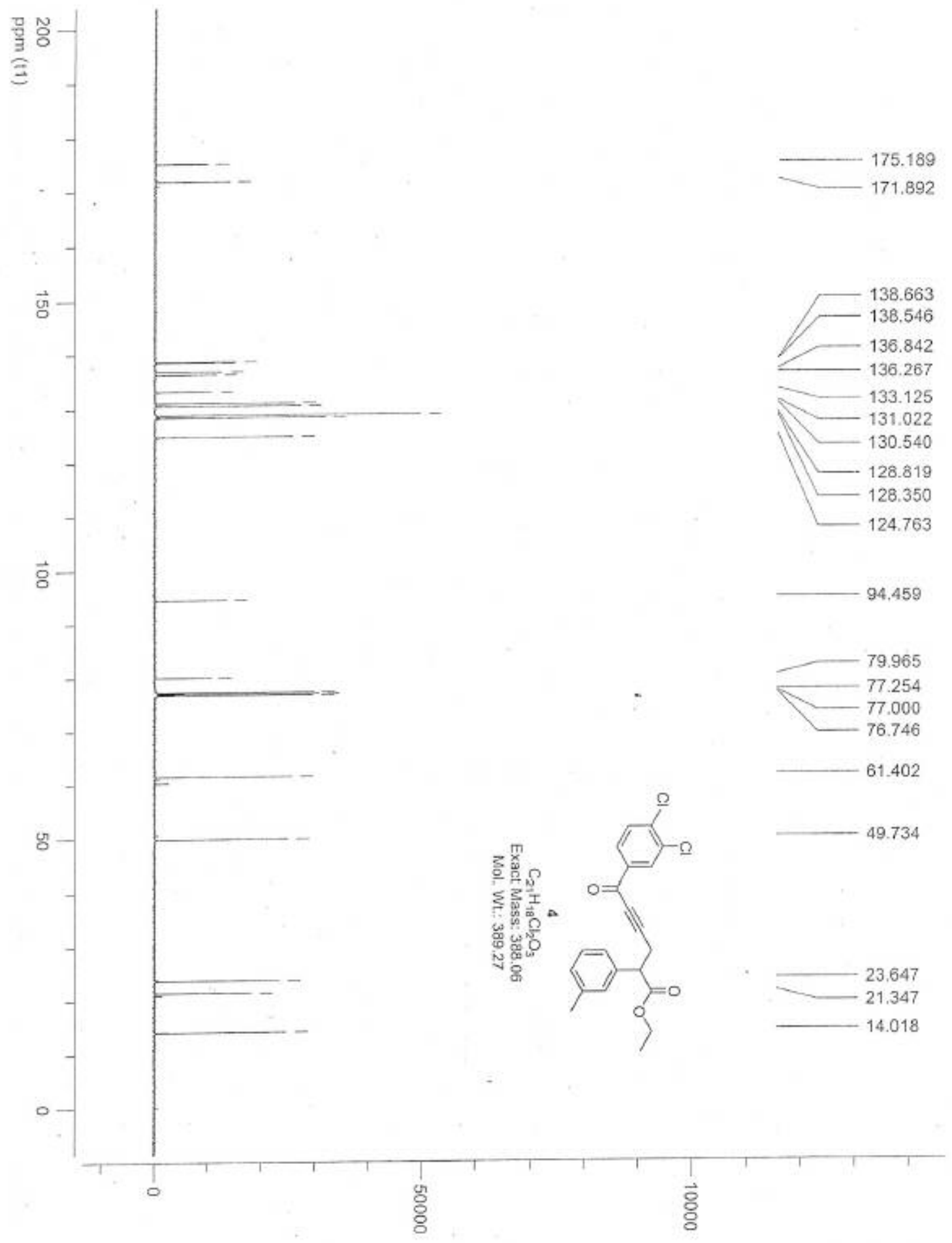


3-[5-(3,4-Dichloro-phenyl)-1-(4-methoxy-phenyl)-1H-pyrazol-3-yl]-2-m-tolyl-propionic acid ethyl ester (5)

${ }^{1} \mathrm{H}$ NMR $\left(\mathrm{CDCl}_{3}, 400 \mathrm{MHz}\right)$

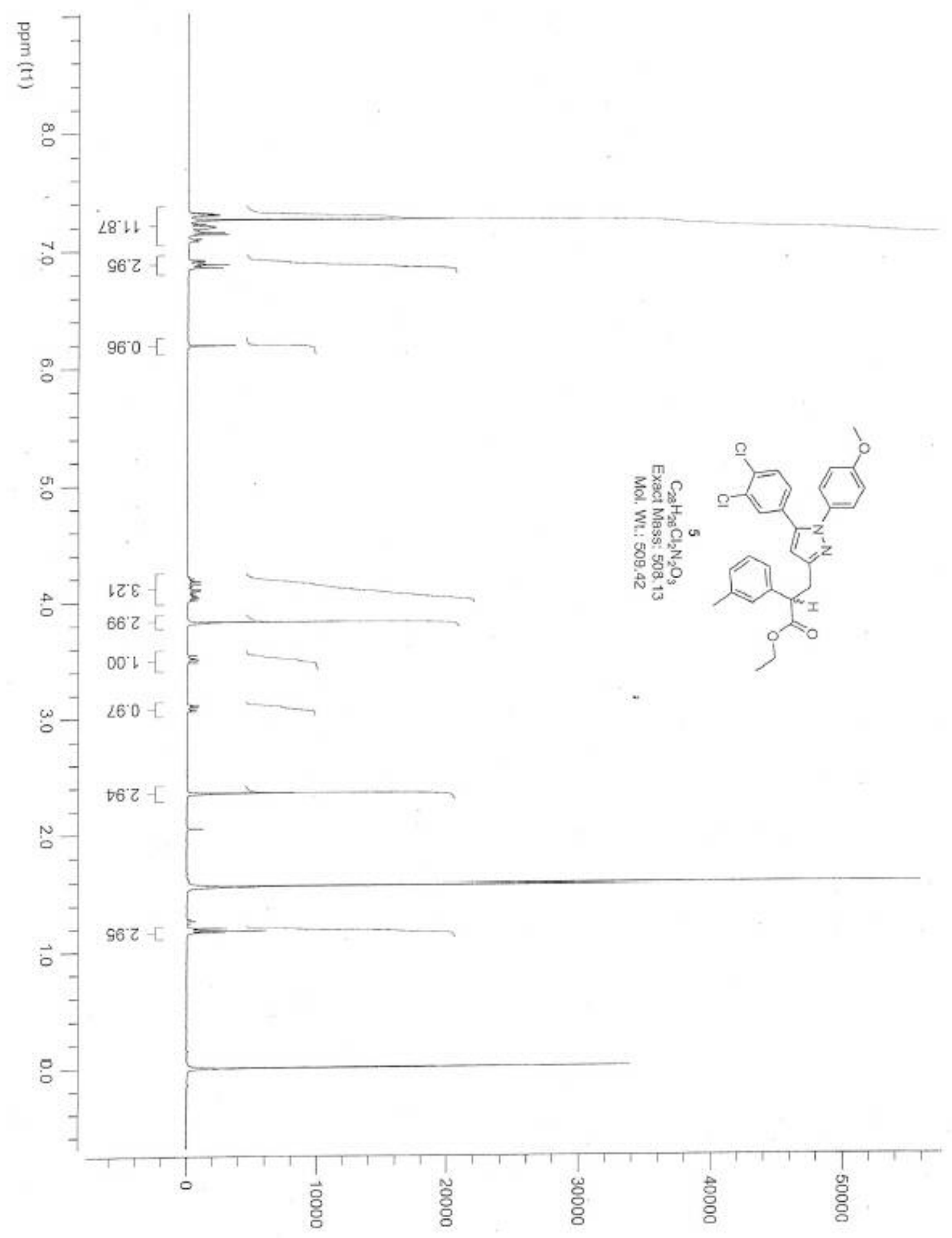


3-[5-(3,4-Dichloro-phenyl)-1-(4-methoxy-phenyl)-1H-pyrazol-3-yl]-2-m-tolyl-propionic acid ethyl ester (5)

${ }^{13} \mathrm{C}$ NMR (CDCl $\left.3,100 \mathrm{MHz}\right)$

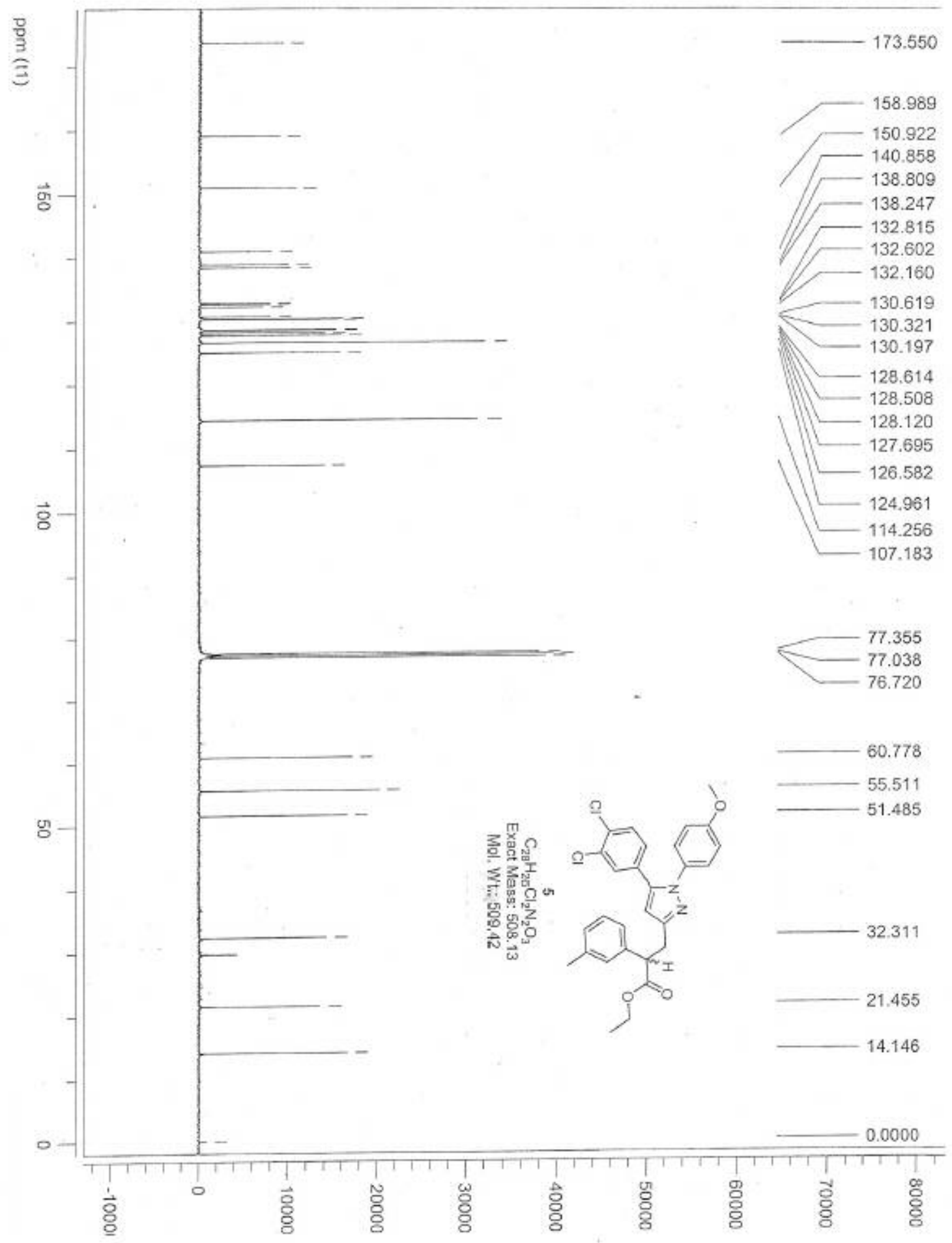


S-34

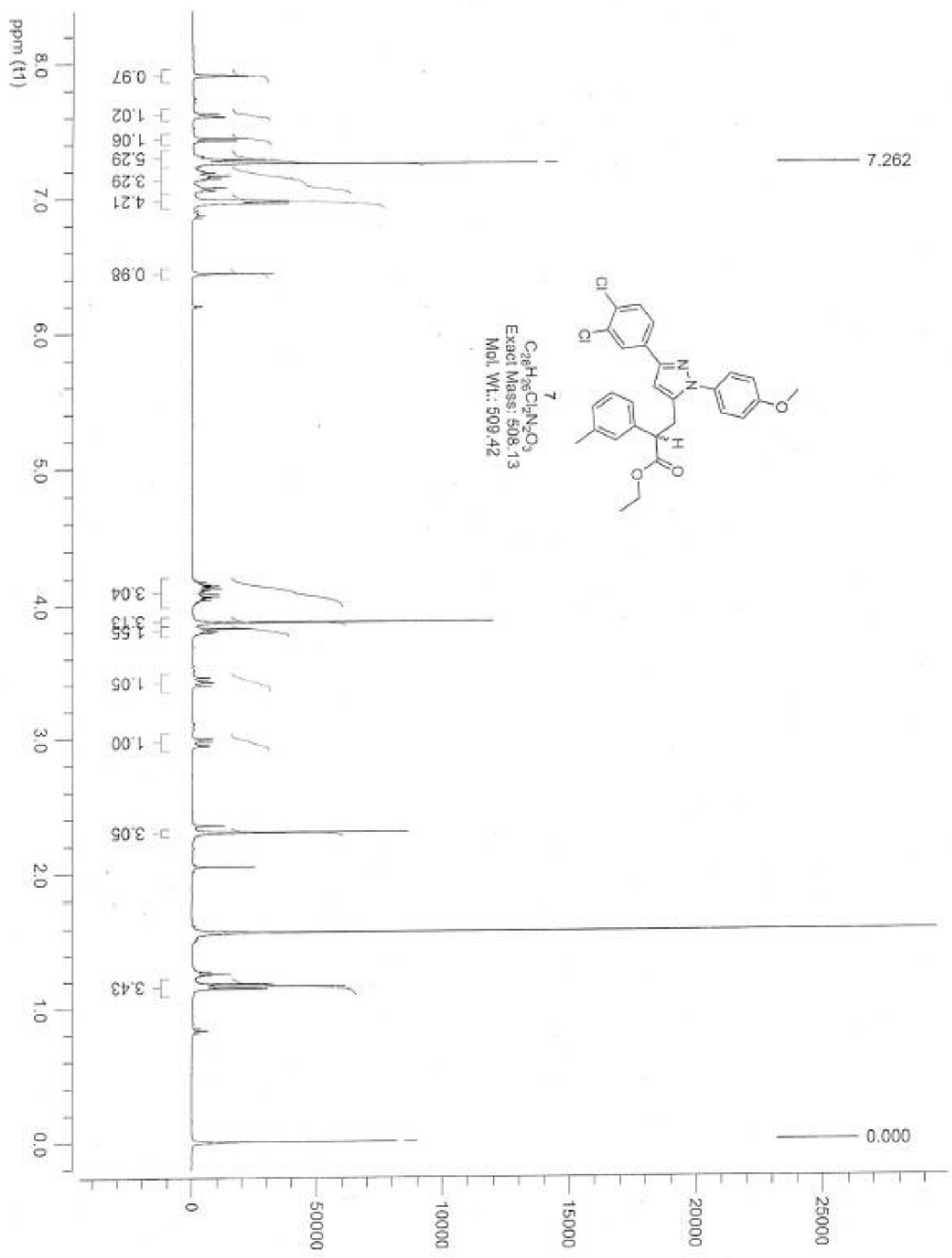


S-35

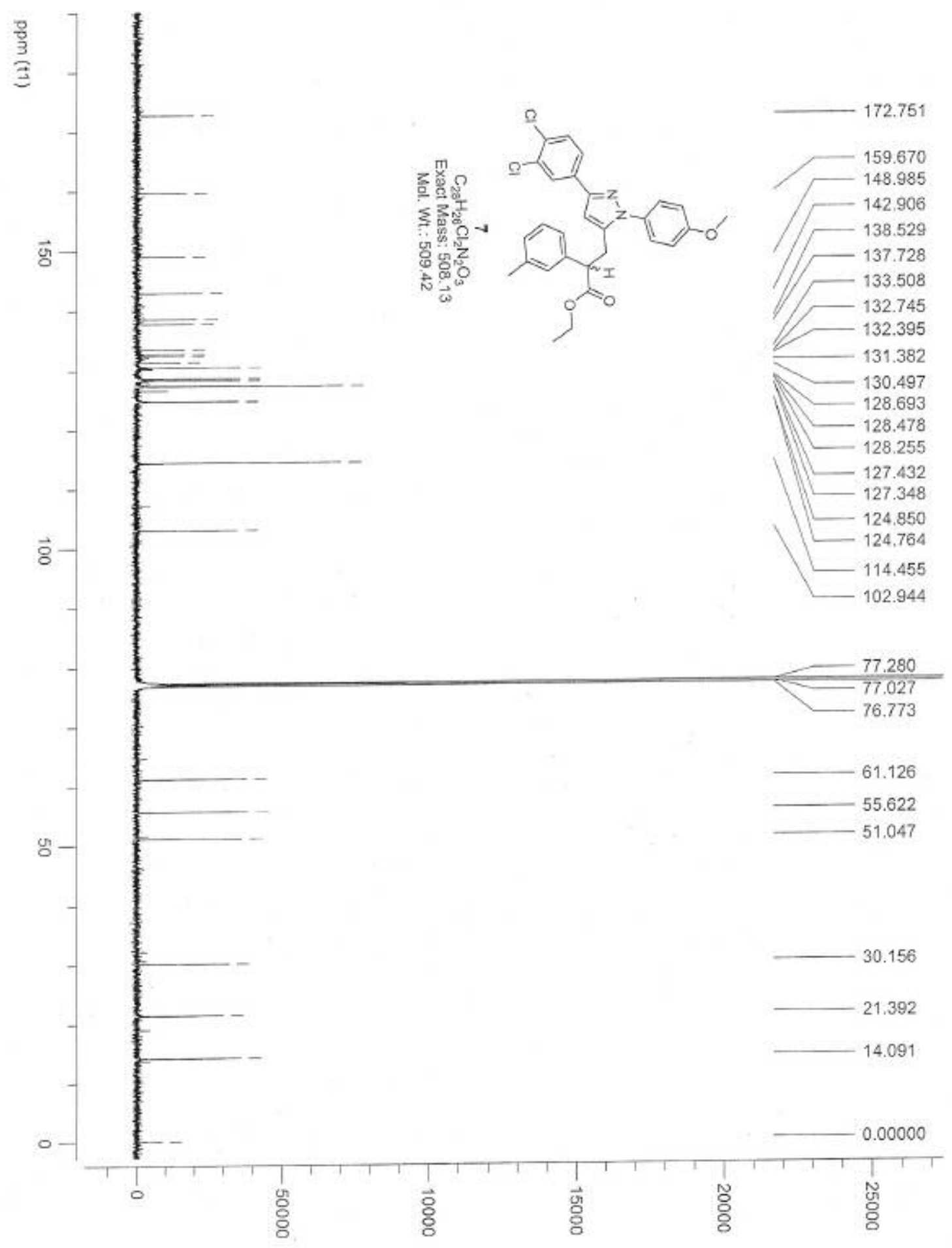


S-36

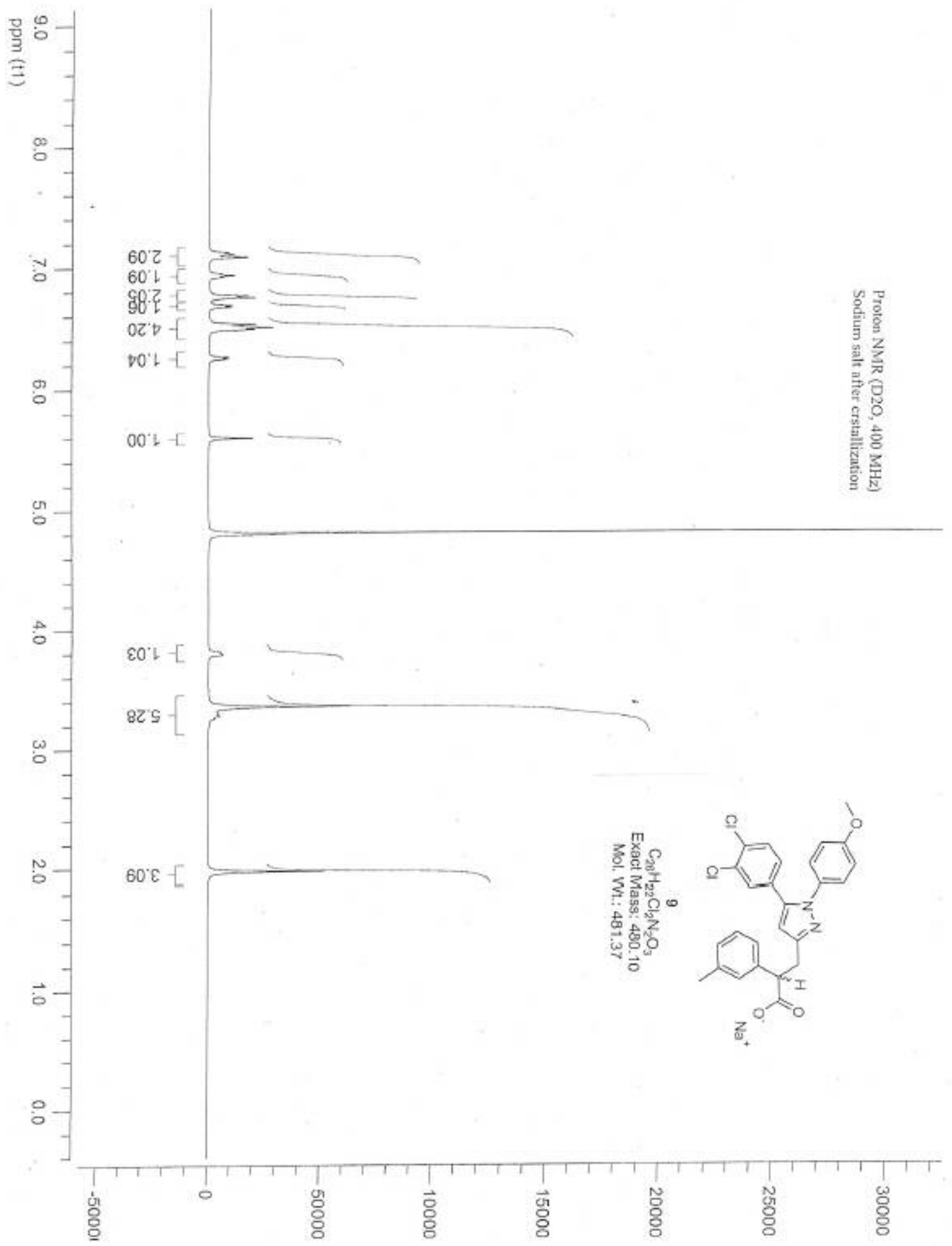


S-37

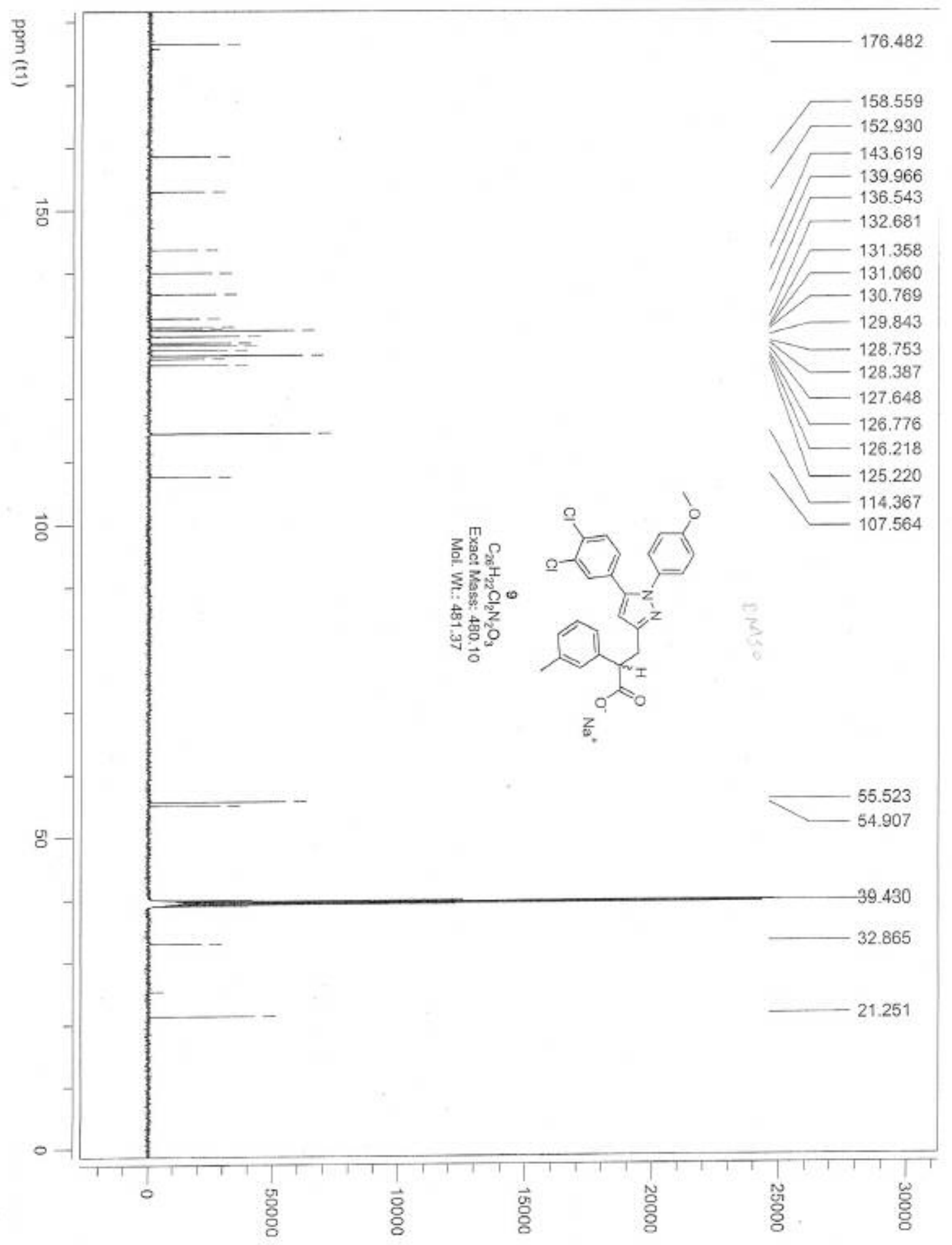


Figure 1. Chromatogram of racemic aryl propionate ester $\mathbf{5}$.

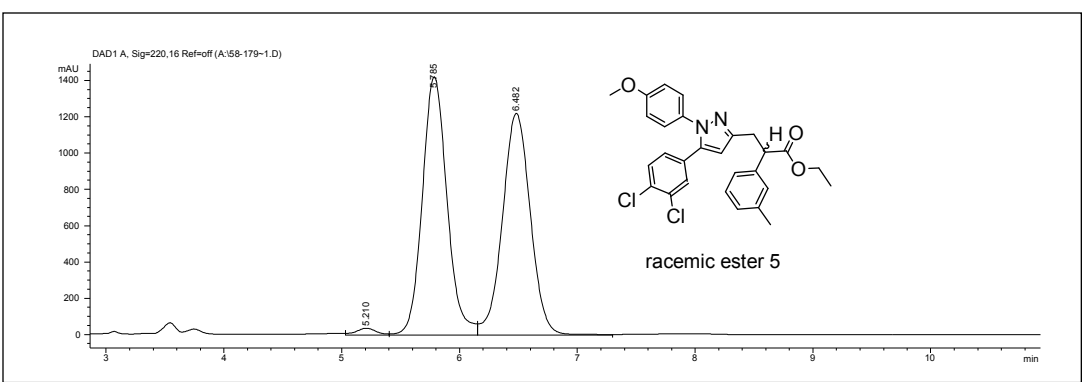

Figure 2. Chromatogram of the crude mixture after enzymatic hydrolysis of 5

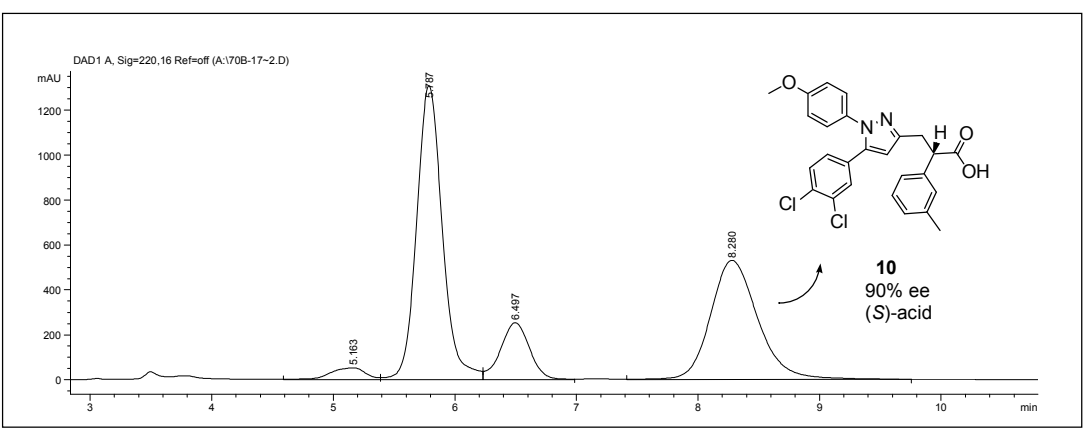

Figure 3. Chromatogram of isolated enriched $(S)$-aryl propionic acid $\mathbf{1 0}$

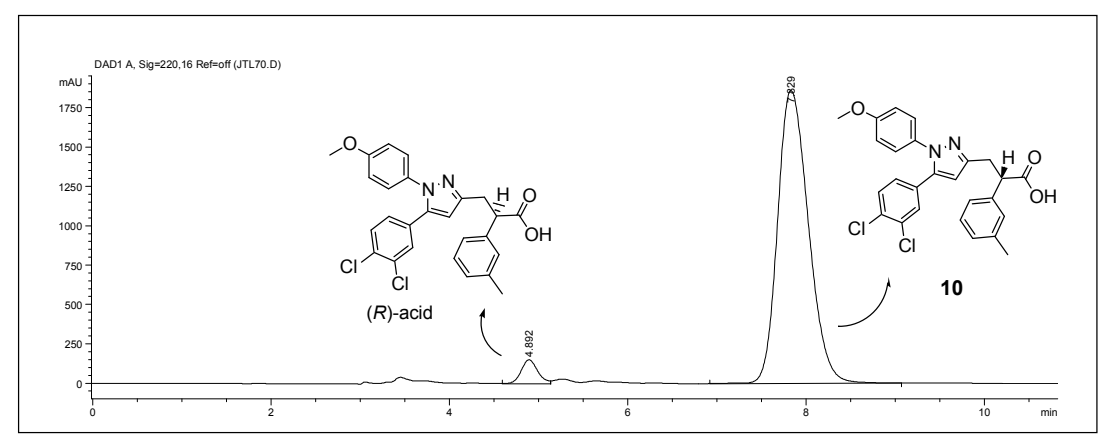

Figure 4. Chromatogram of $(S)$-aryl propionate salt 1 after crystallization

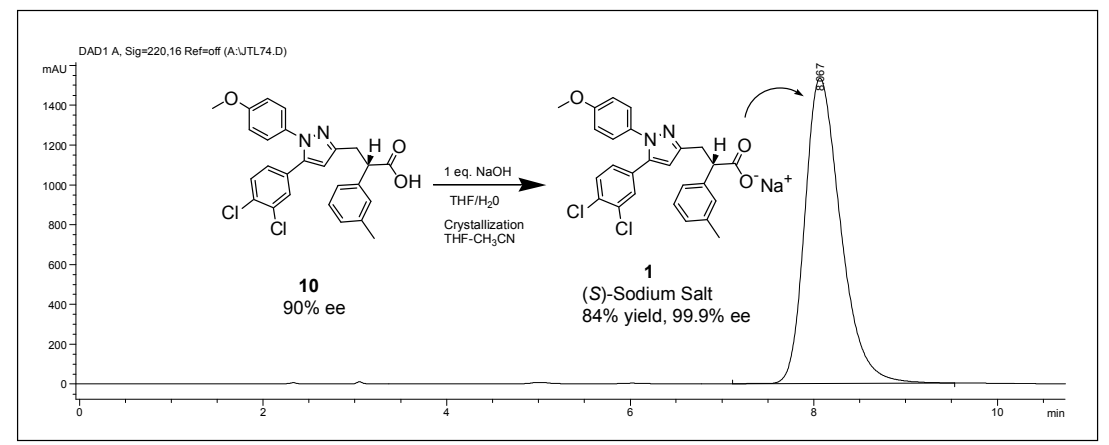


(S)-3-[5-(3,4-Dichloro-phenyl)-1-(4-methoxy-phenyl)-1H-pyrazol-3-yl]-2-m-tolyl-propionic acid (10).

\section{${ }^{1} \mathrm{H}$ NMR (CDCl 3 , 400MHz)}

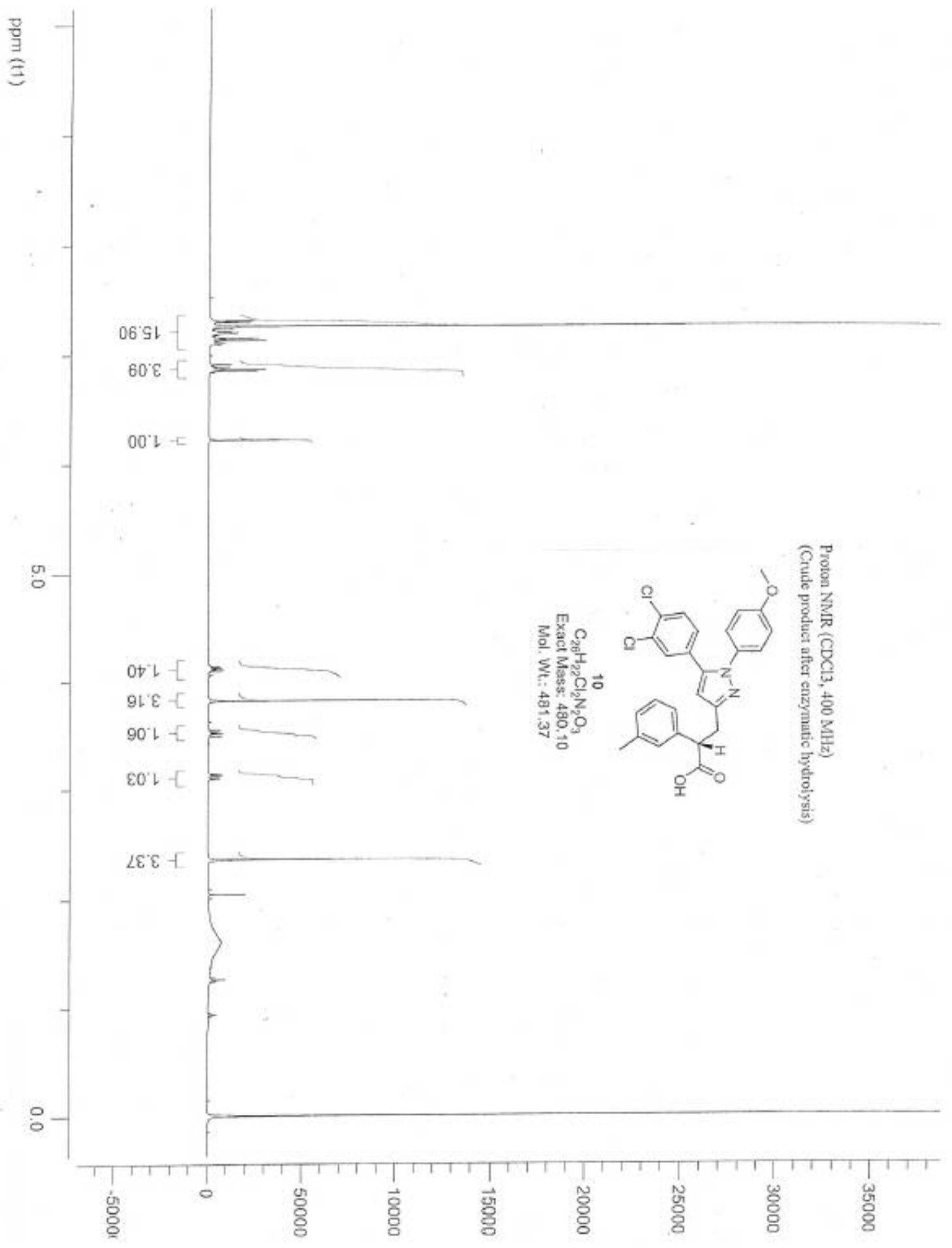


(S)-3-[5-(3,4-Dichloro-phenyl)-1-(4-methoxy-phenyl)-1H-pyrazol-3-yl]-2-m-tolyl-propionic acid (10).

13 NMR

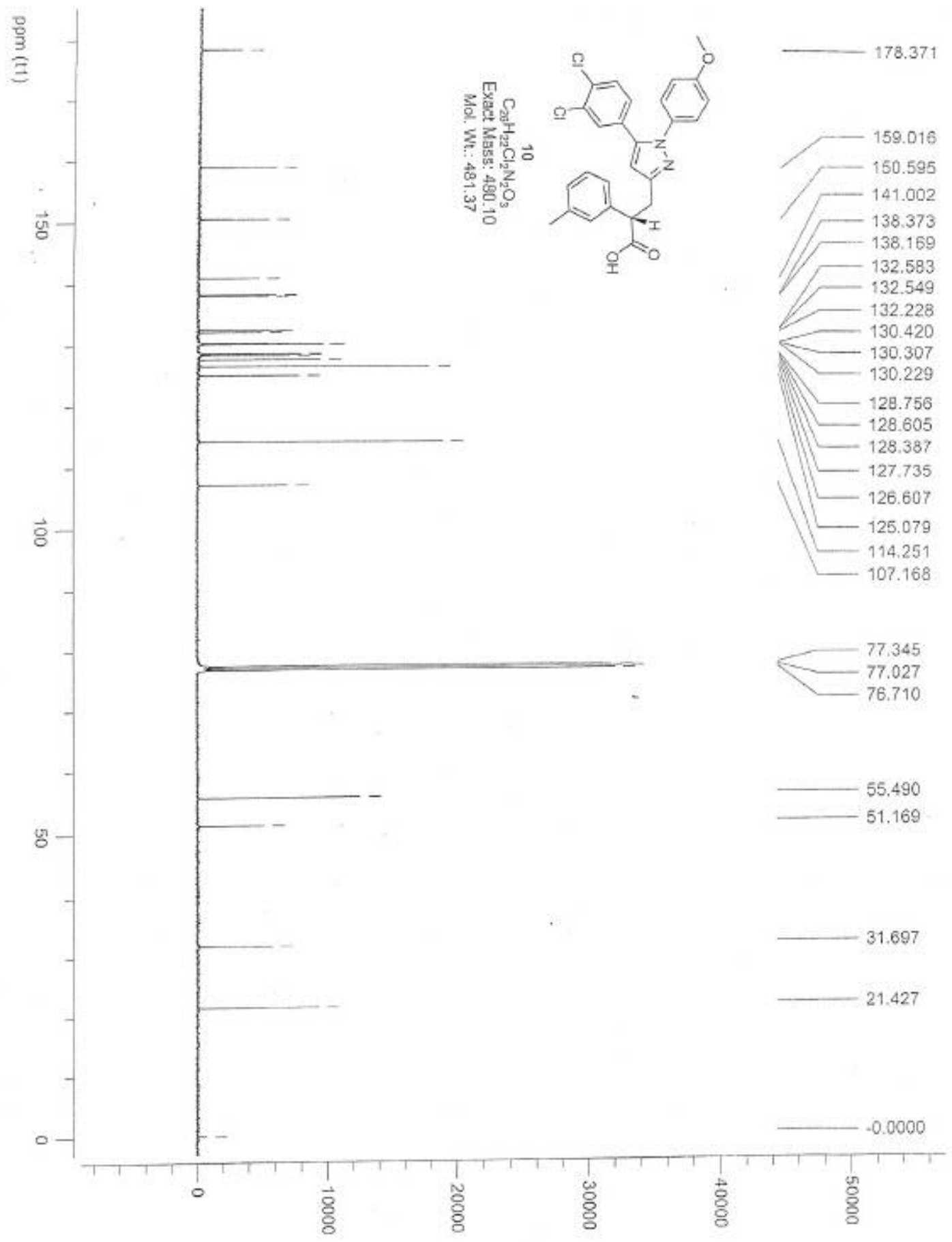




\section{Chiral HPLC trace of the enriched $(R)$-ester 11 isolated by column chromatography}

\section{(Scheme 3)}

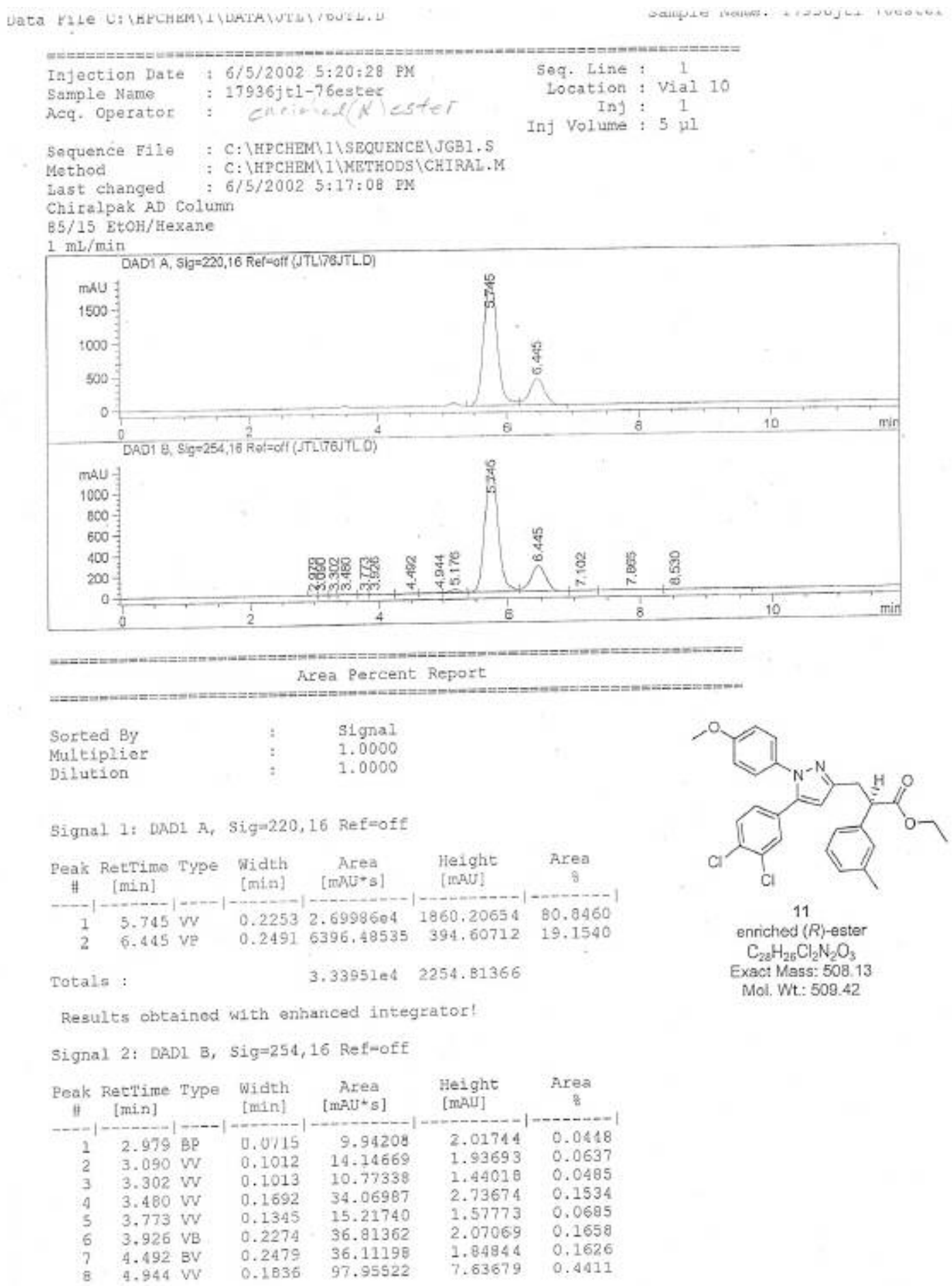

Lab 2952 LC $6 / 5 / 2002$ 5:32:33 PM 
Enriched (R)-ester 11 isolated by column chromatography (Scheme 3)

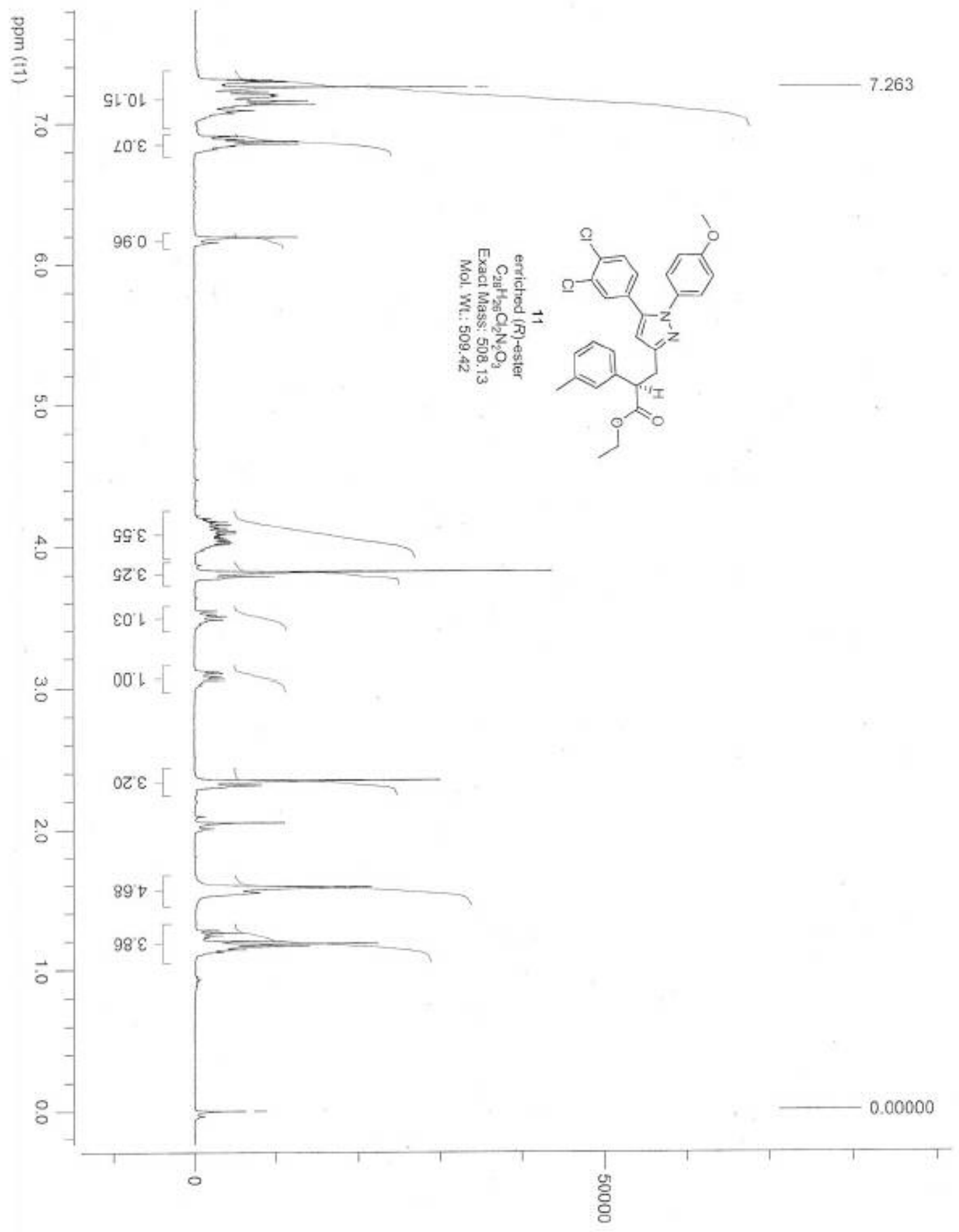


Enriched (R)-ester 11 isolated by column chromatography (Scheme 3)

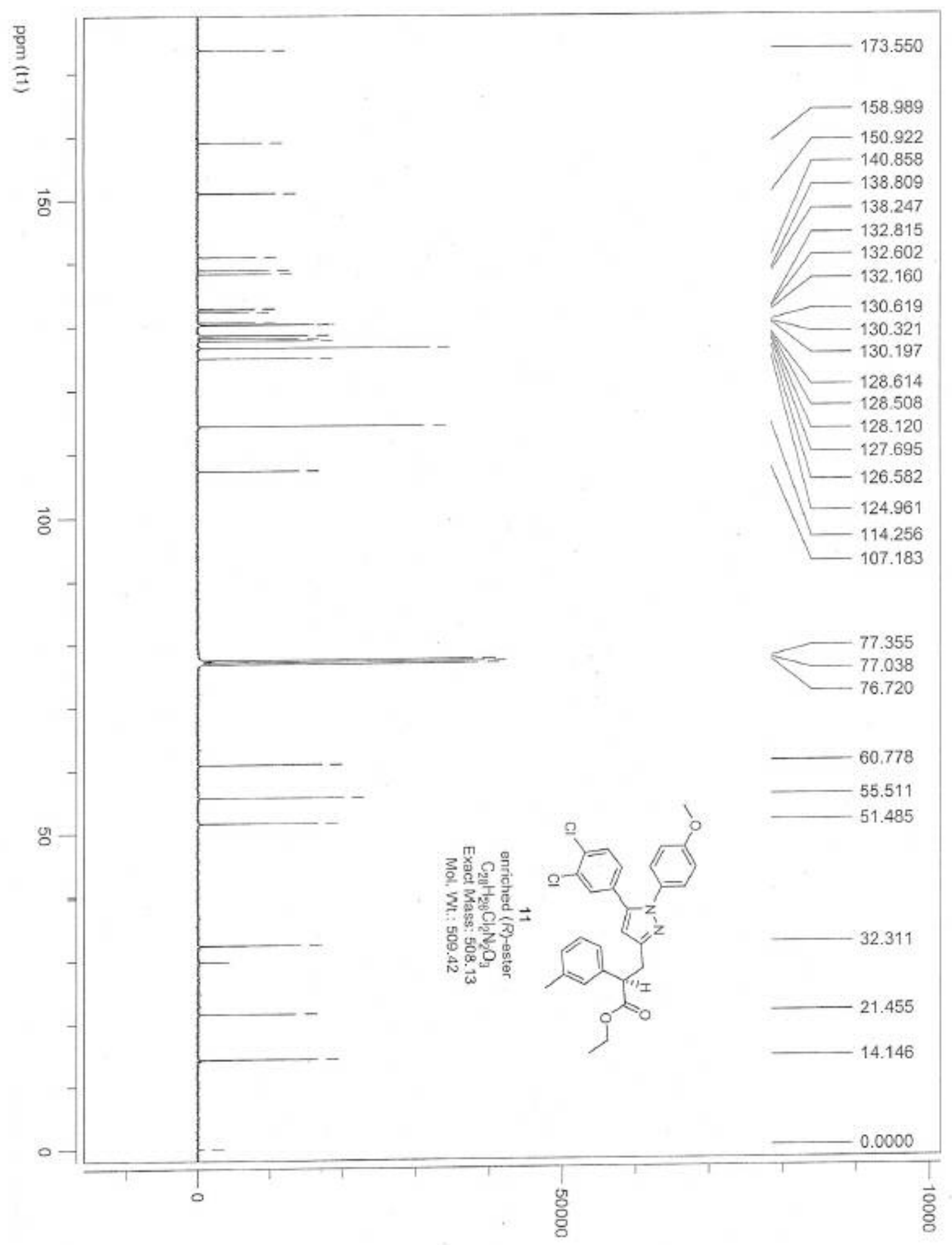




\section{Section 3: 1H and 13C Spectra}

\section{Synthesis of by the third route (Schemes $4 \& 5$ )}

\section{Scheme 4}
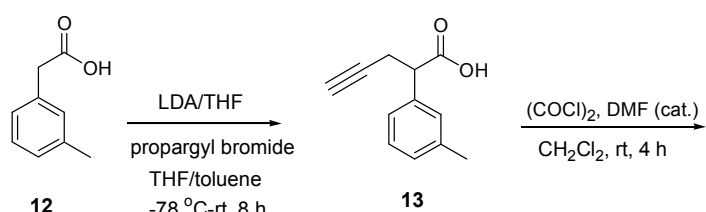

13

$78 \%$ yield

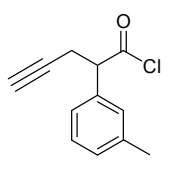

14

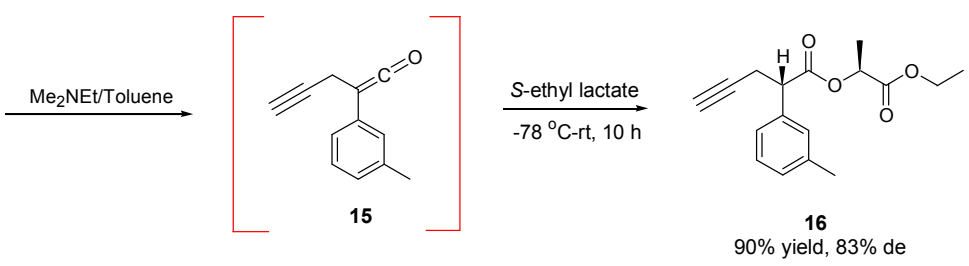

Scheme 5

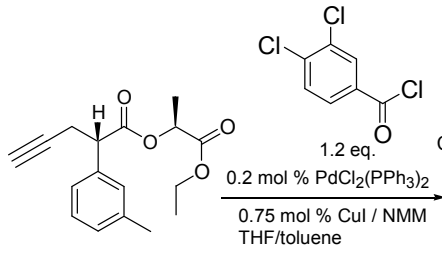

16

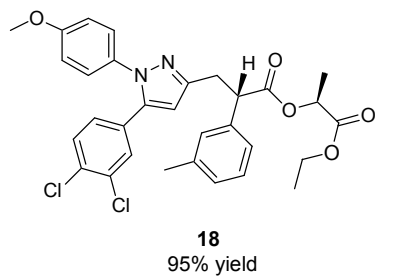

(mixture of regioisomers in $\sim 3: 1$ ratio)

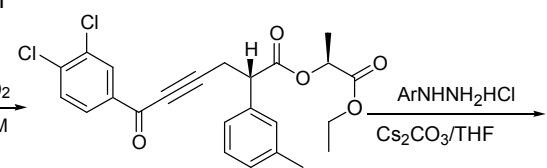

17
$80 \%$ yield

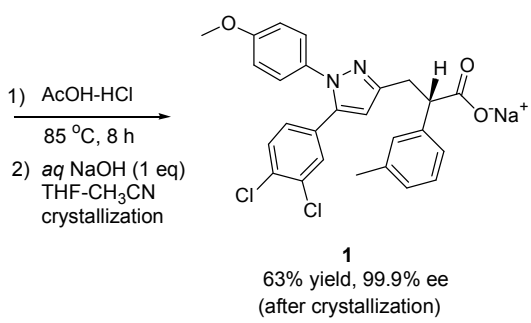


2-m-Tolylpent-4-ynoic acid (13)

\section{${ }^{1} \mathrm{H}$ NMR (CDCl 3 , 400MHz)}

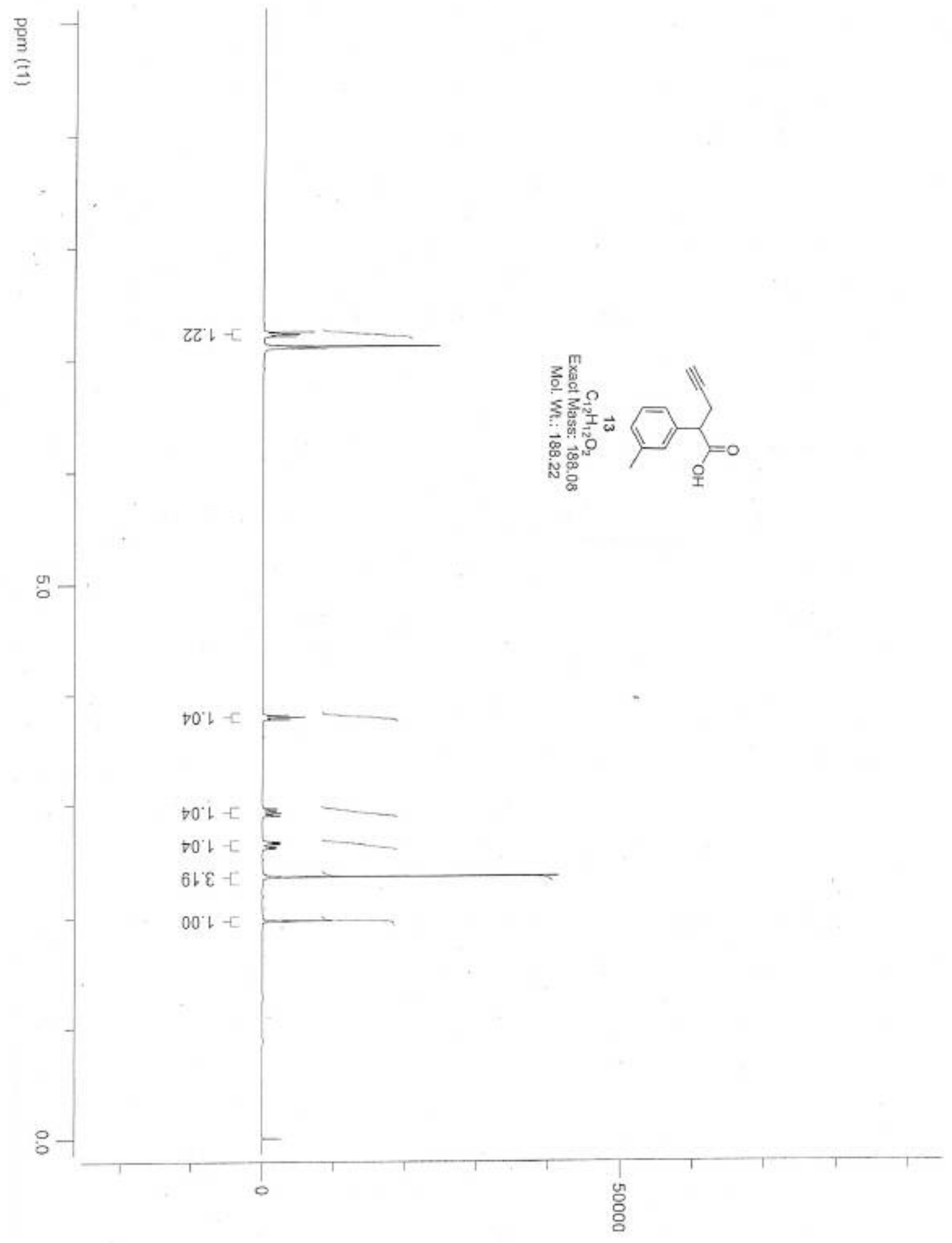


2-m-Tolylpent-4-ynoic acid (13)

\section{${ }^{13} \mathrm{C}$ NMR (CDCl $\left.3,100 \mathrm{MHz}\right)$}

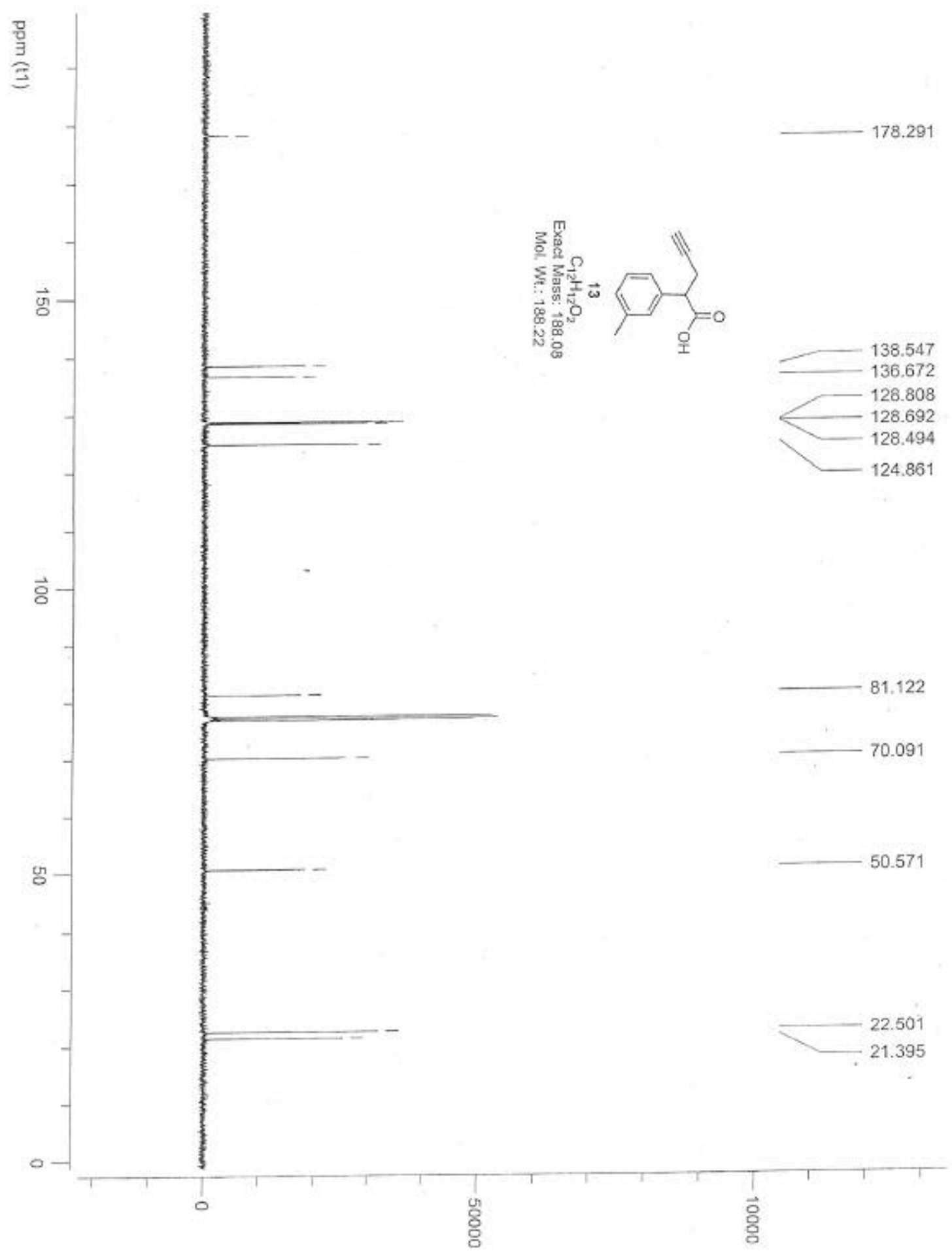


(S,S)-2-m-Tolylpent-4-ynoic acid 1-ethoxycarbonylethyl ester (16)

\section{${ }^{1} \mathrm{H}$ NMR (CDCl 3 , 400MHz)}

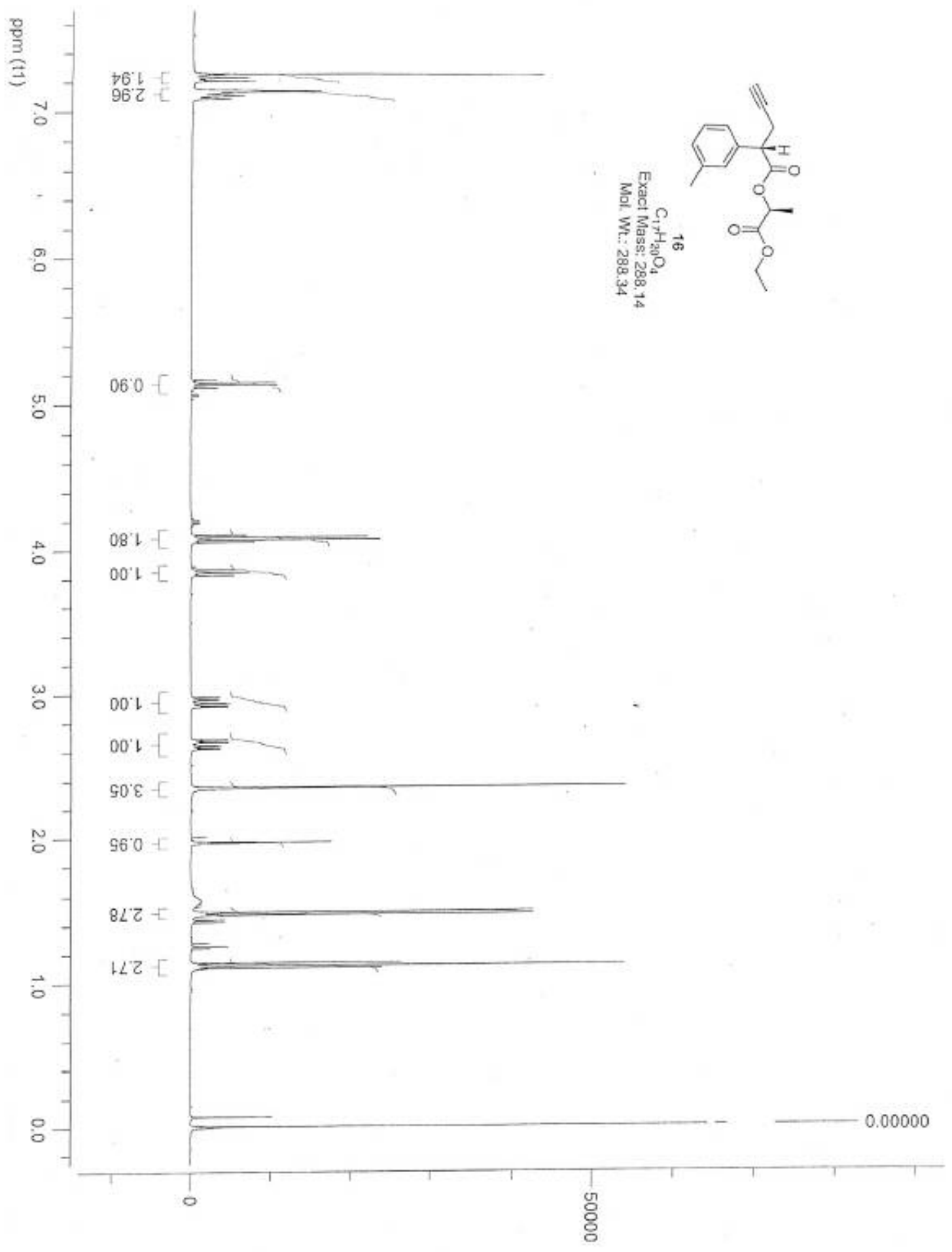


(S,S)-2-m-Tolylpent-4-ynoic acid 1-ethoxycarbonylethyl ester (16)

\section{${ }^{13} \mathrm{C}$ NMR $\left(\mathrm{CDCl}_{3}, 100 \mathrm{MHz}\right)$}

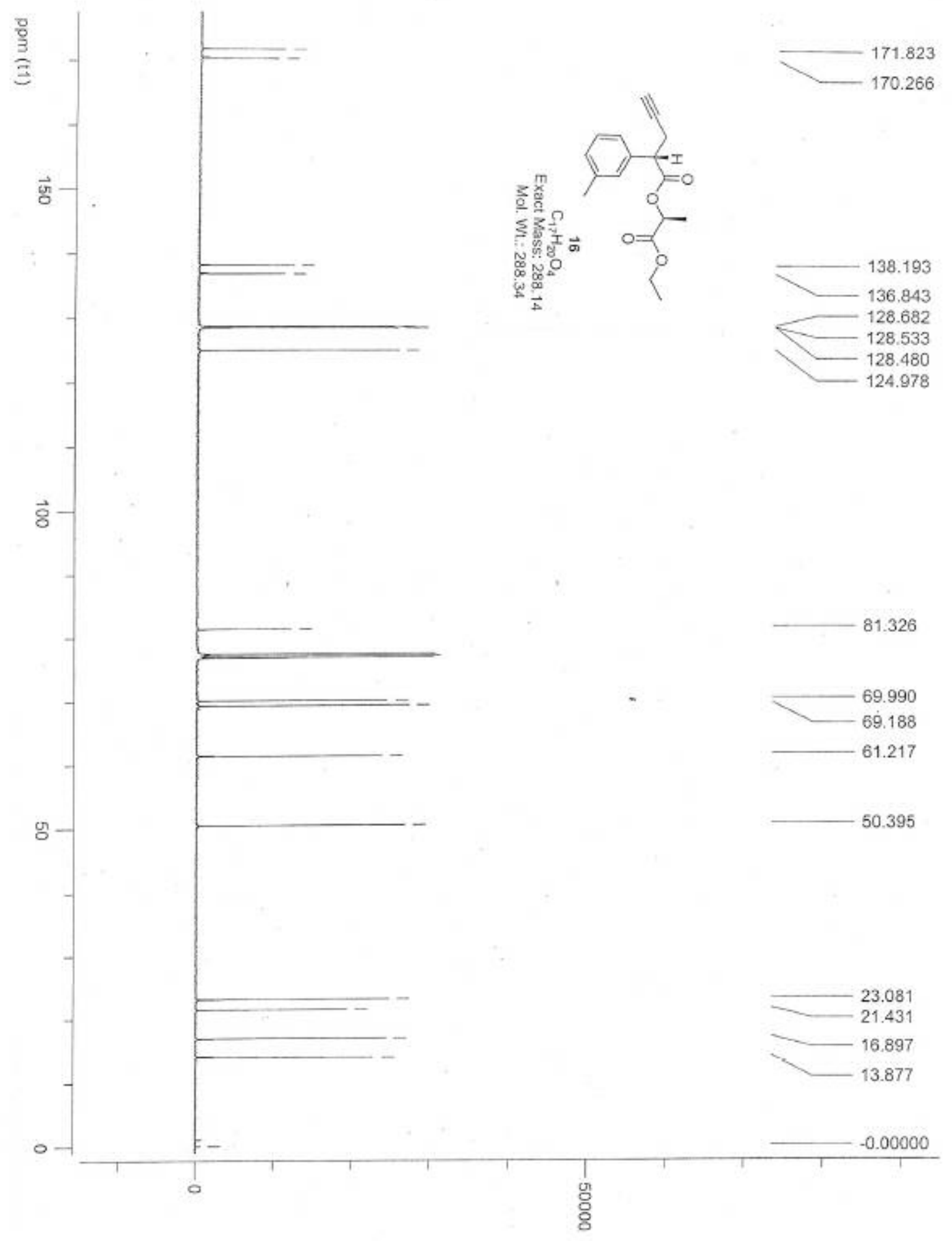


(S,S)-6-(3,4-Dichlorophenyl)-6-oxo-2-m-tolylhex-ynoic acid 1-ethoxycarbonylethyl ester (17)

\section{${ }^{1} \mathrm{H}$ NMR (CDCl 3 , 400MHz)}

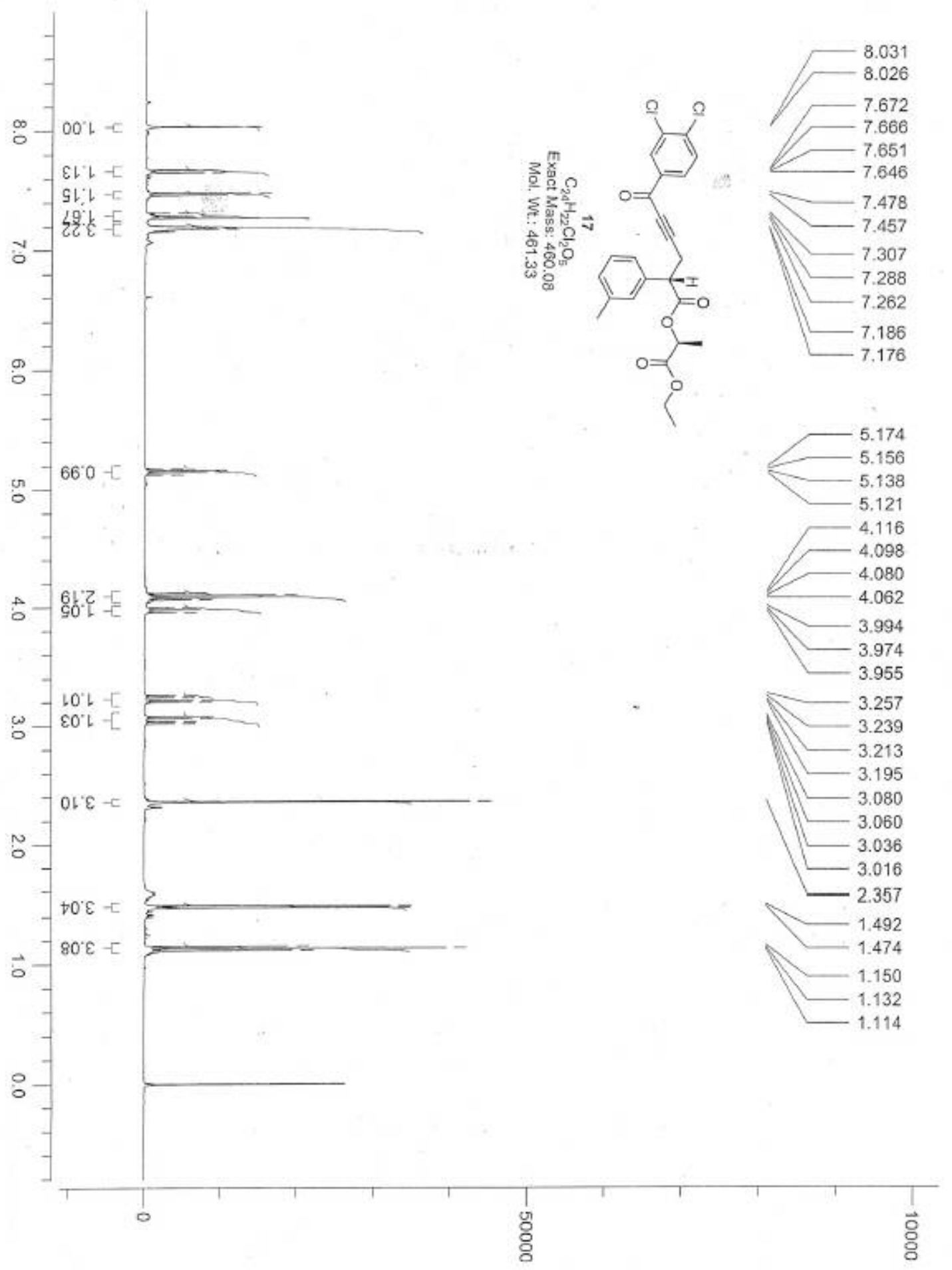


(S,S)-6-(3,4-Dichlorophenyl)-6-oxo-2-m-tolylhex-ynoic acid 1-ethoxycarbonylethyl ester (17)

\section{${ }^{13} \mathrm{C}$ NMR $\left(\mathrm{CDCl}_{3}, 100 \mathrm{MHz}\right)$}

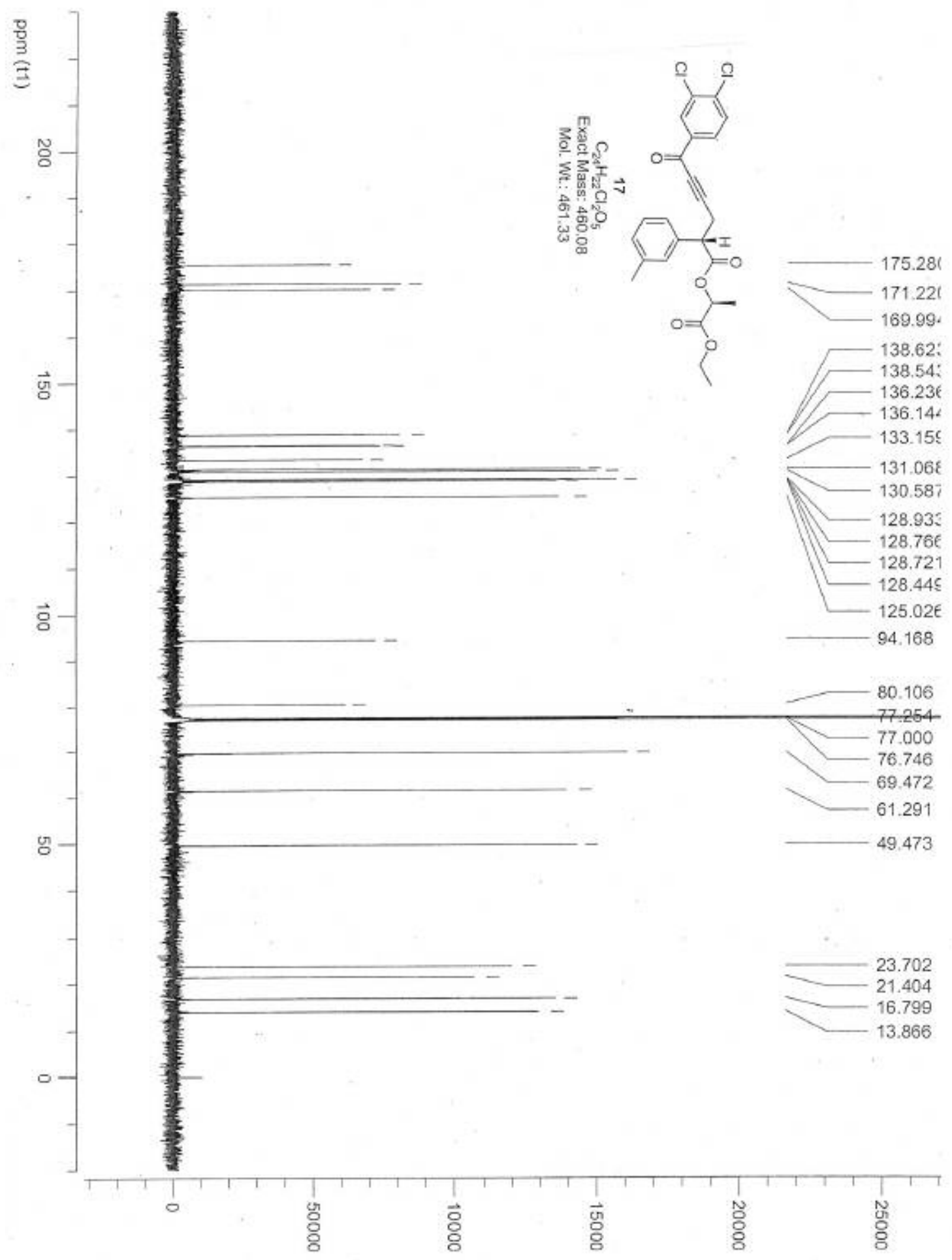


(S,S)-3[5-(3,4-Dichlorophenyl)-1-(4-methoxyphenyl)-1H-pyrazol-3-yl]-2-m-tolylpropanoic acid 1-ethoxycarbonylethyl ester (18).

\section{${ }^{1} \mathrm{H}$ NMR (CDCl 3 , 400MHz)}

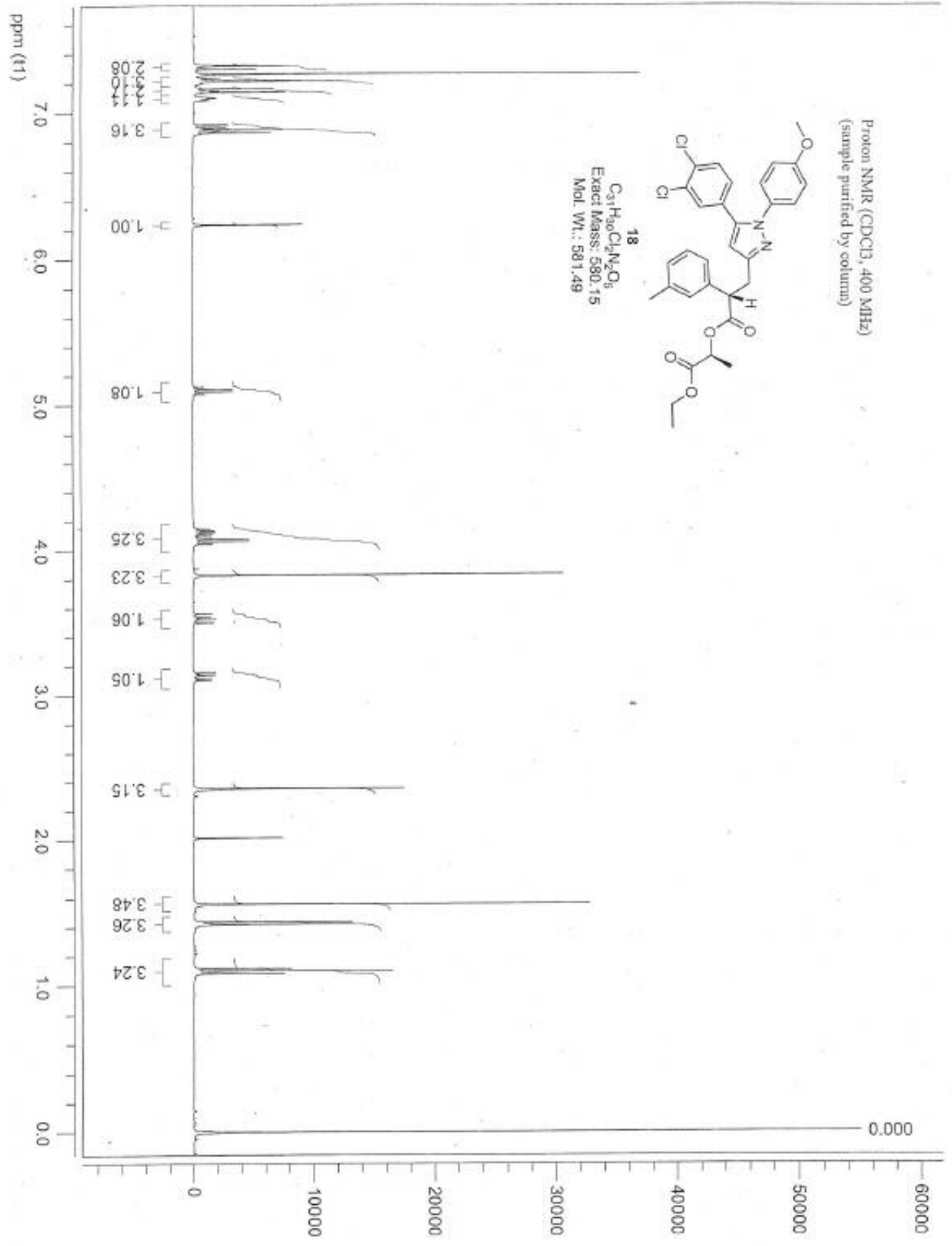


(S,S)-3[5-(3,4-Dichlorophenyl)-1-(4-methoxyphenyl)-1H-pyrazol-3-yl]-2-m-tolylpropanoic acid 1-ethoxycarbonylethyl ester (18).

${ }^{13} \mathrm{C}$ NMR $\left(\mathrm{CDCl}_{3}, 100 \mathrm{MHz}\right)$

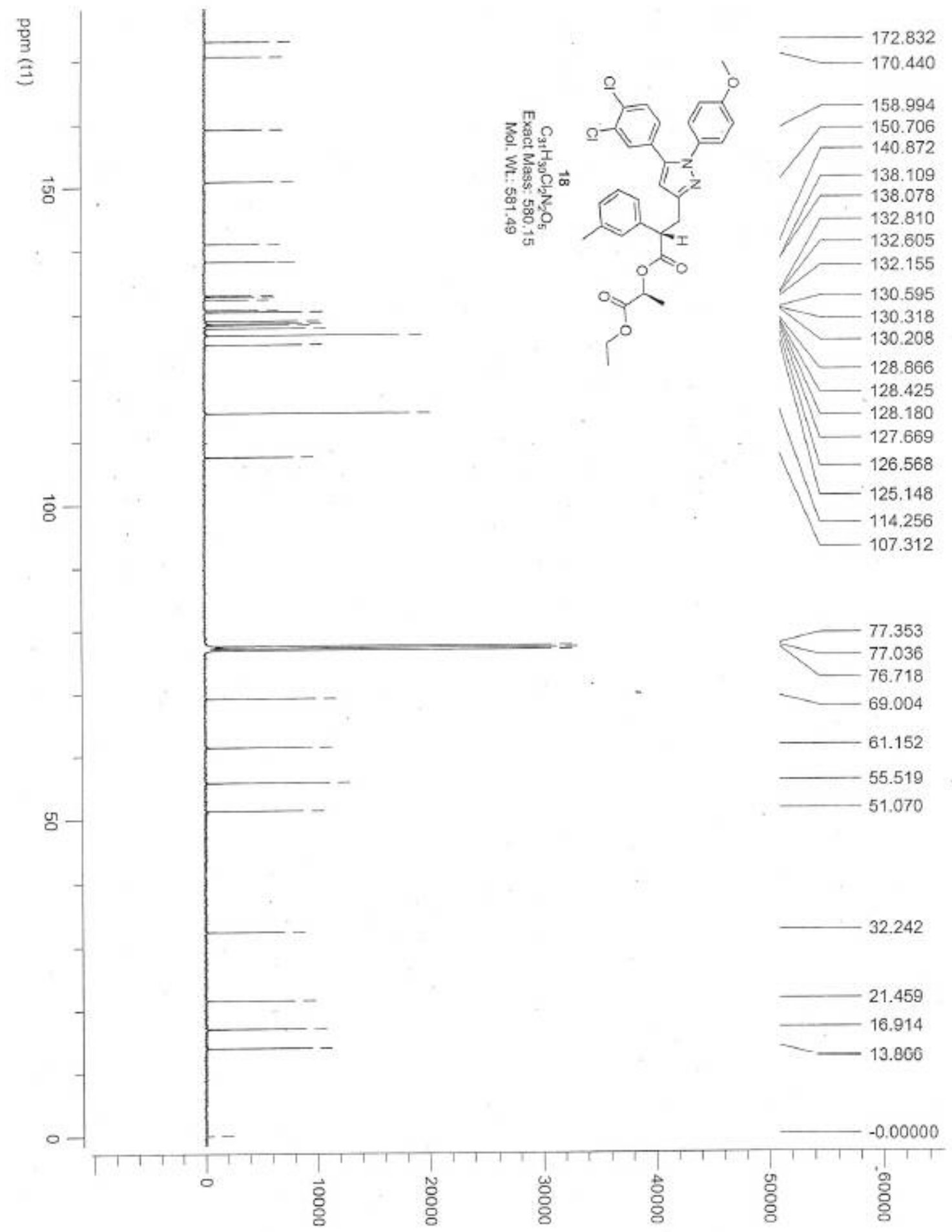




\section{Chiral HPLC trace of sample after hydrolysis of lactate ester 18 (Scheme 5)}

Retention times: $5.002=(R)$-acid; $5.45=$ regioisomer 8 (see Scheme 1); $7.825(S)$-acid 10

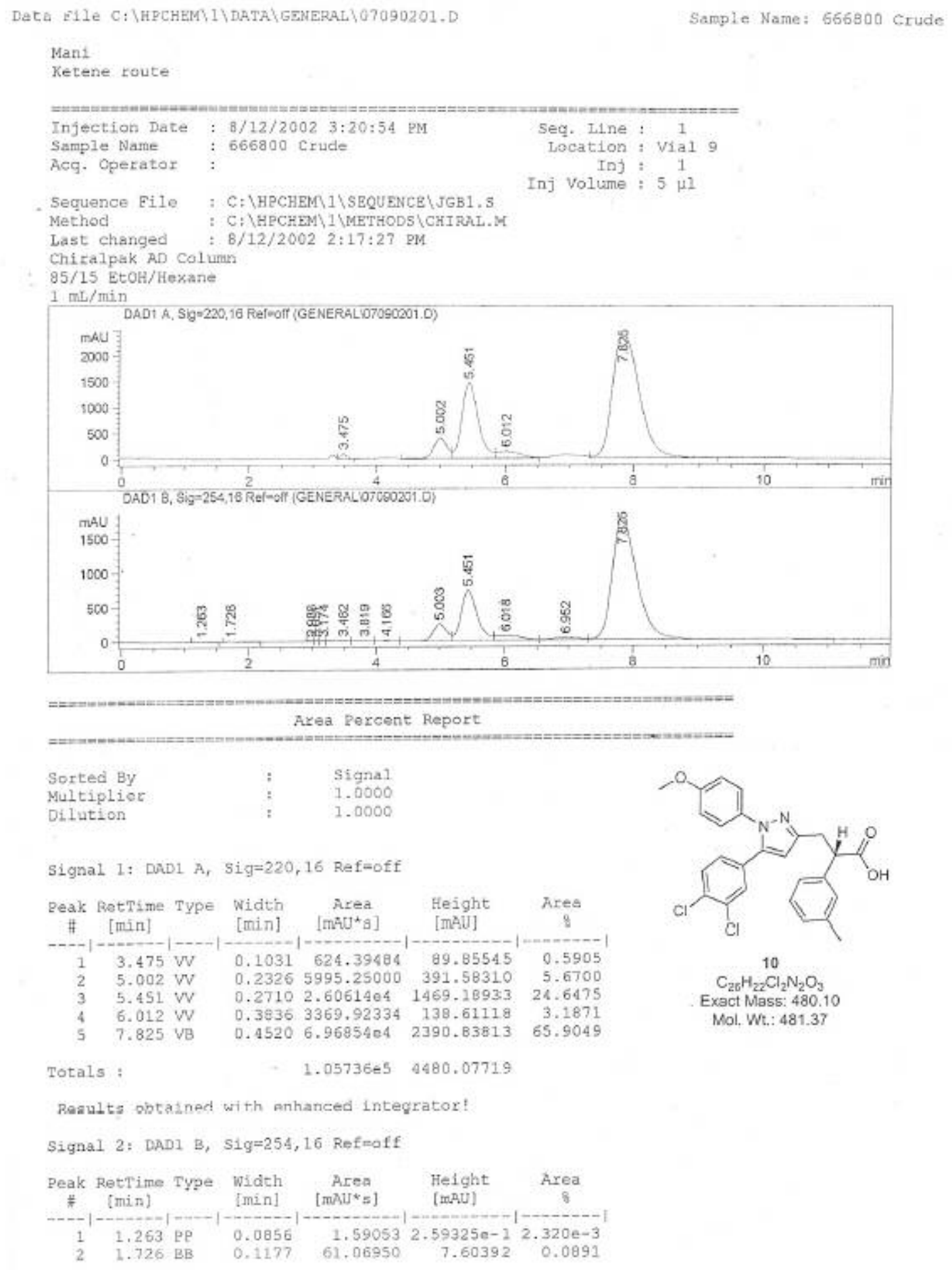




\section{Chiral HPLC trace after salt formation and crystallization}

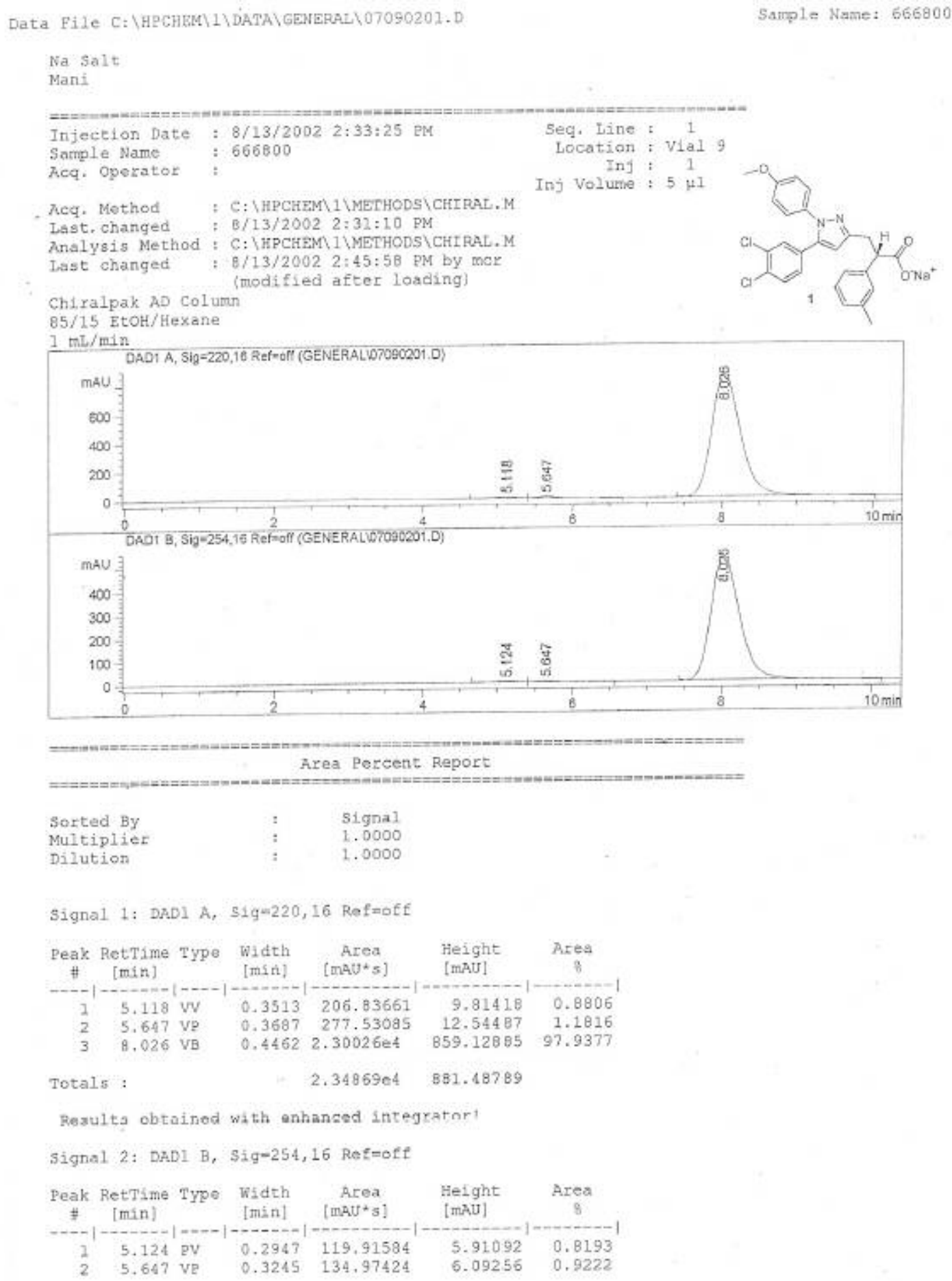


(S)-Sodium 3-[5-(3,4-dichloro-phenyl)-1-(4-methoxy-phenyl)-1H-pyrazol-3-yl]-2-m-tolylpropionate (1).

\section{${ }^{1} \mathrm{H}$ NMR $\left(\mathrm{D}_{2} \mathrm{O}, \mathbf{5 0 0 M H z}\right)$}

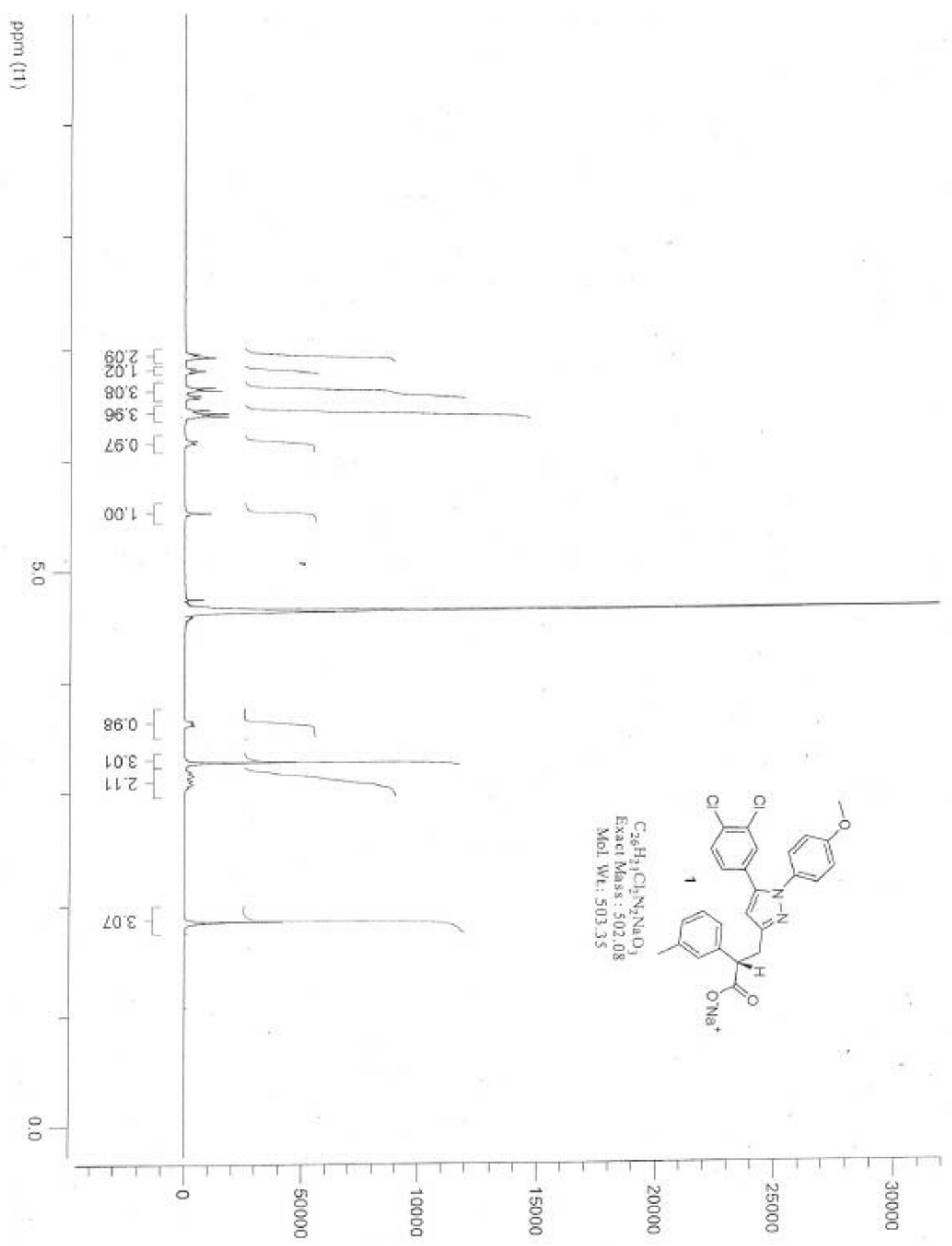


(S)-Sodium 3-[5-(3,4-dichloro-phenyl)-1-(4-methoxy-phenyl)-1H-pyrazol-3-yl]-2-m-tolylpropionate (1).

${ }^{13} \mathrm{C}$ NMR $\left(\mathrm{CDCl}_{3}, 100 \mathrm{MHz}\right)$

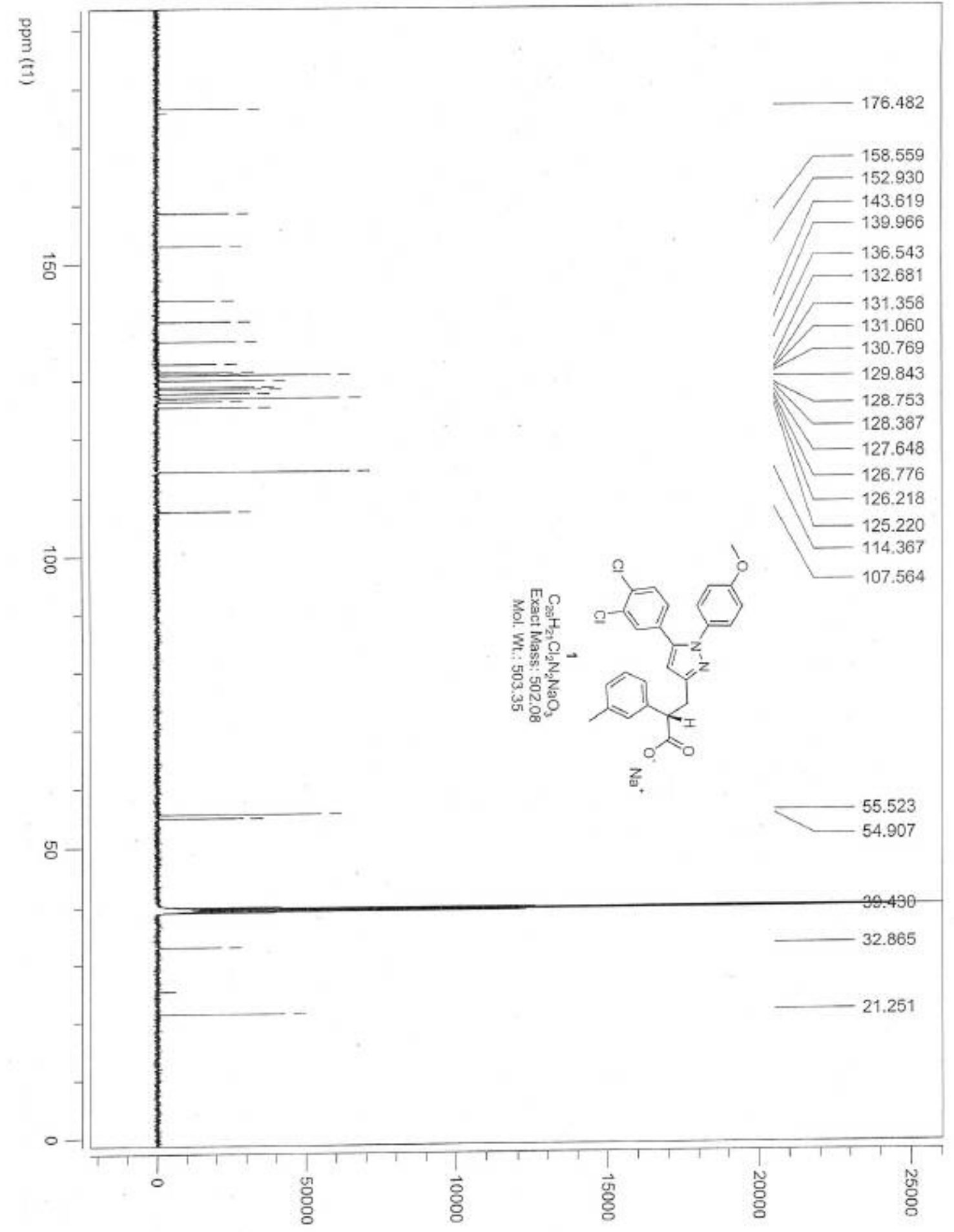

